University of Tennessee Health Science Center UTHSC Digital Commons

\title{
$5-2013$
}

\section{Functional Study of Hemogen Knockout Mouse Model}

Peng Gao

University of Tennessee Health Science Center

Follow this and additional works at: https://dc.uthsc.edu/dissertations

Part of the Genetic Processes Commons, Medical Cell Biology Commons, Medical Genetics Commons, and the Neoplasms Commons

\section{Recommended Citation}

Gao, Peng , "Functional Study of Hemogen Knockout Mouse Model" (2013). Theses and Dissertations (ETD). Paper 92. http://dx.doi.org/10.21007/etd.cghs.2013.0105.

This Dissertation is brought to you for free and open access by the College of Graduate Health Sciences at UTHSC Digital Commons. It has been accepted for inclusion in Theses and Dissertations (ETD) by an authorized administrator of UTHSC Digital Commons. For more information, please contact jwelch30@uthsc.edu. 


\title{
Functional Study of Hemogen Knockout Mouse Model
}

\begin{abstract}
Mouse Hemogen (Hemgn) is regarded as a homologue of human Erythroid Differentiation Associated Gene (EDAG). EDAG overexpression has been postulated for association with some leukemia cases. Meanwhile, Hemgn has been found to contribute to Hoxb4 mediated hematopoietic stem cell expansion. Based on these postulations and evidences, a Hemgn knockout mouse model has been generated to study its function in normal and stress hematopoiesis. I confirmed the Hemgn expression in hematopoietic organs including bone marrow and spleen, as well as round spematids in testis. Hemgn is expressed in mouse hematopoietic stem cells and erythroid progenitor cells. Moreover, Hemgn was also found in basophilic, polychromatic and orthochromatic erythroblast cells and megakaryocytes, but absent in mature red blood cells and other differentiated blood cells. Hemgn knockout animals showed normal steady state and stress hematopoiesis and erythropoiesis. However, upon transplantation, a slight defect in lymphoid reconstitution was observed. By generating a deletion mutant of the predicted nuclear localization signal, I conclude the amino acids 61 to 78 is a functional nuclear localization signal. Both the nuclear localization signal and the predicted coiled-coil domain were required for Hemgn to protect $\mathrm{Ba} / \mathrm{F} 3$ cells from IL-3 withdrawal induced apoptosis. However, the same anti-apoptotic effect of Hemgn was not seen in the myeloid 32D cell line, indicating it may require specific cell context. In conclusion, Hemgn may be an anti-apoptotic protein and may be involved in lymphoid development.
\end{abstract}

\section{Document Type}

Dissertation

Degree Name

Doctor of Philosophy (PhD)

Program

Biomedical Sciences

Research Advisor

Brian P. Sorrentino, M.D.

Keywords

apoptosis, blood, hematopoiesis, Hemgn, knockout, stem cell

\section{Subject Categories}

Diseases | Genetic Processes | Medical Cell Biology | Medical Genetics | Medical Sciences | Medicine and Health Sciences | Neoplasms 


\title{
Functional Study of Hemogen Knockout Mouse Model
}

\author{
A Dissertation \\ Presented for \\ The Graduate Studies Council \\ The University of Tennessee \\ Health Science Center
}

\author{
In Partial Fulfillment \\ Of the Requirements for the Degree \\ Doctor of Philosophy \\ From The University of Tennessee
}

By

Peng Gao

May 2013 
Copyright (C) 2013 by Peng Gao. All rights reserved. 


\section{ACKNOWLEDGEMENTS}

I should thank my research advisor Dr. Brian Sorrentino, committee members Dr. Opferman, Dr. Persons, Dr. McKinnon and Dr. Cox for their time and advices. Dr. Russell in Peter McKinnon lab guided me on ES cell culture. Dr. Cheepala in John Schuetz lab helped carry out the platelet assays. Dr. Zhang in Paul Ney lab gave some suggestions on studies of erythropoiesis. Flow cytometry core facility, transgenic core facility and pathology core facility at St Jude Children's Research Hospital helped through the whole study. 


\begin{abstract}
Mouse Hemogen (Hemgn) is regarded as a homologue of human Erythroid Differentiation Associated Gene (EDAG). EDAG overexpression has been postulated for association with some leukemia cases. Meanwhile, Hemgn has been found to contribute to Hoxb4 mediated hematopoietic stem cell expansion. Based on these postulations and evidences, a Hemgn knockout mouse model has been generated to study its function in normal and stress hematopoiesis.
\end{abstract}

I confirmed the Hemgn expression in hematopoietic organs including bone marrow and spleen, as well as round spematids in testis. Hemgn is expressed in mouse hematopoietic stem cells and erythroid progenitor cells. Moreover, Hemgn was also found in basophilic, polychromatic and orthochromatic erythroblast cells and megakaryocytes, but absent in mature red blood cells and other differentiated blood cells.

Hemgn knockout animals showed normal steady-state and stress hematopoiesis and erythropoiesis. However, upon transplantation, a slight defect in lymphoid reconstitution was observed.

By generating a deletion mutant of the predicted nuclear localization signal, I conclude the amino acids 61 to 78 is a functional nuclear localization signal. Both the nuclear localization signal and the predicted coiled-coil domain were required for Hemgn to protect $\mathrm{Ba} / \mathrm{F} 3$ cells from IL-3 withdrawal induced apoptosis. However, the same antiapoptotic effect of Hemgn was not seen in the myeloid 32D cell line, indicating it may require specific cell context.

In conclusion, Hemgn may be an anti-apoptotic protein and may be involved in lymphoid development. 


\section{TABLE OF CONTENTS}

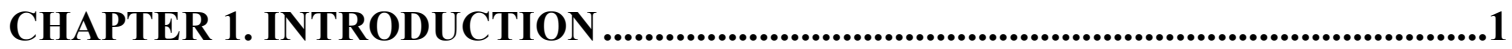

Hematopoiesis and Hematopoietic Stem Cell ........................................................ 1

The Old Wisdom and Modern History ................................................................... 1

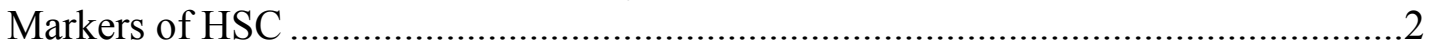

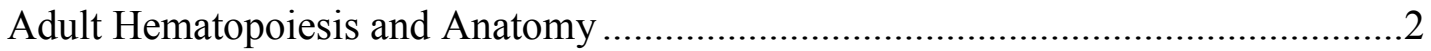

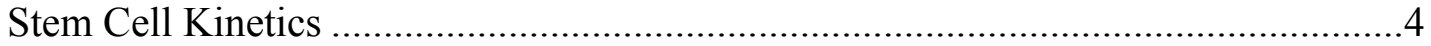

Apoptosis of HSC ............................................................................................. 5

Fetal Hematopoiesis ................................................................................... 7

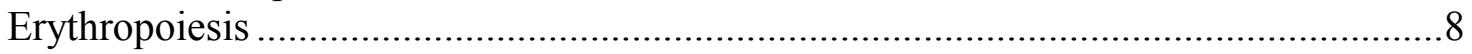

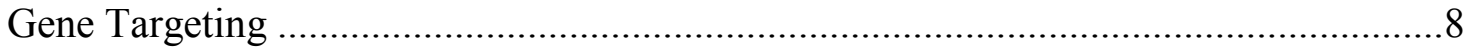

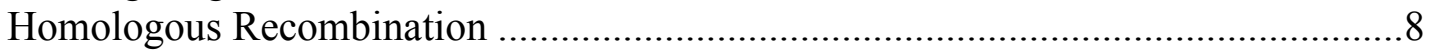

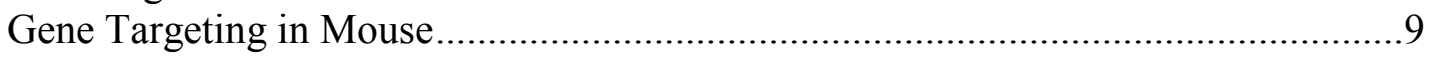

\section{CHAPTER 2. LITERATURE REVIEW OF HEMOGEN AND}

ORTHOLOGUES.................................................................................................................11

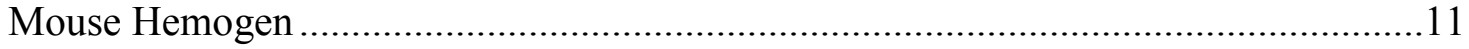

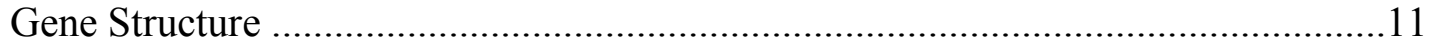

Expression Pattern ................................................................................................. 11

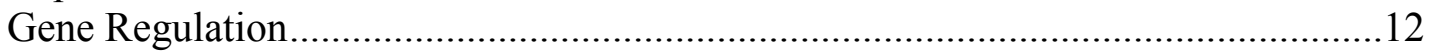

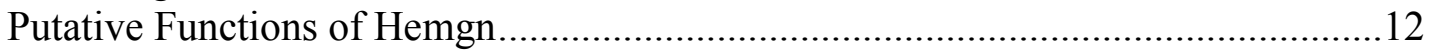

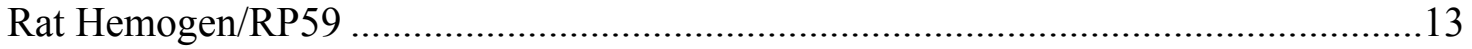

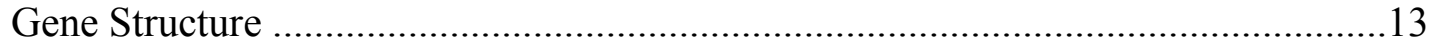

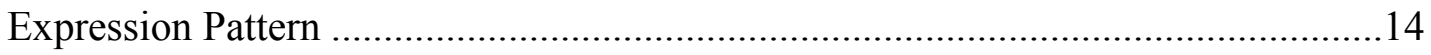

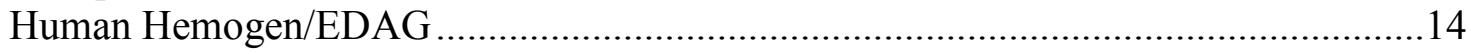

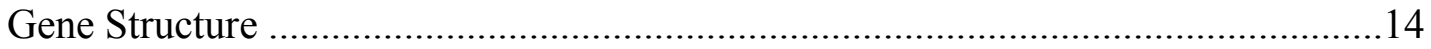

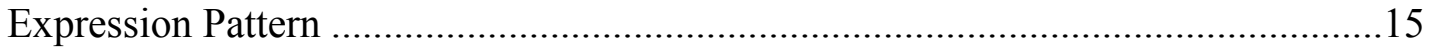

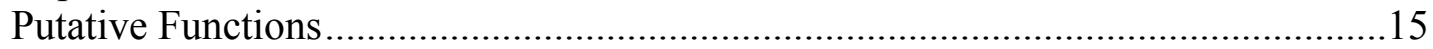

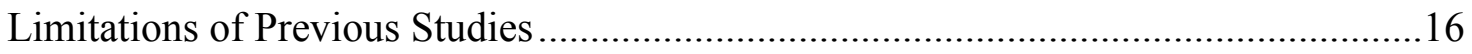

The Ectopic Expression and Overexpression Systems .......................................... 16

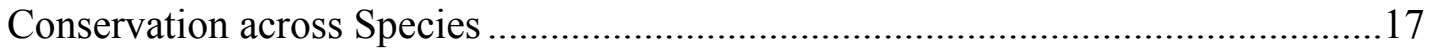

CHAPTER 3. MATERIALS AND METHODS....................................................19

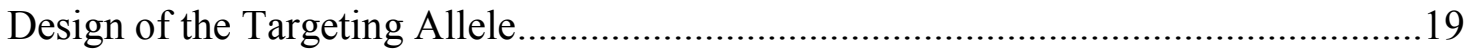

Positions of loxP Sites ....................................................................................... 19

Enzymes and Probes for Southern Blotting ............................................................ 19

The Targeting Construct ....................................................................................20

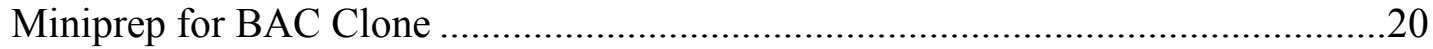

Retrieving Construct and Mini-targeting Constructs ........................................20

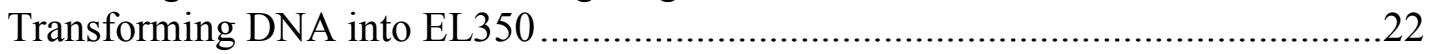

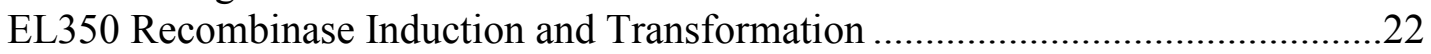

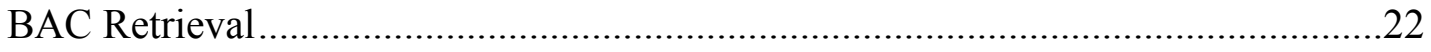

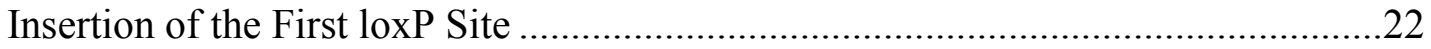

Popping out Neo Cassette .................................................................................23 


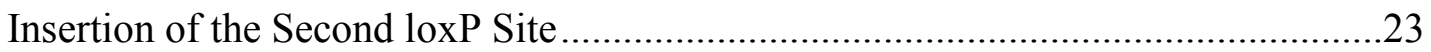

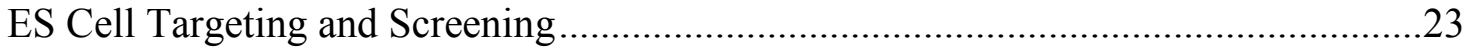

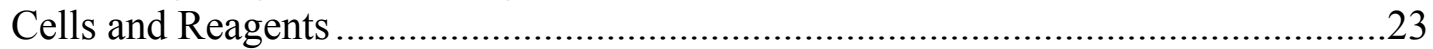

Feeder Cell and ES Cell Preparation ..................................................................24

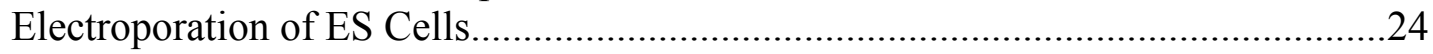

Selection of ES Cell Clones ……………….................................................24

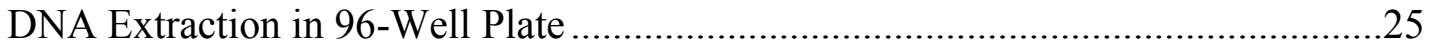

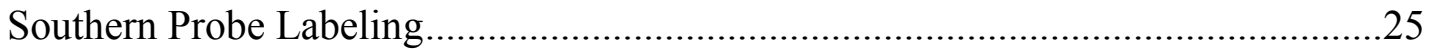

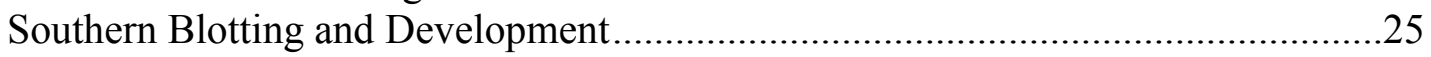

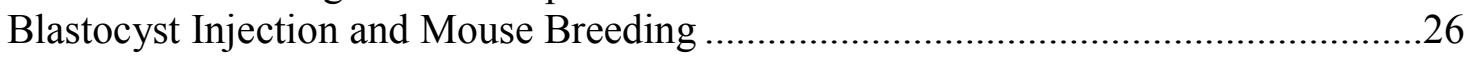

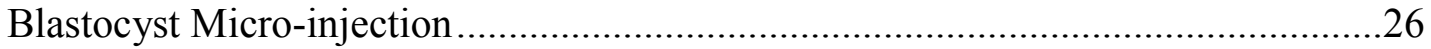

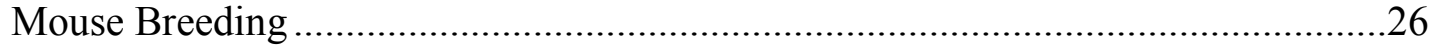

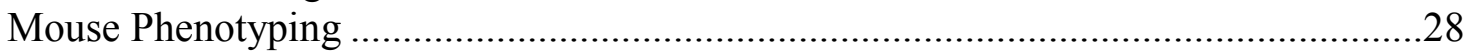

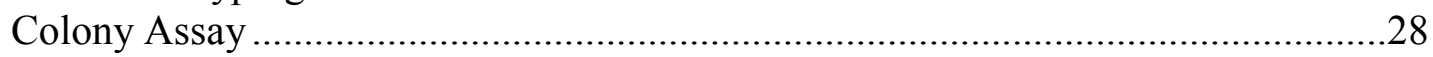

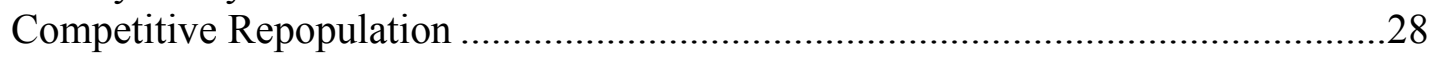

Platelet Aggregation Assay ........................................................................28

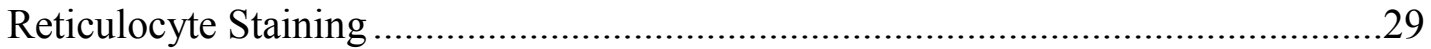

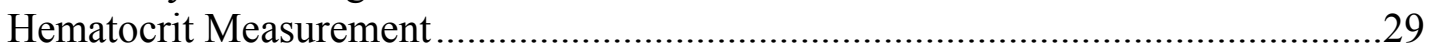

Phenylhydrazine Treatment and Bleeding ..........................................................29

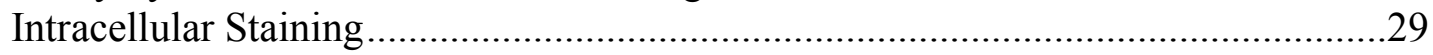

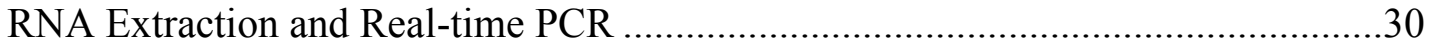

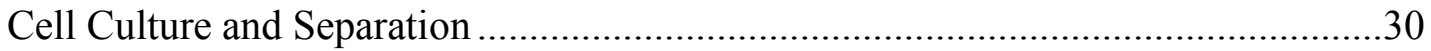

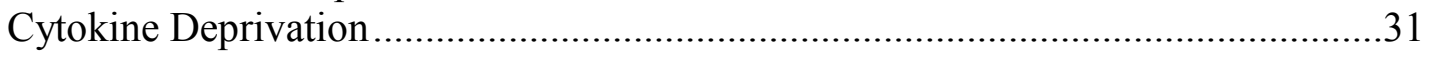

Annexin V Staining ....................................................................................

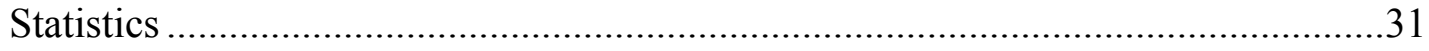

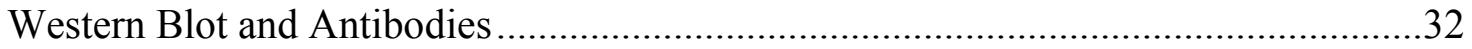

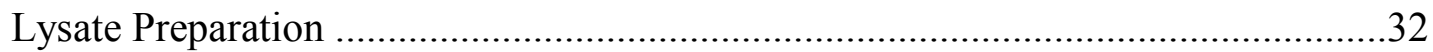

Cytoplasmic and Nuclear Protein Extraction...........................................................32

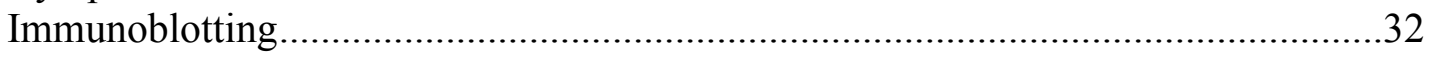

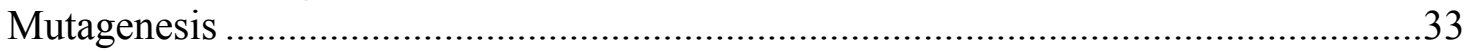

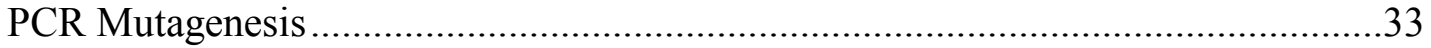

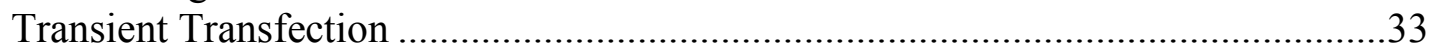

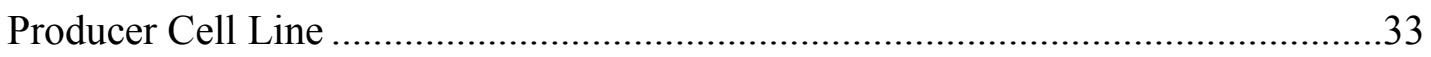

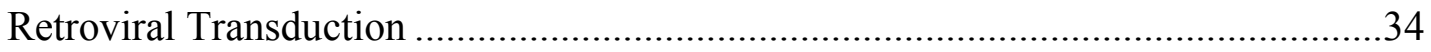

CHAPTER 4. RESULTS..................................................................................................35

Generation of Hemgn Knockout Mouse Model .........................................................35

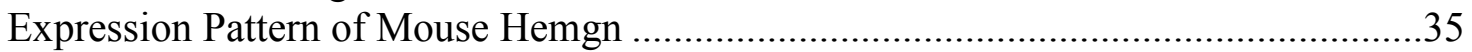

Normal Steady-state Hematopoiesis and Stress Erythropoiesis ....................................38

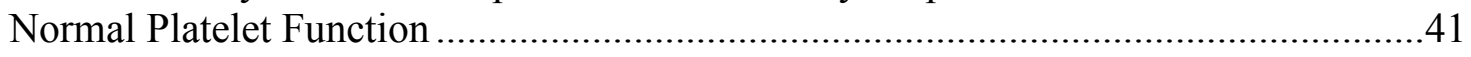

Normal Stem Cell Function and Defect in Lymphoid Reconstitution............................43

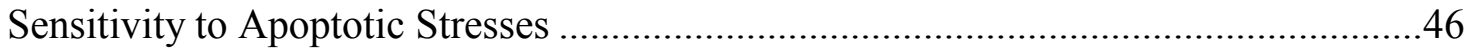

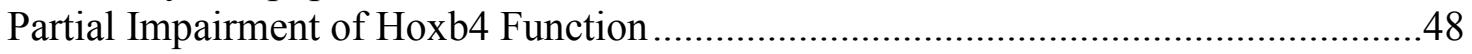

Nuclear Localization and Coiled-coil Domain ..............................................................48 


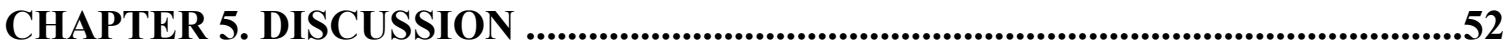

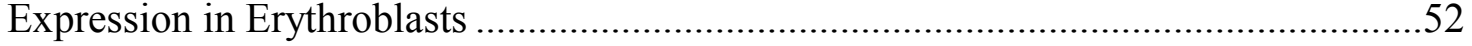

Apoptosis in Heterogeneous Cell Population .........................................................52

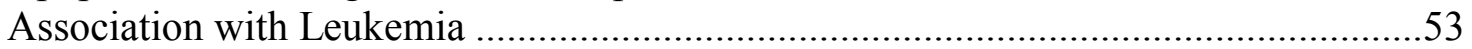

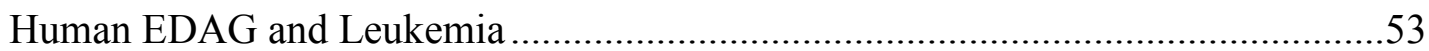

Mouse Hemgn and Leukemia Models ................................................................54

Normal Hematopoiesis and Erythropoiesis ………….........................................56

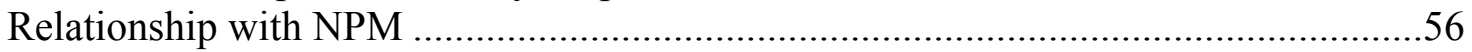

Defect in Lymphoid Cell Reconstitution ..............................................................58

Differences between Myeloid and Lymphoid Cells ………..........................................60

Relationship with Hoxb4 ...................................................................................6

Potential Use of Hemgn Knockout and Mutants to Characterize Co-factors .................61

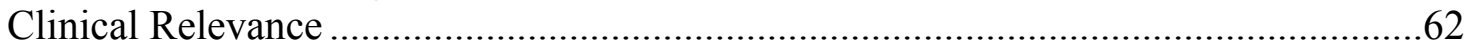

A Proposed Model for Hemgn Function..........................................................................63

LIST OF REFERENCES .................................................................................64

APPENDIX A. SUPPLEMENTARY TABLES .............................................................75

APPENDIX B. SUPPLEMENTARY FIGURES ..............................................................81

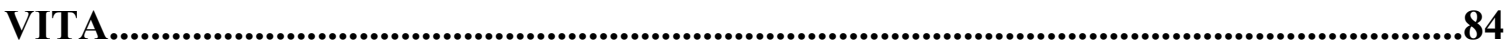




\section{LIST OF TABLES}

Table A-1. Estimated HSC frequency in mouse bone marrow ...................................75

Table A-2. PCR conditions and cloning strategies for targeting construct ....................76

Table A-3. Primer sets for targeting constructs and ES cell screening ........................77

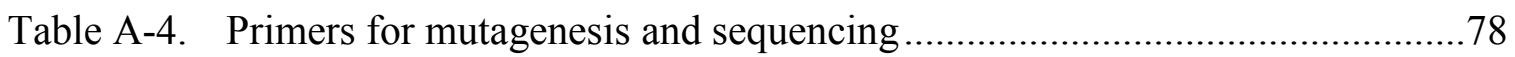

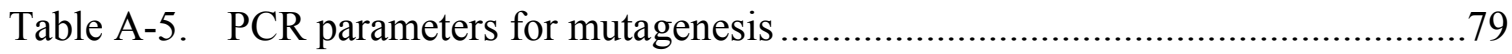

Table A-6. Leukemia mouse models do not show Hemgn overexpression ....................80 


\section{LIST OF FIGURES}

Figure 1-1. Conceptual hematopoietic tree of mouse ...................................................

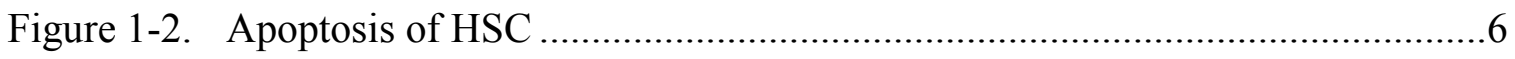

Figure 3-1. Schematic flowchart of generating knockout targeting construct................21

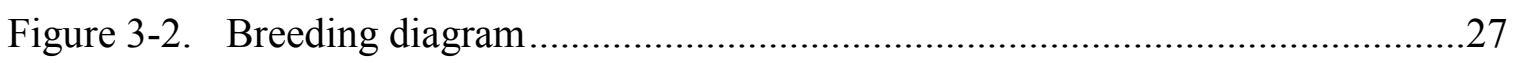

Figure 4-1. Targeting strategy of Hemgn conditional allele......................................36

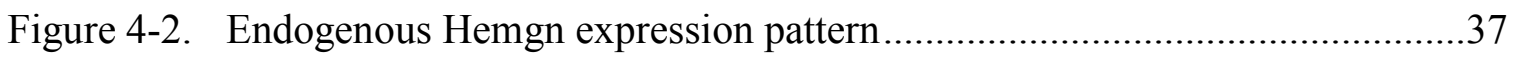

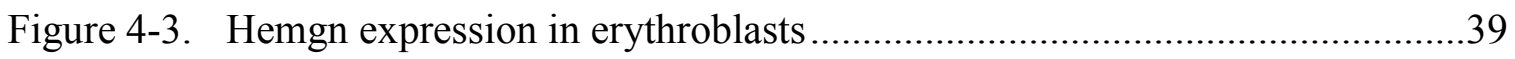

Figure 4-4. Steady-state hematopoiesis of Hemgn knockout mice ..............................40

Figure 4-5. Steady-state and stress erythropoiesis.............................................42

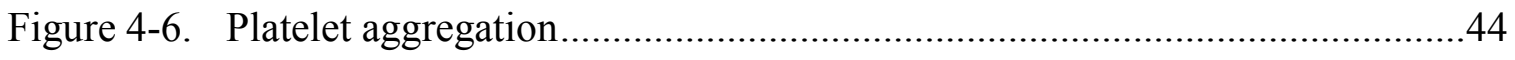

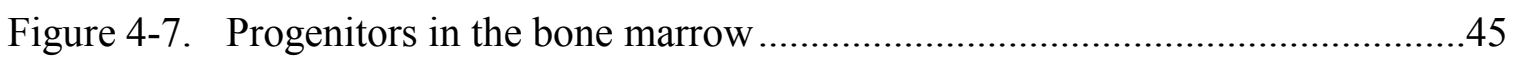

Figure 4-8. Sensitivity to ionizing radiation and cytokine deprivation ........................47

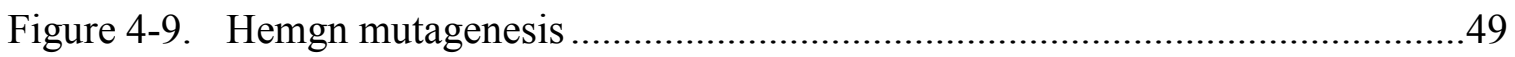

Figure 4-10. IL-3 withdrawal induced apoptosis in Ba/F3 and 32D cells ......................51

Figure B-1. Impairment of Hoxb4 function in Hemgn knockout bone marrow cells ......81

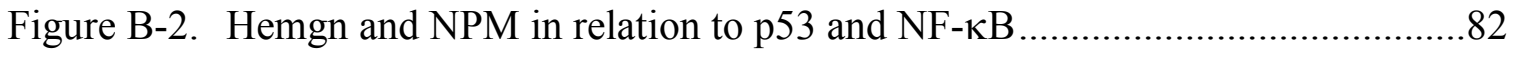

Figure B-3. Hemgn expression is not associated with Bcr-Abl ...............................83 


\section{LIST OF ABBREVIATIONS}

$\begin{array}{ll}\text { 5-FU } & \text { fluorouracil } \\ \text { ACD } & \text { acid citrate dextrose } \\ \text { AGM } & \text { aorta-gonad-mesonephros } \\ \text { ALL } & \text { acute lymphoblastic leukemia } \\ \text { AML } & \text { acute myeloid leukemia } \\ \text { BAC } & \text { bacterial artificial chromosome } \\ \text { BCR } & \text { B cell receptor } \\ \text { BFU-E } & \text { burst forming unit-erythroid } \\ \text { BM } & \text { bone marrow } \\ \text { BMP } & \text { bone morphogenetic protein } \\ \text { BSA } & \text { bovine serum albumin } \\ \text { CFU } & \text { colony forming unit } \\ \text { CFU-E } & \text { colony forming unit-erythroid } \\ \text { CHIP } & \text { chromatin immunoprecipitation } \\ \text { CLP } & \text { common lymphoid progenitor } \\ \text { CMP } & \text { common myeloid progenitor } \\ \text { CN-AML } & \text { cytogenetically normal-acute myeloid leukemia } \\ \text { cpm } & \text { count per minute } \\ \text { DMEM } & \text { Dulbecco's modified Eagle medium } \\ \text { DSB } & \text { double strand break } \\ \text { EPO } & \text { erythropoietin } \\ \text { ESC } & \text { embryonic stem cell } \\ \text { FBS } & \text { fetal bovine serum } \\ \text { G-CSF } & \text { granulocyte colony-stimulating factor } \\ \text { GFP } & \text { green fluorescent protein } \\ \text { GM-CSF } & \text { granulocyte-macrophage colony-stimulating factor } \\ \text { GMP } & \text { granulocyte/monocyte progenitor } \\ \text { Het } & \text { heterozygous } \\ \text { HCT } & \text { hematocrit } \\ \text { HLA } & \text { human leukocyte antigen } \\ \text { HPC } & \text { hematopoietic progenitor cell } \\ \text { HR } & \text { homologous recombination } \\ \text { HSC } & \text { hematopoietic stem cell } \\ \text { ICM } & \text { inner cell mass } \\ \text { IgG } & \text { immunoglobulin G } \\ \text { IHC } & \text { immunohistochemistry } \\ \text { Ihh } & \text { indian hedgehog } \\ \text { IL } & \text { interleukine } \\ \text { IR } & \text { internal ribosome entry site } \\ \text { IRES } & \\ \text { ISH } & \text { in situ hybridization } \\ \text { KO } & \text { L-ML }\end{array}$




\begin{tabular}{|c|c|}
\hline $\mathrm{LOH}$ & loss of heterozygosity \\
\hline LSK & $\mathrm{Lin}^{-} \mathrm{Sca}-1^{+} \mathrm{c}-\mathrm{Kit}^{+}$ \\
\hline LT-HSC & long term hematopoietic stem cell \\
\hline MACS & magnetic-activating cell sorting \\
\hline $\mathrm{MCH}$ & mean corpuscular hemoglobin \\
\hline $\mathrm{MCV}$ & mean corpuscular volume \\
\hline MDS & myelodysplastic syndrome \\
\hline MEP & megakaryocyte/erythroid progenitor \\
\hline MPP & multipotent progenitor \\
\hline MRN & Mre11-Rad50-Nbs1 \\
\hline MSCV & murine stem cell virus \\
\hline NHEJ & non-homologous end joining \\
\hline NLS & nuclear localization signal \\
\hline NPM & nucleophosmin \\
\hline ORF & open reading frame \\
\hline p.c. & post coitum \\
\hline PBMC & peripheral blood mononuclear cell \\
\hline PBS & phosphate buffered saline \\
\hline PBST & phosphate buffered saline Tween 20 \\
\hline PCML & periodic chronic myelogenous leukemia \\
\hline PCR & polymerase chain reaction \\
\hline PFA & paraformaldehyde \\
\hline PLT & platelet \\
\hline pSP & para-aortic splachnopleura \\
\hline PVDF & polyvinylidene fluoride \\
\hline $\mathrm{RBC}$ & red blood cell \\
\hline RNAi & RNA interference \\
\hline ROS & reactive oxygen species \\
\hline rpm & rounds per minute \\
\hline RT-PCR & reverse transcription polymerase chain reaction \\
\hline $\mathrm{SCF}$ & stem cell factor \\
\hline SCID & severe combined immunodeficiency \\
\hline ssDNA & single strand DNA \\
\hline ST-HSC & short term hematopoietic stem cell \\
\hline TCR & T cell receptor \\
\hline TGF & transforming growth factor \\
\hline TO & thiazole orange \\
\hline UTR & untranslated region \\
\hline WAS & Wiskott-Aldrich syndrome \\
\hline WBC & white blood cell \\
\hline WT & wild-type \\
\hline WWII & world war II \\
\hline
\end{tabular}




\section{CHAPTER 1. INTRODUCTION}

This chapter is a brief introduction on the background knowledge related to this study, including general concepts in hematopoiesis, erythropoiesis and gene targeting. More detailed and specific introduction is given in context of results in Chapter 4.

\section{Hematopoiesis and Hematopoietic Stem Cell}

\section{The Old Wisdom and Modern History}

Hematopoiesis literally refers to the formation of blood. The conjugation between hematopoietic system and stem cell biology is not incidental. Hematopoietic stem cell (HSC) is defined by the ability to reconstitute lethally irradiated hosts' hematopoiesis, to self-renew, and to differentiate into all mature blood cell types. Specific hematopoietic cells can be sorted based on surface marker expression profile, and tested by transplantation to study the stem cell activity. The first mention of a stem cell in hematopoietic system could date back to $19^{\text {th }}$ century by Artur Pappenheim [1], who proposed a monophyletic pedigree of all blood cells [2] and was elaborated by Ernst Neumann and Alexander Maximow [3]. On the contrary was Paul Ehrlich of the polyphyletic school, who considered the precursors of lymphocytes and leukocytes were in different organs [2]. The initiation of the unitarian hematopoietic stem cell idea was early, but it was not until 1961 that this idea was experimentally verified by a spleen colony forming assay [4].

Like other findings in medicine, the lack of knowledge of stem cells did not impede the empirical application of stem cell transplantation. The first unsuccessful attempt of human marrow transplant was in 1939 [5]. In 1950s, in dealing with people exposed to lethal dose of radiation during WWII, transplants from spleen and bone marrow were found to rescue survival [6]. The first sustained engraftment was achieved in 1965 for an acute lymphoblastic leukemia (ALL) patient who received marrow infusion from 6 related donors [5]. In 1968 after the discovery of human leukocyte antigen (HLA) system, children with severe combined immunodeficiency (SCID) and with Wiskott-Aldrich syndrome (WAS) were the first cases with successful marrow transplants [5]. In 1970s, more patients with acute leukemia or aplastic anemia underwent marrow transplantation from siblings [5], many of whom are still surviving. Successful cell transplant from unrelated donors were reported in 1977, followed by the first successful autologous hematopoietic cell transplant in 1978 [5]. By 2000, more than 500000 patients had been transplanted since 1970s [5]. 


\section{Markers of HSC}

HSCs, though a heterogeneous population, still share some common features between individual cells. Several combinations of markers can enrich highly purified HSCs. At this time, there is no "magical" combination of markers to exclusively separate HSCs from other cell types.

A commonly used marker combination is $\mathrm{LinScal}^{+}{ }^{+} \mathrm{c}-\mathrm{Kit}^{+}$or LSK. Only a small fraction of LSK cells are true stem cells, approximately 1 out of 100 . To further enrich, CD34 or Thy-1 is regularly added. The expression patterns of these two markers are different in humans and mice. HSC of rat and human expresses high level of Thy-1 [7], whereas its level is low in mouse HSC [8]. The relationship between CD34 expression and stem cell identity is dynamic in mouse. Under homeostatic conditions, CD34-LSK population represents stem cell activity. However during the reconstitution phase after transplantation, these cells become $\mathrm{CD} 34^{+}$without loss of stem cell activity, whereas they turn back to $\mathrm{CD}^{-}$once reconstitution phase is finished. Human is different from mouse in CD34 expression in HSC. Human HSC is always CD34 ${ }^{+}$. A relatively new marker is CD150, which in combination with LSK and CD48 can separate highly enriched HSC population [9].

Besides cell surface markers, HSCs exhibit a biological feature that renders them drug resistant. Stem cells are responsible for tissue regeneration throughout the whole life,

so there is an intrinsic need for them to be resistant to various environmental insults such as chemicals and drugs. Stem cells meet this biological need by making pumps across cell membrane. Once the chemicals diffuse into a stem cell, they can be actively pumped out through ATP-binding cassette transporters [10]. Enabled by this feature, stem cells are resistant to DNA dyes like Hoechst-33342, thus can be sorted via flow cytometry as a population of low fluorescence in both blue and red spectrum. This is referred to as the "side population" [11].

\section{Adult Hematopoiesis and Anatomy}

Adult hematopoiesis is a series of hierarchical events (Figure 1-1). In adult, a long term hematopoietic stem cell (LT-HSC) first becomes a short term hematopoietic stem cell (ST-HSC), and then further turns into multipotent progenitor (MPP). The difference between LT-HSC, ST-HSC and MPP is their ability to self-renew. LT-HSC can self-renew for whole life time, whereas ST-HSC can only support self-renewal for 6 to 8 weeks [12]. The self-renewal ability of MPP is very limited, and under transplant conditions it is difficult to detect [13], yet this population is undifferentiated [14]. This cascade is not reversible. MPP gives rise to lineage restricted progenitor cells, including common lymphoid progenitor (CLP) and common myeloid progenitor (CMP) in the bone marrow. CLP can transiently give rise to $\mathrm{B}, \mathrm{T}, \mathrm{NK}$ and dendritic cells upon transplantation [15]. CMP is marked by high CD34 and c-Kit expression, low FcRgII/III expression, and lack of Sca-1 in the Lin population. When CMP further develops into granulocyte/monocyte progenitor (GMP), the FcRgII/III expression goes up; when the 


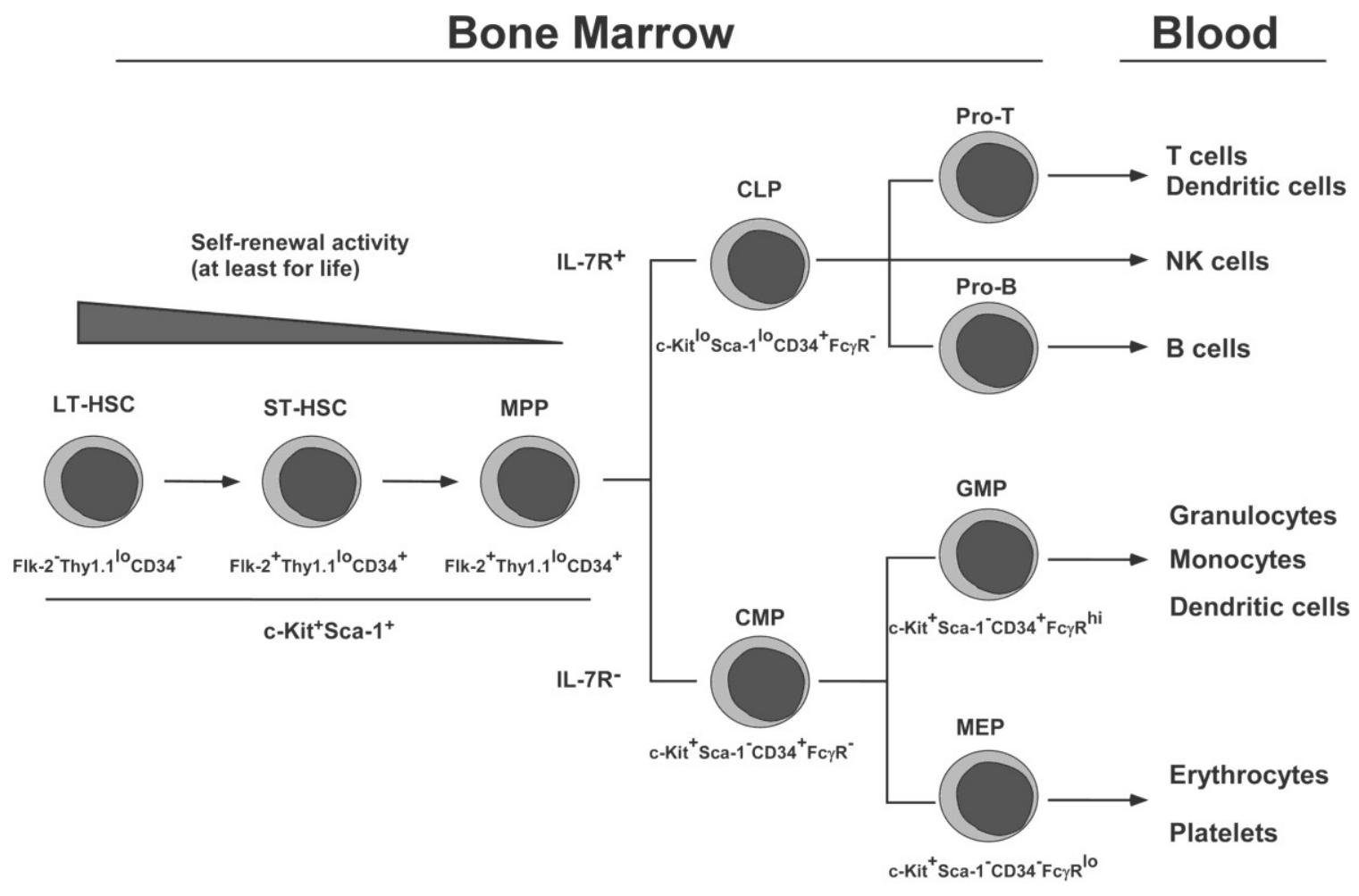

Lineage negative

\section{Figure 1-1. Conceptual hematopoietic tree of mouse}

LT-HSC, Long-term hematopoietic stem cell; ST-HSC, short-term hematopoietic stem cell; MPP, multipotent progenitor; CLP, common lymphoid progenitor; CMP, common myeloid progenitor; GMP, granulocyte/macrophage progenitor; MEP, megakaryocyte/erythrocyte progenitor.

Reprinted with permission. Shizuru, J.A., R.S. Negrin, and I.L. Weissman, Hematopoietic stem and progenitor cells: Clinical and preclinical regeneration of the hematolymphoid system. Annual Review of Medicine, 2005. 56(1): p. 509-538. 
CMP develops into megakaryocyte/erythroid progenitor (MEP), it loses FcRgII/III and CD34 expression. GMP develops into granulocytes including neutrophils, eosinophils and basophils, as well as monocytes that can differentiate into macrophages and dendritic cells. MEP can give rise to red blood cells (RBCs) and megakaryocytes. Platelet is the fragment of megakaryocyte [13].

Most of the above processes take place in bone marrow under homeostasis. The anatomic structure for T cell development is thymus. Splenic hematopoiesis is different between mice and humans. Mouse spleen actively produces RBCs throughout the life. In adult human, spleen is not an active hematopoietic organ under steady-state [16], but becomes important under stress conditions such as anemia. Under pathological conditions, hepatic erythropoiesis also takes place [17].

In the bone marrow compartment, HSCs are enriched in endosteal surface. It has been noted that osteoblast cells within the endosteal region have the potential to produce important cytokines to maintain and expand HSCs, including granulocyte colony-stimulating factor (G-CSF), granulocyte-macrophage colony-stimulating factor (GM-CSF), interleukine-6 (IL-6), transforming growth factor beta (TGF- $\beta$ ), Jagged-1 and chemokine ligand 12 (CXCL12) [18]. In two mouse models, bone morphogenetic protein (BMP) receptor IA conditional knockout and parathyroid hormone transgenic mice, with increased osteoblast cells, the number of HSCs also increase $[19,20]$. The fact that HSCs are also present in extramedullary tissues such as liver [21] and spleen [9] where osteoblast cells are absent, indicates HSC niches other than osteoblast. Anatomically, most HSCs mobilized to adult spleen localize adjacent to sinusoids. Even in the bone marrow, endosteal niche region is abundant in vasculature, suggesting the role of blood vessel as niche [9]. The discovery of osteoblast niche and vascular niche raises a question: are there multiple niches that regulate HSCs in different ways, or a common mechanism that regulates HSCs in both vascular and endosteal locations? An observation that HSCs are consistently found adjacent to CXCL12-secreting cells irrespective of their locations in vascular or endosteal region [22] raises the possibility that all HSCs may be regulated by a common mechanism [23].

Even though the majority of HSCs remain confined to the endosteal or vascular niches, a small portion of HSCs constantly circulate in the peripheral blood. The amount of circulating HSCs in peripheral blood is estimated 100-fold lower than that of bone marrow [24], probably 100 to 400 LT-HSCs in the blood of a mouse [25, 26]. The use of G-CSF to mobilize HSC from bone marrow for the collection has become a conventional clinical practice long before the understanding of the underlying mechanism.

\section{Stem Cell Kinetics}

The knowledge on the kinetics of stem cell population is largely obtained from mouse. It has been estimated all mammals, including humans, posses $1-2 \times 10^{4} \mathrm{HSCs}$ [27]. This estimation is based on the estimated HSC frequency and estimated bone marrow cellularity [28]. By single cell transplantation in mouse, the frequency of stem 
cell is estimated a few out of $10^{5}$ bone marrow cells (Table A-1), and may vary in different genetic backgrounds and ages [29].

Among this rare population, only a small fraction are actively cycling at any given time point. In a highly enriched $\mathrm{HSC}$ population $\left(\mathrm{Lin}^{-} \mathrm{Sca} 1^{+} \mathrm{c}-\mathrm{Kit}^{+} \mathrm{CD} 150^{+} \mathrm{CD} 34^{-} \mathrm{CD} 48^{-}\right.$ CD135 ), 70\% cells are dormant, and only $1.6 \%$ are in S/G2/M phase [30]. These several hundred dividing stem cells must replace billions of RBCs and nonlymphoid peripheral blood cells every day [16]. Some studies by BrdU labeling propose the HSC population is a group of slow dividing cells that asynchronously enter the cell cycle [31,32]. A mathematical model based on long term BrdU pulse-chase or H2B-GFP chase observation indicates $85 \%$ of the HSCs divide every 36 days, while the left $15 \%$ HSCs are highly dormant and divide every 145 days [30, 33]. Several mathematical models have been proposed to fit the experimental data [30-33], but all models assume nearly fixed cell cycle for the fast dividing and slow dividing population, the validity of which assumption is questionable. From the existing knowledge of the immune system, the inter-division time interval, or the duration of G0 phase, is unlikely to be homogenous in a cell population [34]. This compromises the validity of the proposed models, and the actual kinetics of HSCs may be more complicated.

\section{Apoptosis of HSC}

Mouse Hemogen has been postulated with an anti-apoptotic function in hematopoietic cells. A brief introduction on the apoptosis of HSC is included here. Mouse gene Hemogen is introduced in Chapter 2.

The apoptotic cells in stem cell population are rare under homeostatic conditions, and can be removed rapidly. HSC does respond to at least two common apoptotic signals: ionizing radiation (IR) and cytokine deprivation (Figure 1-2).

IR induced apoptosis is related to DNA damage. Generally speaking, apoptosis induced by genotoxins is largely due to DNA damage. These DNA damages include [35]: covalently modified nucleotides, such as O6-methylguanine, N-methylation, and O6-chloroethylation; mismatches; breaks in the backbone including single strand break and double strand break (DSB); and DNA cross- linking. IR can create DNA double strand break, in response to which ATM-CHK2-p53 will be activated for apoptosis or DNA repair. ATR can respond to UV radiation and chemical reagents that stall the DNA replication fork [35]. The latter would also be referred as $\mathrm{S}$ phase checkpoint. Several genes known for their roles in HSC apoptosis in response to IR are listed below.

Bcl-2 overexpression can protect stem cell from IR induced apoptosis [36], but knockout animal shows no stem cell abnormality [37]. Puma knockout bone marrow cells are IR resistant [38]. The activation of Puma is both p53 dependent and independent [38]. The p53 independent activation of Puma is possibly through the transcriptional regulation by Slug [39], and Slug knockout animal shows increased sensitivity to IR [40]. The protection by Slug is via its antagonizing effect on the pro-apoptotic Puma, and Slug 


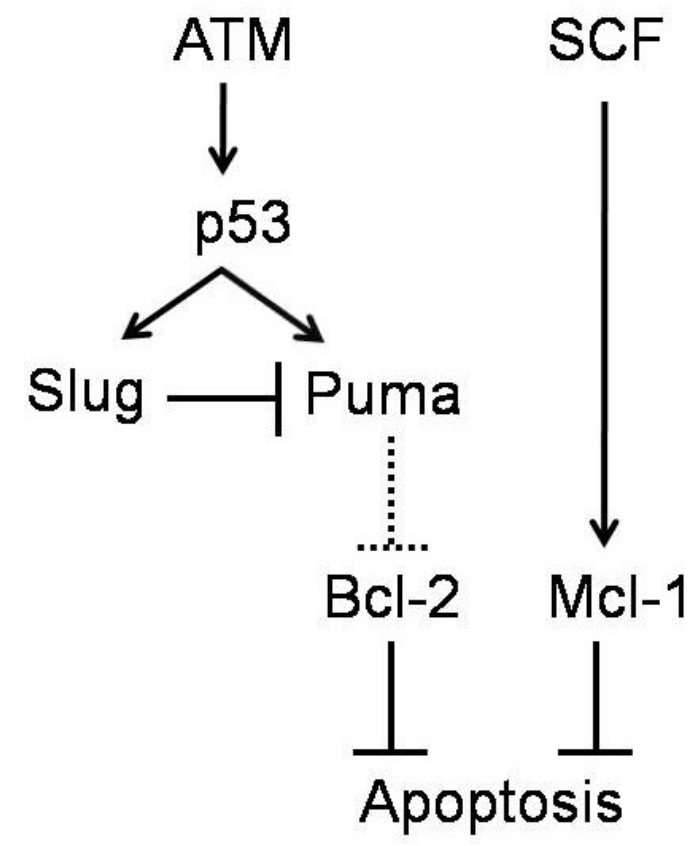

\section{Figure 1-2. Apoptosis of HSC}

Ionizing radiation induced apoptosis involves p53, Slug, Puma and Bcl-2. Cytokine may protect the HSC from apoptosis via Mcl-1. The expression of Mcl-1 is regulated by SCF.

Sources: Opferman, J.T., et al., Obligate role of anti-apoptotic Mcl-1 in the survival of hematopoietic stem cells. Science, 2005. 307(5712): p. 1101-1104. Wu, W.-S., et al., Slug antagonizes p53-mediated apoptosis of hematopoietic progenitors by repressing Puma. Cell, 2005. 123(4): p. 641-653. 
itself is also a p53 target gene [39].

The other pro-apoptotic stress is cytokine deprivation. Under serum free conditions, HSCs undergo rapid apoptosis and cannot be protected by overexpression of Bcl-2 [41]. This is because HSC needs another signaling from SCF/c-Kit at the same time to prevent apoptosis [41]. In coherence with the role of c-Kit and its ligand SCF is the Mcl-1 knockout mouse model. Mcl-1 is an anti-apoptotic Bcl-2 family member. Its expression in HSC is regulated by SCF signaling, which is required for HSC survival in vivo [42]. Mcl-1 knockout animal has anemia and reduced bone marrow cellularity due to a loss of the progenitor population [42], and the knockout bone marrow progenitor cells cannot survive even in the presence of growth factors [42]. There is also report Mcl-1 is required for the UV induced apoptosis [43].

\section{Fetal Hematopoiesis}

Vertebrate hematopoiesis takes place in two waves: a transient primitive (embryonic) wave and the definitive (adult) wave. The primitive hematopoiesis is to initiate the circulation and provide the initial blood cells; the definitive hematopoiesis is to generate more cell types and maintain the HSC pool for lifetime. In humans, the primitive hematopoiesis occurs in yolk sac until week 7 of gestation. The definitive hematopoiesis starts in fetal liver from week 9 and 24 [16]. Because primitive hematopoiesis is primarily erythropoiesis, it is discussed under Erythropoiesis in detail.

During mouse development, by embryonic day 7.0, a group of cells in the posterior primitive streak have developed into hemangioblast, the common precursor of blood cells and endothelial cells [44]. Hemangioblast cells migrate to yolk sac, become committed endothelial and hematopoietic progenitors, and give rise to blood islands, where the first primitive erythrocyte appears [45].

The definitive myeloerythroid progenitors can be identified in the yolk sac as early as E8.25 [46], soon after the primitive erythroid precursors. Over the next 2 days, these progenitors are confined within the yolk sac for proliferation, and migrate to fetal liver for terminal differentiation later. Definitive erythrocytes first enter circulation between E11.5 and E12.5 [46]. The yolk sac definitive hematopoiesis may also produce myeloid and megakaryocytic progenitors [46].

The presence of functional HSCs in yolk sac may be controversial. Although yolk sac cells can engraft into newborn animals with intrahepatic transplantation, they cannot generate adult reconstituting HSC [46]. The quantity of HSC in yolk sac would be low, if there is any. The second site for fetal hematopoiesis is aorta-gonadmesonephros (AGM) region. HSCs in AGM region may develop in situ rather than being imported from other sites, because in vitro cultured para-aortic splanchnopleurae (pSP) tissue from precirculation embryos can give rise to transplantable HSCs [47]. Placenta is also an HSC pool. There is no consensus on the exact anatomic sites where HSCs reside within the placenta. Different HSC markers indicate HSCs may be present within the placental 
labyrinth, trophoblast giant cell layer, and chorionic plate [48]. Placental HSCs may be generated de novo as HSC activity has been detected in the absence of circulation [49].This HSC pool is transient, and diminishes while the fetal liver HSC pool expands. It is possible the placental HSCs may migrate to fetal liver for definitive hematopoiesis [48].

\section{Erythropoiesis}

As stated above, RBC is the first blood cell type appearing during mouse development, detected as early as E7.5 in blood islands. At this stage, the visceral endoderm cells can secrete soluble signals such as Indian hedgehog (Ihh) to activate erythropoiesis [50]. Wnt/ $\beta$-catenin signaling may regulate the specification process [51].

The two waves of erythropoiesis produce primitive and definitive erythrocytes respectively. The two populations share some common features, including development from lineage restricted progenitors, progressive maturation from nucleated erythroblasts, decrease in cell size during maturation, nuclear condensation and finally enucleation during late stages [52]. But these two types of erythrocytes are of different developmental origins. Primitive erythrocytes originate from posterior plate of mesoderm, and definitive erythrocytes are developed from lateral plate [52]. Primitive erythrocytes are larger than definitive erythrocytes, express different globin genes, and have higher oxygen carrying capacity. At the $\beta$-globin locus, primitive erythrocytes express Hbb-y and Hbb-bh1, while the definitive erythrocytes switch to Hbb-b1 and Hbb-b2 [52]. The yolk sac is the only anatomic site for primitive erythrocytes, and definitive erythrocytes are found both in yolk sac and fetal liver. As the heart begins to beat at E9.0, primitive erythrocytes enter the circulation and continue with the maturation process in bloodstream. Primitive erythrocytes develop from nucleated proerythroblast to orthochromatic erythroblast and to reticulocytes with loss of nucleoli. This maturation process is also accompanied by loss of CD71 expression and gain of Ter119 expression. These mature enucleated primitive erythrocytes could live for a long time until birth [52].

\section{Gene Targeting}

\section{Homologous Recombination}

The fundamental science behind targeted mutagenesis is homologous recombination (HR) and DNA double strand break (DSB) repair. Once DSB is detected, there are two main pathways available for the purpose of repair, non-homologous end joining (NHEJ) and homologous recombination. HR can take place in late S-G2 phase of cell cycle, and NHEJ can occur throughout the whole cell cycle [53]. HR is known as the error free pathway because a sister chromatid is used as a template for repair. In replicating cells, HR is the preferred pathway. The crossover exchange between nonsister chromatids during meiosis is an example of naturally occurring HR. For a complete review, please refer to reference [54]. 
The first step in HR mediated repair is strand resection. Once a DSB is created either by intrinsic factors like radical oxygen species (ROS) or by extrinsic factors such as ionizing radiation (IR), Mre11-Rad50-Nbs1 (MRN) complex acts as a sensor [53]. Once MRN complex binds the DSB ends, it recruits ATM/ATR to activate DNA damage signaling and promotes strand resection. Strand resection involves generating single stranded DNA (ssDNA) at the site of DSB by degrading nucleotides from the 5 ' end on both sides of the break, making 3' overhang single-stranded regions. The recombinase Rad51 at this stage is loaded to ssDNA and forms a highly extended structure called presynaptic filament [54]. The formation of presynaptic filament is a slow process, and Brca2 has a role in delivering Rad51 to the ssDNA. The Rad51-ssDNA nucleoprotein presynaptic filament then invades into the homologous region on the sister or non-sister chromatid by displacing one strand of the template. The invading strand continues elongation by repair synthesis, and eventually becomes long enough to cover the entire length of the gap. The newly synthesized region then anneals with the far side of the gap, forming heteroduplex DNA on each side of the gap. Branch migration converts this structure into a molecule with 2 recombinant joints, named Holiday Junction. If both Holiday Junctions are resolved in the same direction, the result would be the noncrossover original molecule with newly synthesized region; if 2 Holiday Junctions are resolved in different directions, the outcome would be crossover of the genetic codes between homologous regions [53-55].

\section{Gene Targeting in Mouse}

Besides HR, generation of a mouse model with targeted mutation also requires successful culture of embryonic stem (ES) cell. In general, ES cells can be cultured in petri dish, electroporated with targeting construct, selected for correct homologous recombination events, transferred to mouse blastocyst embryos, and transplanted to surrogate females. The delivered offspring of the surrogate female is called chimera, because part of the individual animal develops from ES cells and part from the original blastocyst. If ES cells develop into germ cells, the targeted mutation can be passed to the next generation to establish a stable mouse strain carrying this mutation [56]. Details of this method are included in Chapter 3.

A problem with the conventional gene knockout strategy is embryonic lethality. Although the chimeras and heterozygous animals can be born, sometimes it is impossible to obtain the homozygous animals because the targeted gene is so important that the homozygous animals die in uterus or even cannot implant. The second problem with conventional knockout methodology is the tissue specificity. Some genes are universally expressed in many tissues. When such gene is knocked out, it is impossible to distinguish the primary effects from the secondary effects and to attribute the phenotypes to specific tissues. The third consideration is from the selection cassette used for ES cell screening. Constitutive expression of the selection marker may be toxic to the cell or affect the phenotypes. One such example is Men1 knockout mouse model. Men $1^{+/}$was 
unexpectedly lethal because the bidirectional transcriptional activity of PGK promoter in the selection cassette produced aberrant transcript [57].

To address the temporal and spatial control problems, the conditional gene knockout strategy was developed. This system is developed from phage P1. The loxP site is a 34 bp DNA sequence discovered in bacteriophage P1. It consists of two inverted 13 bp repeats and a central asymmetric 8 bp core region [58]. The phage recombinase Cre can mediate recombination between two identical loxP sites. When the two loxP sites are in the same orientation, the outcome is excision of the sequence between; when the two loxP sites are in the opposite directions, the outcome is inversion of the sequence between [59]. In this sense, the selection marker can be excised after selection, and the gene can be knocked out only in the desired cell types at the desired time point, whereas Cre expression is driven by tissue specific or temporal controllable promoter [60].

The first batch of gene targeted mouse models came in 1989 [61-63]. By 2001, more than 4000 genes had been knocked out [64]. There has been rapid progress since the initiation of the International Knockout Mouse Consortium in 2007. By 2011, approximately 17000 genes had been disrupted [65]. In 2011, as the second phase of the Knockout Mouse Project, another 2500 knockout mice strains are to be developed in 5 years. 


\section{CHAPTER 2. LITERATURE REVIEW OF HEMOGEN AND ORTHOLOGUES}

The function of Hemogen (Hemgn) is relatively unexplored. With a focus on mouse Hemgn and its orthologues in human and rat in the perspective of comparative genomics, this chapter gives a literature review of the published research data and analysis in the publicly available databases.

\section{Mouse Hemogen}

\section{Gene Structure}

Hemgn is located in the mouse chromosome 4B1 region. The whole gene spans around $19.5 \mathrm{~kb}$, and contains 5 exons. The first exon is non-coding. There is no known microRNA in this region according to database search (www.mirbase.org).

Two transcript variants encoding the same 503 amino acid protein product have been identified, one as the hematopoietic tissue isoform and the other as a testis-specific isoform. The testis-specific transcript is $2321 \mathrm{bp}$ containing all 5 exons, whereas the 2363 bp hematopoietic isoform is spliced from exon 2-5. The two isoforms differ in both the 5' and 3' UTR [66].

The first ATG is the translation initiation codon with the sequence AAG consistent with Kozak sequence with $A$ at position -3 and $G$ at position +4 . The polyA signal is ATTAAA, a common variant of the canonical AATAAA. The protein contains a predicted nuclear localization signal (NLS, amino acids 61-78) and a predicted coiled-coil domain (amino acids 34-50) in the N-terminus [67]. There is no other identifiable functional domain or family member.

\section{Expression Pattern}

By in situ hybridization (ISH) with an antisense RNA probe, Hemgn is detected in the blood islands of yolk sac and in primitive blood cells as early as E8.5. From E10.5 on, Hemgn expression is detected in hepatic primordial with the onset of organogenesis of liver. By E11.5, Hemgn expression is found exclusively in the fetal liver, while in circulating blood cells it became undetectable. The same expression pattern persists in E12.5 and E14.5 embryos [67].

In adult animals, Hemgn expression is also examined by ISH. Hemgn is detected in the round spermatids in testicle [66], in the red pulp of spleen, where active hematopoiesis takes place, but not in the white pulp of spleen [67]. Northern blotting with an antisense Hemgn RNA probe does not detect its expression in thymus, brain, heart, kidney, liver, lung, skeletal muscle and stomach [67]. Hematopoietic cells are examined 
with RT-PCR. Hemgn is primarily expressed in $\mathrm{Lin}^{-}$and $\mathrm{Lin}^{-} \mathrm{Scal}{ }^{+} \mathrm{c}-\mathrm{Kit}^{+}$cells. Cultured macrophages and natural killer cells also show weak expression, but no expression is detected in other differentiated blood lineages including $\mathrm{CD}^{+}{ }^{+} \mathrm{T}$ cell, B220 ${ }^{+} \mathrm{B}$ cell, Ter $119^{+}$erythrocyte and $\mathrm{Gr}^{+}$granulocyte [67]. However, it is not specifically noted whether these differentiated cells are isolated from bone marrow or peripheral blood, which is discussed in Chapter 5. In sum, Hemgn is selectively expressed in hematopoietic progenitor cells, but diminishes in mature and differentiated cell types.

\section{Gene Regulation}

By luciferase assay, a minimum promoter region from -831 to +196 is identified, and a $184 \mathrm{bp}$ fragment in 5' UTR may contain critical regulatory elements for Hemgn transcription. This 184 bp sequence contains 3 GATA boxes (TATAA). Gata-1, but not Gata-2, binds and transactivates Hemgn promoter [68].

Hemgn has been identified as a direct transcriptional target of Hoxb4 [69]. Hoxb4 can promote mouse hematopoietic stem cell self-renewal in vitro and ex vivo. When hematopoietic stem cells or hematopoietic progenitor cells (HPCs) are transduced with Hoxb4, Hemgn is found highly up-regulated. In a chromatin immunoprecipitation (CHIP) assay, Hoxb4 binds Hemgn promoter directly and regulats its transcription, as indicated by luciferase activities in MEL cell line. There are also multiple Hoxb4 binding sites TAAT in Hemgn promoter region [69]. Functional assays also show that Hemgn is a downstream target gene of Hoxb4. Hemgn transduced HSCs/HPCs gain growth advantage over wild-type cells, similar to Hoxb4 transduced cells [69].

There are multiple predicted miRNA target sites in 3' UTR. Some with the highest score in miRanda Target database (www.microrna.org) include miR-377, miR-208a, miR-208b, miR-499, miR-128, miR-542-3p. Among these microRNAs, miR-128 can target Bmi-1 to inhibit glioma stem cell self-renewal [70], but whether this is also true for HSC is unknown.

\section{Putative Functions of Hemgn}

The exact function of Hemgn is less known. Whether the predicted NLS is functional and indispensible for its nuclear localization has not been experimentally tested. Hemgn is transported to nucleus of COS-7 cell upon transfection [67]. The nuclear localization might imply its possible function in transcription, chromatin structure, DNA repair, RNA splicing and other biological processes in the nucleus. The other predicted motif is the coiled-coil domain. The function of $\alpha$-helical coiled-coil structure is to mediate subunit oligomerization or other type of protein-protein interaction through ionic interaction or hydrophobic interaction $[71,72]$. A typical coiled-coil motif consists of helices of 7 residues in each. The number of the 7 residue repeats can go up to 200 in a protein [71]. With analysis by NCOILS (embnet.vital-it.ch/software/COILS_form.html) and COILS/PCOILS (toolkit.tuebingen.mpg.de/pcoils) programs, mouse Hemgn may 
contain 2 such repeats between amino acid 34 to 50 with high score (score $>0.9$ ). In contrast, the same programs can only find human homologous sequence with very low score for coiled-coil structure formation $($ score $<0.2$ ). Because no other motifs like the canonical DNA or RNA binding domains are identified, it is less likely Hemgn binds DNA or RNA directly to regulate transcription or splicing. It is possible Hemgn interacts with other nuclear proteins through its coiled-coil motif and carry out its function. Hemgn function may also be regulated by posttranslational modification. Serine 380 has been characterized as a phosphorylation site in $\mathrm{Ba} / \mathrm{F} 3$ cell line [73]. However, the physiological or pathological significance of S380 phosphorylation is not known. From published literatures, Hemgn may be related to apoptosis and HSC self-renewal as stated below.

Anti-apoptosis. Hemgn overexpression in bone marrow progenitor cells has been shown with the ability to protect these cells from cytokine withdrawal induced apoptosis. 5-FU treated mouse bone marrow cells are transduced with Hemgn retroviral vector or control vectors, and cultured for additional 6 days in the presence of cytokine supplements. After 16 hours culture in medium with 1\% FBS but without cytokine supplements, the Annexin $\mathrm{V}^{+}$cells in Hemgn transduced cells are less than $20 \%$ while in control the percentage is more than $50 \%$. Hoxb4 transduction shows a stronger protection effect on the progenitor cells [69]. It is yet unclear what upstream or downstream factors of Hemgn might be accounted for this protective effect.

HSC self-renewal. Overexpression of Hemgn can recapitulate the Hoxb4 mediated HSC expansion. Hemgn transduced cells show growth advantage in both liquid culture and colony assay. Secondary colony assay is a measurement of the self-renewal ability of stem cells. When 5-FU treated bone marrow cells are transduced with Hemgn and cultured in M3434 medium, increased secondary colony number is seen [69]. This phenotype may be due to the anti-apoptotic function of Hemgn [69]. Meanwhile, Hoxb4 mediated HSC expansion is impaired, but not totally ablated, when Hemgn is silenced by RNA interference (RNAi), indicating Hemgn independent function of Hoxb4 [69]. The involvement of Hemgn in Hoxb4 function initiated my interest in the physiological and pathological roles of Hemgn itself in hematopoiesis.

\section{Rat Hemogen/RP59}

\section{Gene Structure}

Rat Hemogen, also known as RP59, locates in chromosome 5q22 region. The gene spans $10 \mathrm{~kb}$, and consists of 4 exons. There is only one transcript encoding a 514 amino acids protein. Rat RP59 is 75\% identical to mouse Hemogen in protein alignment, but is only $46 \%$ identical to human Hemogen. 


\section{Expression Pattern}

By ISH and immunohistochemistry (IHC), RP59 expression is detected in [74]:

1. The yolk sac of day 9 post coitum (p.c.) rat embryos, corresponding to mouse E7;

2. Extraembryonic mesodermal layers with its prospective blood islands;

3. The intraembryonic primary ectoderm at day 9 p.c., including the primitive streak;

4. Well-developed blood islands containing mainly erythropoietic cells at day 12 p.c.;

5. Fetal liver erythroblast cells, megakaryocytes and circulating cells at day 17 p.c.;

6. Bone marrow and spleen red pulp of 5-day-old rat;

7. Young osteoblast [75];

8. Newly secreted tooth enamel and ameloblast [76].

The expression pattern of Hemgn is better characterized in rat than in mouse. In late prenatal stages, RP59 is also found in peripheral circulating blood [74]. The same may not be true for mouse [77]. Hemgn is not expressed in the blood cell of E11.5 mouse embryo, and the expression level is very low in adult mouse peripheral blood [67]. Similar to mouse, RP59 is absent in most tissue, among which including fetal spleen, liver (after birth), and the white pulp of adult spleen [74].

Different from the cell line based assay of mouse Hemgn, IHC staining of rat bone marrow shows cell type specific subcellular localization of the protein. It predominantly localizes in the cell periphery of erythroblast, and in the nucleus of osteoblast and megakaryocyte [75].

\section{Human Hemogen/EDAG}

Human Hemogen, known as Erythroid Differentiation Associated Gene (EDAG, or EDAG-1) is a homologue of mouse Hemogen with $46 \%$ identity. The sequences of NLS and coiled-coil motif are partly conserved between species. However, as stated above, programs only predict very low score for the coiled-coil structure formation in human EDAG.

\section{Gene Structure}

Human EDAG/Hemgn is located in chromosome 9q22.33 region. The gene spans around $18 \mathrm{~kb}$, and consists of 6 exons of which the first two exons are non-coding. There are two transcript variants. The long transcript contains all 6 exons and exon 2 is missing in the short isoform. The 2 transcripts produce the same 484 amino acids protein product, which shares $46 \%$ identity with mouse Hemgn. 


\section{Expression Pattern}

The expression pattern of human EDAG is similar to mouse Hemogen. It has been detected by northern blotting at high level in adult bone marrow and fetal liver [67], but not in other tissues including spleen, lymph node, thymus, adult liver, heart, skeletal muscle, kidney, pancreas, tonsil, colon and peripheral blood mononuclear cells (PBMC) [68]. Child thymus shows low level of expression [67].

Pathological expression is found in AML and ALL patients' PBMC. Measured by real-time PCR in 10 AML patient samples, a positive correlation is reported between Gata-1 and EDAG transcription in myeloblast $(\mathrm{R}=0.93)$ [68]. This is consistent with the observation mouse Hemgn may be transcriptionally regulated by Gata-1. Mouse Hemgn promoter region contains multiple Gata binding motifs where Gata-1 actually binds [68]. Whether Gata-1 also binds human EDAG promoter is not known.

\section{Putative Functions}

An EDAG transgenic mouse model driven by the human CD11a promoter displays increased myelopoiesis and impaired lymphopoiesis [77]. The transgenic mice develop no abnormality up until 6 months. However by 6-24 months, their leukocyte numbers in peripheral blood are 2-fold higher than that of control animals. The increased number of mature granulocytes primarily accounts for this change. Flow cytometry reveals a significant increase of the $\mathrm{CD} 11 \mathrm{~b}^{+} \mathrm{Gr} 1^{+}$granulocytes. In contrast, the number of monocytic cells does not change dramatically. Bone marrow of the transgenic animal is found with hyperplasia in dominance of granulocytes. Spleens show a similar increase of the myeloid cells. These results indicate the onset of myeloid hyperplasia in the transgenic animals, with increase in the number of granulocytes [77]. Although both bone marrow and spleen share a similar phenotype, their responses during in vitro cell culture are quite different. When cultured in Methocult 3534 with supplement of stem cell factor (SCF), IL-3 and IL-6, the CFU-GM numbers are comparable between the transgenic animals and control animals. However in the same assay, splenocytes of the transgenic mice show a 2-fold increase in the colony number. When stimulated with GM-CSF supporting the growth of myeloid progenitors, transgenic splenocytes also give rise to 2.5-fold colony numbers [77]. These results suggest the differentiation rate of CMP to granulocytes is normal, but there is a promotion in extramedullary myelopoiesis.

In contrast to the increase in granulocytes, the number of $\mathrm{B} 220^{+}$lymphoid cells decreases in the transgenic bone marrow. Flow cytometry analysis reveals a 95\% reduction in $\mathrm{B} 220^{+} \mathrm{CD} 25^{+}$pre-B II cells and $50 \%$ decrease in the $\mathrm{B} 220^{+} \mathrm{IgM}^{+}$ immature/mature B cells within the bone marrow compartment. The B220 ${ }^{+} \mathrm{c}-\mathrm{Kit}^{+}$ pro/pre-B I cells are comparable between transgenic and control animals. These observations indicate the pro/pre-B I to pre-B II transition is hindered by constitutive EDAG expression [77]. The transgenic mice also display reduction in thymus cellularity 
and $\mathrm{CD} 4^{+} \mathrm{CD} 8^{+}$population. There is a dramatic increase of the $\mathrm{CD} 44^{+} \mathrm{CD} 25^{-}$cells within the $\mathrm{CD}^{-} \mathrm{CD}^{-}$compartment, indicating early T cells are arrested at DN I stage [77].

As a result of the myeloid hyperplasia, $34 \%$ of the transgenic mice die of severe organ infiltration by neutrophils during the period of 6-24 months. The moribund animals develop severe splenomegaly and the spleen weight shows a 3-fold increase. Morphology of the liver is abnormal, with large pale regions on the surface. Necropsy shows prevalent infiltration of liver, lung and kidney by neutrophils [77].

The physiological significance of this gene is unclear, but leukemic breakpoints in human chromosome 9q22 involving the EDAG locus implies its potential role in leukemia development [67]. There are several putative tumor associated genes in 9q22 region: NR4A3 is a member of nuclear hormone receptor family implicated in regulation of proliferation, differentiation and $\mathrm{T}$ cell apoptosis [78]; Foxel is the genetic determinant in certain thyroid carcinoma cases [79]; and EDAG is one of the potential leukemogenic genes. Most associated leukemia cases reported are AML, and the most frequent lesion type is deletion involving a break point in the $9 \mathrm{q} 22$ region [80]. Among 950 cancer cell lines screened, EDAG mRNA is detected in several human leukemic cell lines including K562, KU812 [81], both carrying Bcr-Abl translocation [82], as well as in Bcr-Abl- [83] human erythroleukemia cell line HEL 92.1.7 [81]. The expression level in bone marrow mononuclear cells of AML patients with complete remission is also significantly lower than those with no remission after therapy [84].

Similar to the mouse Hemgn, human EDAG has been proposed for an antiapoptotic function. Overexpression of human EDAG in IL-3 dependent pro-B cell line $\mathrm{Ba} / \mathrm{F} 3$ promotes survival in the absence of IL-3 by activation of the NF- $\kappa \mathrm{B}$ signaling, and up-regulating c-Myc, Bcl-2 and Bcl-xL, as determined by Western blotting [85]; Bcl-2 down-regulation is also seen in EDAG knockdown K562 cells, measured by semiquantitative RT-PCR [84]. This anti-apoptotic effect has been attributed to its physical interaction with nucleophosmin (NPM or NPM-1), which prevents the degradation of NPM [86]. The interaction between the two proteins is confirmed by coimmunoprecipitation (Co-IP) in K562 cells with monoclonal NPM antibody. In K562 cells, silencing of EDAG is also associated with decreased NPM protein level [86].

\section{Limitations of Previous Studies}

\section{The Ectopic Expression and Overexpression Systems}

Previous studies are mostly based on overexpression and ectopic expression systems. However gain of function study is different from the loss of function study. It is necessary to address the differences between the two systems and some intrinsic problems with ectopic expression and overexpression models. 
Loss of function model and gain of function model are the two sides of a coin. However, effects observed in gain of function model may not guarantee an opposite observation in the other. For example, overexpression of Hoxb4 leads to strong proliferation of HSC population [87], but the gene knockout model shows no obvious phenotype; overexpression of the anti-apoptotic factor Bcl-2 can protect HSC from ionizing radiation induced apoptosis [36], but the knockout mouse does not present defects in HSC [37].

One explanation is gain of non-physiological function when too much protein is expressed and binds to its non-physiological partners or substrates [88]. In the perspective of chemistry, the association and dissociation of a protein and its partners are under delicate equilibrium under homeostatic conditions. Increase in the concentration of specific protein will enhance not only the specific interaction with its physiological substrates, but also the interaction with other partners of low specificity and low affinity, especially in ectopic expression system, where the physiological co-factors might be absent. A positive result from overexpression or ectopic expression model might be nonphysiological. This is why loss of function study can complement the overexpression model for the physiological research. Gene knockdown by RNAi or inhibitors may elicit the concerns on incomplete knockdown and off target effect, but gene knockout model is relatively clean and specific. Although a lack of phenotype may be attributed to reasons like genetic redundancy, a positive phenotype in gene knockout model unequivocally demonstrates the physiological function of specific gene.

\section{Conservation across Species}

The human gene EDAG has been studied in mouse cells. Human EDAG is ectopically expressed in the hematopoietic system of the transgenic mouse model [77]; and the anti-apoptotic function of EDAG is also tested in murine $\mathrm{Ba} / \mathrm{F} 3$ cell line [85]; its function in the erythroid and megakeryocyte development is studied in 32D cell line [89], an IL-3 dependent myeloid cell line established from $\mathrm{C} 3 \mathrm{He} / \mathrm{J}$ mice injected with the Friend murine leukemia virus. None of these studies are carried out in human cells.

Indeed there have been transgenic mouse models of human genes, such as transgenic mouse of human $\beta$-globin [90]. However, such examples are highly conserved across species. The sequence identity of $\beta$-globin between mouse and human is $80 \%$; human and mouse K14 keratin are identical by $90 \%$ [91]. The validity of such across species transgenic models is based on the assumption that, the transgenic genes, though not in their original cell contexts, should behave similarly as they were. The above mentioned examples can satisfy this assumption by their highly conserved sequences across species. But the homology between mouse Hemgn and human EDAG is only $46 \%$. Even by comparing only the first 124 amino acids of the two proteins, which region may be required for the protein-protein interaction and where the predicted NLS and coiled-coil domain locate, the identity is $58 \%$ only. This fact is not a guarantee the human EDAG may function still in the same way in murine cells. The information obtained from such chimeric system might be limited, or even misleading. Instead, data of human 
EDAG and mouse Hemgn obtained respectively from the correct species may make better sense than those cross-species assays. It is also necessary to answer the question whether mouse Hemgn is the functional equivalence of human EDAG.

To address the above two problems, a mouse Hemgn knockout mouse model would be an appropriate tool to study its physiological function. 


\section{CHAPTER 3. MATERIALS AND METHODS}

This chapter introduces all materials and methods used in this study. Brief introduction of the methodology is included where needed.

\section{Design of the Targeting Allele}

The initial design process is a database and software based bioinformatics research. This section includes basic step-by-step instructions on genomic databases analysis. However the design process by nature should be considered case by case. The method described below is gene specific, and may not be applied to other genes without modification.

\section{Positions of loxP Sites}

Bioinformatic resources were found in Ensemble Genome Browser (www.ensembl.org). In the location view of mouse Hemgn, the page was configurated by turning on the following tracks: KO Alleles, KO Designs, GeneTrap, BAC map, Mouse miRNAs, miRNAs (miRBase), Reg. Feats, cisRED, RFAM ncRNAs, All Repeats, InterPro, miRanda Target and VISTA Enhancer. All available information listed in Mouse Genome Informatics (www.informatics.jax.org) was also checked.

With the help of InterPro track, a general idea of which exons to be knocked out was formulated based on the structure of the protein. The mRNA sequence of Hemgn was retrieved to VectorNTI from NCBI (www.ncbi.nlm.nih.gov) with its Accession Number. Exon sequences were manually deleted in different combinations. The new open reading frame (ORF) products were aligned to the wild-type protein product to figure out the best knockout strategy. loxP sites were placed at least $150 \mathrm{bp}$ from the exons without interruption of the regulatory elements listed above.

The sequence data of the gene with $10 \mathrm{kp}$ upstream of the proposed 5' loxP and $10 \mathrm{~kb}$ downstream of the 3' loxP was retrieved from Ensemble Genome Browser in Genbank format as txt file, with selection of Repeat Features and Gene Information in Genbank options. The coordination of the sequence was reset in VectorNIT to its coordination in Ensemble database.

\section{Enzymes and Probes for Southern Blotting}

With the facility of VectorNTI, the candidate enzymes for Southern blotting were selected. These enzymes cut only in the flanking sequences of the homology arms but not within the homology arms. Each enzyme was further analyzed for the expected band 
sizes. Enzymes with less than $1 \mathrm{~kb}$ difference between the wild-type and targeted allele were excluded.

The flanking sequences of the homology arms were screened for around $400 \mathrm{bp}$ probes free from Repeat Features coverage. These candidate probes were searched by Blast (blast.ncbi.nlm.nih.gov) to check the specificity. For each end of the targeting locus, 2 probes were initially designed but only one was used in this study.

\section{The Targeting Construct}

The protocols for generating targeting construct was developed from Dr. Pentao Liu's protocol, published on Frederick Natioinal Laboratory for Cancer Research website (ncifrederick.cancer.gov/research/brb/protocol.aspx). The bacteria mediated recombineering system is based on E.coli strain EL350 expressing $\lambda$ phage RED system [92]. The whole process is summarized in Figure 3-1.

\section{Miniprep for BAC Clone}

BAC clone RP23-259O2 was obtained from Children's Hospital Oakland Research Institute (Oakland, CA). The BAC containing bacteria cells were cultured in LB with $12.5 \mu \mathrm{g} / \mathrm{ml}$ chloramphenicol. The cells were lysed and neutralized by Qiagen miniprep kit (Qiagen, \#27104) according to the manufacturer's instruction. DNA was precipitated by adding equal volume of isopropanol. The tube was inverted repeatedly to mix (25-50 times), left at room temperature for incubation of 10 minutes, and then spun at $14000 \mathrm{~g}$ for 10 minutes. The DNA pellet was washed with $70 \%$ methanol, left air-dry for 10-20 minutes, and resuspended in 20-50 $\mu 1$ TE buffer. The DNA was dissolved by incubation at $50^{\circ} \mathrm{C}$ for 30 minutes to an hour. The DNA concentration was measured with Nanodrop.

\section{Retrieving Construct and Mini-targeting Constructs}

The retrieving vector VP101, and two vectors for mini targeting PL451 and PL452 were obtained from previous lab members. All constructs were generated by PCR, restriction enzyme digestion and ligation, and were sequenced before use.

For all PCR reactions, the initial denaturing was 5 minutes at $95^{\circ} \mathrm{C}$, and the final extension was 10 minutes at $72^{\circ} \mathrm{C}$. The annealing temperatures and extension times within cycles were different, as listed in Table A-2. PCR primer sets and the restriction enzymes used are summarized in Table A-3. All oligos synthesis and sequencing were done at St Jude Children's Research Hospital Hartwell Center. The PCR equipment was MJ Research PTC-200 Peltier Thermal Cycler. 


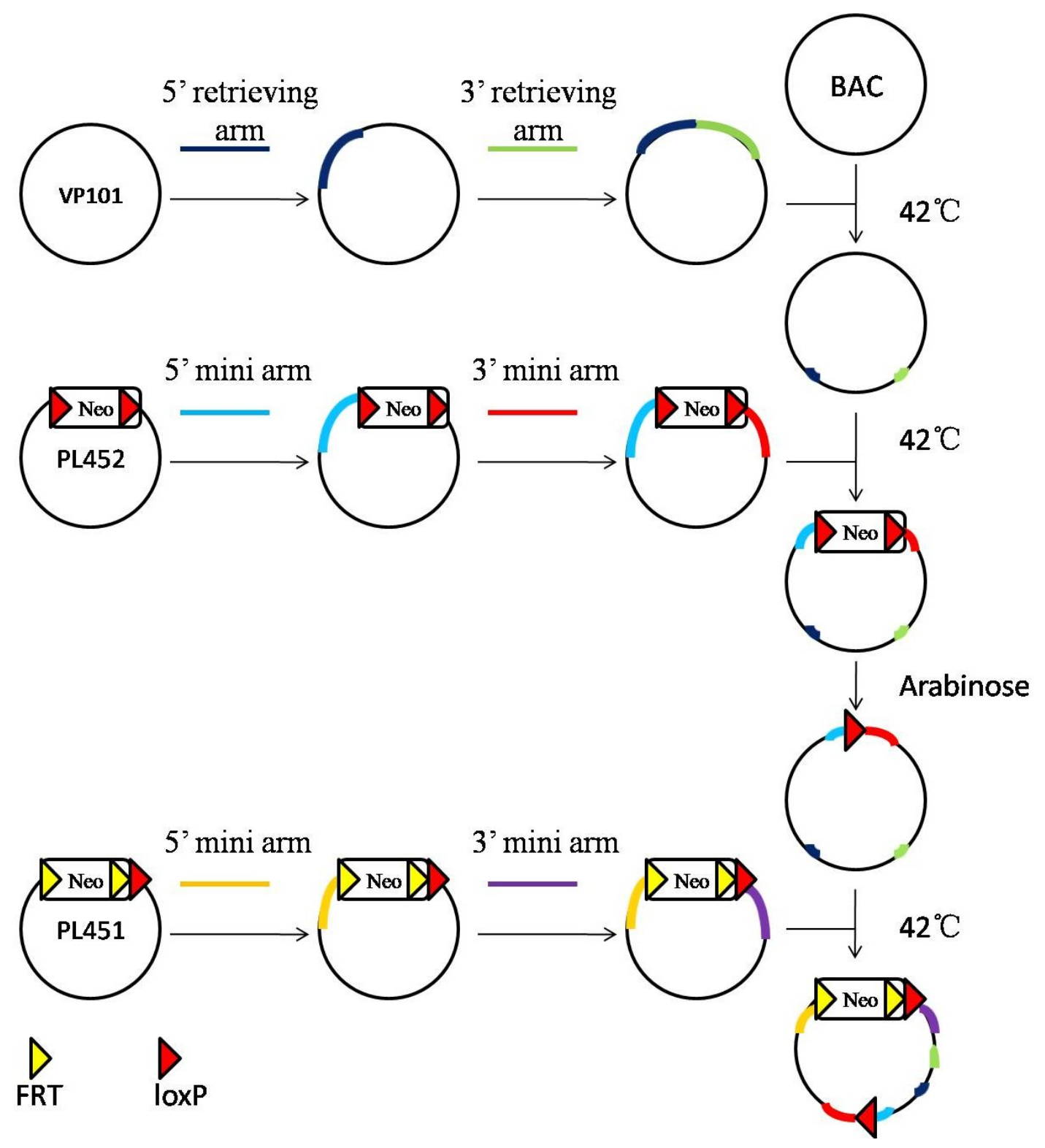

Figure 3-1. Schematic flowchart of generating knockout targeting construct

2 retrieving arms were ligated into vector VP101, and the resulting construct were electroporated into EL350 for BAC retrieval. 2 mini targeting arms were ligated into vector PL452 to make the first mini targeting construct. Another 2 mini targeting arms were cloned into vector PL451 to make the second mini targeting construct. The first mini targeting construct were electroporated into EL350 to insert the first loxP cassette. After arabinose induction, the second mini targeting construct were subsequently electroporated into EL350 to insert the second FRT-loxP cassette. 


\section{Transforming DNA into EL350}

EL350 cells used in this study were all cultured at $32^{\circ} \mathrm{C}$. Other bacteria strains were cultured at $37^{\circ} \mathrm{C}$. Transformation of EL350 was carried out by electroporation. Overnight culture of EL350 cells were centrifuged at $5000 \mathrm{rpm}$ for 6 minutes at $0^{\circ} \mathrm{C}$. The cells were then washed with $888 \mu$ ice-cold water for 3 times, resuspended in $50 \mu \mathrm{l}$ icecold water, and transferred into a cuvette (BioRad, \#165-2089). BAC DNA (50-200 ng) or other DNA vector (200 ng) was added to the cuvette. Electroporation was carried out using Biorad GenePulser with following conditions: $1.75 \mathrm{kV}, 25 \mu \mathrm{F}, 200 \Omega$. Time constant was around 4.0. The electroporated cells were incubated in $1 \mathrm{ml} \mathrm{SOC}$ (Invitrogen, \#15544-034) at $32^{\circ} \mathrm{C}$ for 1 hour, and cultured on agar plate with appropriate antibiotics $(12.5 \mu \mathrm{g} / \mathrm{ml}$ chloramphenicol, $100 \mu \mathrm{g} / \mathrm{ml}$ ampicillin, and/or $25 \mu \mathrm{g} / \mathrm{ml}$ kanamycin) overnight. Individual colonies were picked up to check the integrity of the vector by restriction enzyme digestion.

\section{EL350 Recombinase Induction and Transformation}

The vectors were purified by electroporation into the original EL350 again before each recombination. $10 \mathrm{ml}$ EL350 cells containing BAC or intermediate vector were transferred to a new flask for a 15 minutes water bath at $42{ }^{\circ} \mathrm{C}$ with shaking. Immediately after the $42^{\circ} \mathrm{C}$ incubation, the flask was put into ice-water mixture, shaken continuously and left in wet ice for another10-20 minutes. The cells were then washed, electroporated and selected as stated above.

\section{BAC Retrieval}

BAC DNA was electroporated into the original EL350 and selected with chloramphenicol. The BAC containing EL350 was cultured in $5 \mathrm{ml} \mathrm{LB}$ medium with choloramphenicol. The cells were heatshocked and electroporated with the retrieving vector (derived from VP101) as stated above. The transformed cells were cultured under ampicillin selection. At least 20 individual clones were picked up and the plasmids were extracted using Qiagen miniprep kit. The plasmid samples were analyzed on 1\% agarose gel with empty VP101 vector as control. The clones with larger plasmid size were further digested with restriction enzymes to check the integrity. For the purpose of discussion, this positive clone is named Retrieved Vector.

\section{Insertion of the First loxP Site}

The Retrieved Vector containing EL350 was cultured in $5 \mathrm{ml}$ LB medium with ampicillin, heatshocked and electroporated with the first mini-targeting vector (derived from PL452) as stated above. Transformed cells were cultured under ampicillin (100 $\mu \mathrm{g} / \mathrm{ml})$ and kanamycin $(25 \mu \mathrm{g} / \mathrm{ml})$ double selection. Individual clones were picked up and the plasmids were extracted and digested to check the presence of neo cassette. To make 
sure of single copy in each clone, plasmid was electroporated into the original EL350 strain and selected again for ampicillin and kanamycin double resistant. Single colonies were finally picked up and checked by restriction enzyme digestion.

\section{Popping out Neo Cassette}

A single colony of the targeted cell (with the first loxP site and the neo cassette) was inoculated to $5 \mathrm{ml} \mathrm{LB}$ for overnight culture, then transferred to a $10 \mathrm{ml}$ LB culture for 2-3 hours until OD600=0.5. $100 \mu 1$ 10\% L-arabinose (Sigma Aldrich, \#A-3256) was added to the culture (final concentration $0.1 \%$ ) and Cre induction was kept for one hour. The diluted culture was plated to ampicillin plates. On the next day, several colonies were picked up to 96-well plate for additional culture of 2-3 hours. An aliquot of the culture was copied to another 96-well plate with kanamycin to screen for the kanamycin sensitive clones. The kanamycin sensitive clones were identified on the next day visually by the clear LB.

\section{Insertion of the Second loxP Site}

EL350 cells with the above vector (with the first loxP site, without neo cassette) were cultured in $5 \mathrm{ml} \mathrm{LB}$ medium with ampicillin and heatshocked as stated above. The second mini-targeting vector (derived from PL451) was electroporated into the cultured cells. Elecroporated cells were selected for ampicilllin and kanamycin double resistant clones. All exons and loxP sites were sequenced with appropriate primer sets in Table A-3. The final DNA targeting construct was prepared by maxiprep (Qiagen, \#12963).

\section{ES Cell Targeting and Screening}

The ES cell culture and gene targeting protocols were developed from the instruction manual of The Mouse Kit (LEXICON, \#745002) with modification.

\section{Cells and Reagents}

W9.5 ES cells were obtained from Dr. Peter McKinnon's lab. The specific passage of the cell line was not noted. Feeder cells (mouse embryonic fibroblast cells) and other reagents were provided in Embryomax knockout kit (Millipore, \#ES-100). The feeder medium consisted of Dulbecco's Modified Eagle Medium (DMEM) with 7\% FBS, $2 \mathrm{mM}$ L-glutamine, $50 \mathrm{U} / \mathrm{ml}$ penicillin, and $50 \mu \mathrm{g} / \mathrm{ml}$ streptomycin. ES cell medium consisted of DMEM with 15\% FBS, $100 \mathrm{mM} \beta$-mecaptoethanol, $2 \mathrm{mM}$ L-glutamine, 50 $\mathrm{U} / \mathrm{ml}$ penicillin, and $50 \mu \mathrm{g} / \mathrm{ml}$ streptomycin. ESGRO (Millipore, ESG1107) was added at $1000 \mathrm{U} / \mathrm{ml}$. 


\section{Feeder Cell and ES Cell Preparation}

The cell culture plates were coated with gelatin at room temperature for at least 2 hours before use. Feeder cells were seeded in gelatin coated $10 \mathrm{~cm}$ plates at $5 \times 10^{6}$ cells/plate, and in 96-well plates at $3.3 \times 10^{4}$ cells/well. The feeder cells were cultured for at least 5 days prior to plating ES cells.

ES cells were cultured on feeder cells in ES cell medium for 3 days. ES cell medium was replenished daily. When the plate reached $70-80 \%$ confluence, the medium was refreshed again. Two hours later, the cells were rinsed twice with PBS, trypsinized for 15 minutes and vigorously triturated by rapidly pipetting up and down for 40-50 strokes. The ES cells were spun down at 1000 rpm for 7 minutes, resuspended in ES cell medium, and split to 3 feeder plates for subculturing. The ES cell medium was changed daily.

\section{Electroporation of ES Cells}

The targeting construct was linearized with overnight digestion by NotI. Prior to harvesting the cells, both ES cells and feeder cells were cultured in fresh ES cell medium for 2 hours. ES cell plates were rinsed twice with PBS, and trypsinized for 20 minutes. ES cells were pooled and gently pipetted to make single cell suspension. The total number of cells was counted with hemacytometer. The cells were centrifuged and resuspended in PBS to make a suspension of $11 \times 10^{6}$ cells $/ \mathrm{ml}$. Electroporation was carried out in the cuvette ( $0.4 \mathrm{~cm}$ electrode gap). To each cuvette, $15-20 \mu \mathrm{g}$ linerized targeting construct DNA and $0.9 \mathrm{ml}$ ES cell suspension were added and mixed gently by pipetting. Electroporation was performed at $230 \mathrm{~V}, 500 \mu \mathrm{F}$ capacitance. The time constant was in the range of 5.8 to $7.0 \mathrm{msec}$. The electroporated ES cells were pooled, resuspended in ES cell medium and dispensed to feeder plates. One plate of ES cells electroporated with control PGKneo cassette was also prepared. The electroporated cells were cultured for 24 hours before starting the selection.

\section{Selection of ES Cell Clones}

One day after the electroporation, ES cells were cultured in the medium with 200 $\mu \mathrm{g} / \mathrm{ml} \mathrm{G} 418$ and $2 \mu \mathrm{M}$ ganciclovir. The selective medium was replenished every day for the first 4 days then only every other day thereafter. The selection continued for 11 days, until the resistant colonies became visible to the naked eye. To pick up colonies, each gene targeting plate was rinsed twice with PBS, and covered with $8 \mathrm{ml}$ PBS finally. Individual colony was circled with the pipette tip in the border, and the feeder layer below was cut by the pipette tip. The colony was detached and drawn into the pipette tip and transferred to a 96-well plate with $30 \mu 1$ trypsin, one colony per well. Only small colonies were picked up. The picked colonies were trypsinized for 10 minutes, after which $70 \mu \mathrm{l}$ ES cell medium was added to inactivate trypsin. The cells were disaggregated by pipetting up and down 40 times. Then the trypsinized cells were 
transferred to another 96-well feeder plate containing $100 \mu \mathrm{l}$ ES cell medium. The ES cell clones were cultured for the next 2 days, and copied to another 96-well plate for DNA extraction.

\section{DNA Extraction in 96-well Plate}

When the majority of ES cell clones were fully confluent, the cells were washed twice with PBS. The plates were then placed at $-80^{\circ} \mathrm{C}$ overnight and brought to room temperature to warm up for 5 minutes. To each well, $50 \mu l$ lysis buffer $(10 \mathrm{mM}$ Tris $\mathrm{pH}$ 7.5, $10 \mathrm{mM}$ EDTA $\mathrm{pH} 8,10 \mathrm{mM} \mathrm{NaCl}, 0.5 \%$ sarcosyl, $1 \mathrm{mg} / \mathrm{ml}$ proteinase $\mathrm{K}$ ) was added. The plates were incubated overnight at $60^{\circ} \mathrm{C}$ in a humidified chamber. The next day, 100 $\mu \mathrm{l}$ cold $100 \%$ ethanol (with $75 \mathrm{mM} \mathrm{NaCl}$ ) was added to each well. The plates were left at room temperature for 30 minutes until the DNA became visible. The plates were gently inverted to drain the ethanol, and washed with $70 \%$ ethanol for 3 times. The plates were left uncovered at $37^{\circ} \mathrm{C}$ until moisture was gone. The DNA was finally dissolved in water.

\section{Southern Probe Labeling}

The probes were generated by PCR (Table A-2, Table A-3), and purified with QIAquick PCR purification kit (Qiagen, \#28104).

$25 \mathrm{ng}$ probe DNA was dissolved in nuclease free water. The total volume was adjusted to $33 \mu \mathrm{l}$. The DNA was denatured in boiling water bath for 5 minutes, and then quickly placed in ice for 5 minutes. The tube was centrifuged briefly at $4{ }^{\circ} \mathrm{C}$. The probes were labeled with NEBlot labeling kit (New England BioLabs, \#N1500S) in designated area with protection. The following reagents were added to DNA: $5 \mu \mathrm{l}$ octadeoxyribonucleotides in 10x Labeling Buffer, $6 \mu \mathrm{dNTP}$ mixture $(2 \mu \mathrm{l}$ of dATP, dTTP, and dGTP), $5 \mu \mathrm{l} \alpha^{32} \mathrm{P}$ dCTP $(3000 \mathrm{Ci} / \mathrm{mmol}, 50 \mu \mathrm{Ci})$ and $1 \mu \mathrm{l}$ DNA Polymerase I-Klenow Fragment ( 5 units). The reaction was incubated at $37^{\circ} \mathrm{C}$ for 1 hour, and terminated by adding $5 \mu \mathrm{l}$ of $0.2 \mathrm{M}$ EDTA ( $\mathrm{pH} 8.0$ ). The probes were purified with Illustra G-50 Micro Column (GE Healthcare, \#28903408) by centrifugation. The activity of labeled probes was measured with radioactivity counter (Bioscan QC 2000). The readout was above $1 \times 10^{6} \mathrm{cpm}$.

\section{Southern Blotting and Development}

For a typical Southern blotting, $10 \mu \mathrm{g}$ genomic DNA was digested overnight. For mini-Southern blotting, approximately $2 \mu \mathrm{g}$ DNA was digested. To each DNA sample, 35 $\mu$ digestion cocktail (1x restriction buffer specified for the enzyme being used, $1 \mathrm{mM}$ spermidine, $100 \mu \mathrm{g} / \mathrm{ml} \mathrm{BSA}, 50 \mu \mathrm{g} / \mathrm{ml}$ RNase, and 15 units of enzyme) was added and mixed well. The enzymes used in this study were SpeI and NheI. The plates or tubes were sealed and incubated overnight at appropriate temperature for the enzymes in a 
humidified chamber. On the next day, the digested DNA was loaded to $1 \%$ agarose gel for electrophoresis. The DNA was transferred from gel to Hybond membrane overnight and crosslinked with the membrane by UV. The membrane was incubated with $25 \mathrm{ml}$ hybrid solution (Hybrisol, Millipore, \#S4040) for prehybridization at $42^{\circ} \mathrm{C}$ in a cylinder with rotation.

The probes were labeled as stated above. The labeled probes were added to the hybrid cylinder and incubated overnight at $42^{\circ} \mathrm{C}$ with rotation. The membrane was then washed with $500 \mathrm{ml} 3 \mathrm{x} \mathrm{SSC} / 0.5 \%$ SDS for 30 minutes at $65^{\circ} \mathrm{C}$, followed by another 500 $\mathrm{ml} 0.5 \mathrm{x} \mathrm{SSC} / 0.5 \% \mathrm{SDS}$ for 30 minutes at $65^{\circ} \mathrm{C}$. The radioactivity on the membrane was checked by Geiger counter. The membrane was exposed to phosphor screen (Molecular Dynamics) overnight. The phosphor screen was scanned with a phosphorimager (STORM 860 Molecular Imager, Molecular Dynamics). The clones with the desired recombination were sent for karyotyping at the cytogenetic lab.

\section{Blastocyst Injection and Mouse Breeding}

Blastocyst micro-injection and surgeries were done by technicians in St Jude Children's Research Hospital transgenic core facility. The procedures are under animal protocol 191 Appendix I.

\section{Blastocyst Micro-injection}

For each blastocyst micro-injection, at least 20 blastocysts were collected in DMEM with HEPES from the uterine horns of pregnant C57BL/6 females on day 3.5 post coitum. ES cells were trypsinized and disaggregated by vigorous strokes to make single cell suspension. The cells were washed with ES medium before injection. Under high power magnification, 10 to 20 small and round ES cells were selected, drawn into the injection needle and expelled into the blastocyst cavity. The injected blastocysts were transferred to the uterine horn of female CD1 mice. After delivery and weaning of the pups, the foster females were euthanized.

\section{Mouse Breeding}

Chimeras were bred to wild-type C57BL/6 animals. Those with germline transmission were told by the coat color of the offspring. Only pups with agouti coat were kept for further breeding. All agouti animals were genotyped by PCR. Breeding pairs were set up according to Figure 3-2. Heterozygous animals were obtained by crossing the agouti animals with E2A-Cre strain (The Jackson Laboratory, \#003724), and knockout animals were obtained by interbreeding of heterozygous animals. The wild-type offspring were kept as 129 and C57BL/6 outbred controls. Genotypes of the animals were confirmed by Southern blotting and PCR (Table A-2, Table A-3). 


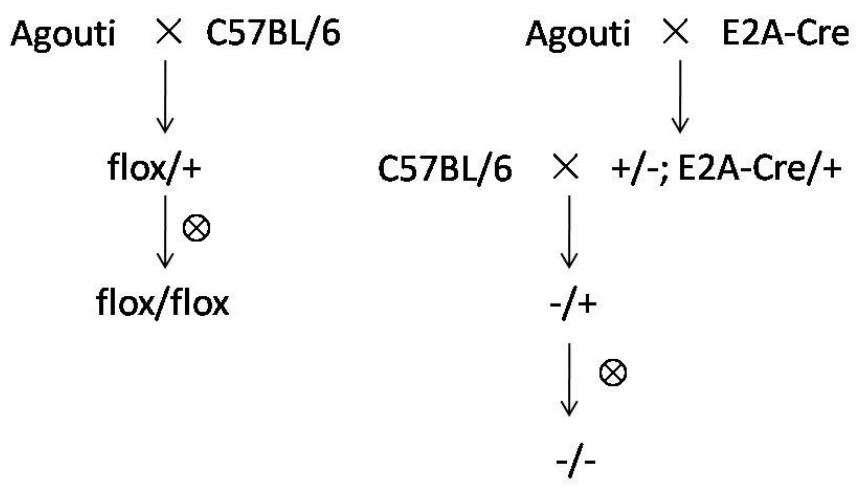

\section{Figure 3-2. Breeding diagram}

Agouti pups from the chimera parent were bred with wild-type C57BL/6 animals. F1 animals were PCR screened and interbred to generate the homozygous flox/flox F2 animals. To generate the homozygous knockout animals, agouti pups were bred with E2A-Cre strain; F1 were PCR screened and bred to wild-type C57BL/6 to expand the colony; F2 were PCR screened again and interbred to produce homozygous knockout animals. 


\section{Mouse Phenotyping}

\section{Colony Assay}

Mouse bone marrow cells were harvested in 2\% FBS, counted with hemacytometer, and diluted to $2 \times 10^{6}$ cells $/ \mathrm{ml}$ in Iscove's Modified Dulbecco's Medium with $2 \%$ FBS. $0.4 \mathrm{ml}$ cell suspension was added to $4 \mathrm{ml}$ MethoCult GF M3334 (Stemcell Technologies, \#03334) or M3434 (Stemcell Technologies, \#03434) medium for triplicate cultures, and tubes were thoroughly vortexed. To each $35 \mathrm{~mm}$ culture dish, $1.1 \mathrm{ml}$ medium was gently dispensed. The $35 \mathrm{~mm}$ dishes were placed into a $10 \mathrm{~cm}$ petri dish with one extra uncovered dish containing sterile water to maintain humidity during culture. CFU-E numbers were counted 3 days later. When using MethoCult GF M3434 (Stemcell Technologies, \#03434), total colony numbers were counted 10 days later.

\section{Competitive Repopulation}

Recipient animals (C57BL/6J, The Jackson Laboratory, \#000664, 6-8 weeks female) were given $1100 \mathrm{rad}$ Cs137 radiation one day prior to the transplant, and fed on baytril water. Bone marrow cells of the donor animals and the competitors (CD45.1 B6.SJL-PtprcaPepcb/BoyJ, The Jackson Laboratory, \#002014, 8-10 weeks) were harvested from the femurs and tibias in 2\% FBS. Bone marrow cells were filtered with $40 \mu \mathrm{m}$ nylon mesh. Cell numbers were then counted with hemacytometer. Donor cells and competitor cells were mixed with a 1:1 ratio, and resuspended in appropriate volume of ice-cold $2 \%$ FBS. The volume was determined by the number of recipients. Each recipient animal received $500 \mu \mathrm{l}$ cell suspension via tail vein injection. In ionizing radiation sensitivity assay, each recipient received 10 million donor cells and 10 million competitor cells. Some transplant recipients later received $2 \mathrm{G}$ or $4 \mathrm{G}$ irradiation again after full reconstitution at 20 weeks. The peripheral blood was obtained from the recipients by retro-orbital bleeding at the 8 weeks, 14 weeks and 20 weeks after the transplant. White cells were analyzed by staining with Mac1, Gr1, B220 and CD3 antibodies to tell the relative contribution of CD45.2 and CD45.1 cells in each lineage by flow cytometry.

\section{Platelet Aggregation Assay}

Blood was collected by cardiac puncture from anesthetized animals in the presence of $60 \mu 13.8 \%$ acid citrate dextrose (ACD) buffer $(6.8 \mathrm{mM}$ citric acid, $11.2 \mathrm{mM}$ trisodium citrate, and $24 \mathrm{mM}$ glucose, $\mathrm{pH}$ 6.5). Whole blood was diluted in $400 \mu \mathrm{l}$ Tyrode's buffer $\left(0.1 \% \mathrm{BSA}, 0.1 \%\right.$ glucose, $2 \mathrm{mM} \mathrm{MgCl}_{2}, 137.5 \mathrm{mM} \mathrm{NaCl}, 12 \mathrm{mM}$ $\mathrm{NaHCO}_{3}, 2.6 \mathrm{mM} \mathrm{KCl}, \mathrm{pH} 7.4$ ) and centrifuged at $600 \mathrm{~g}$ for 3 minutes. The cloudy supernatant was collected and centrifuged for 5 minutes at $1300 \mathrm{~g}$ to pellet platelets. Washed platelets were counted on FORCYTE Hematology Analyzer, and diluted to $2.5 \times 10^{5} / \mu 1$ in Tyrode's buffer. $300 \mu$ l diluted platelets was transferred into each glass 
tube with magnetic stir bars. Diluted patelet samples were put into a Fibrintimer 4 channel aggregometer (APACT Laborgeräte und Analysensysteme). Aggregation was induced by adding $0.01 \mathrm{U}$ or $0.1 \mathrm{U}$ thrombin, $0.3 \mathrm{nmol}$ or $1.5 \mathrm{nmol} \mathrm{ADP}$ (final concentration $1 \mu \mathrm{M}$ or $5 \mu \mathrm{M}$ ), or $600 \mathrm{ng}$ collagen (final concentration $2 \mu \mathrm{g} / \mathrm{ml}$ ) into 300 $\mu \mathrm{l}$ washed platelets respectively while stirring. Light transmission of the platelet solution was recorded for a 4 minute period.

\section{Reticulocyte Staining}

Thiazole Orange (Sigma Aldrich, \#390062) was dissolved in ethanol as $1 \mathrm{mg} / \mathrm{ml}$ (2000x) stock solution and kept at $-20^{\circ} \mathrm{C} .2 \mu$ peripheral blood was stained in $1 \mathrm{ml} 0.5$ $\mu \mathrm{g} / \mathrm{ml}$ Thiazole Orange in PBS for 90 minutes at room temperature, washed twice with PBS and analyzed by flow cytometry in the FITC channel.

\section{Hematocrit Measurement}

Peripheral blood was collected by retro-orbital bleeding with micro-hematocrit capillary tubes. The tubes were planted on tube sealer (SEAL EASE ${ }^{\circledR}$, Becton Dickinson and Company, \#36-1050) to seal one end of the capillary. Capillary tubes were spun at $4000 \mathrm{rpm}$ for 5 minutes in a micro-hematocrit centrifuge. The sealed end of the tube was aligned to the center of micro-capillary reader. The percentage of red cells was recorded by rotating the reading plate.

\section{Phenylhydrazine Treatment and Bleeding}

Phenylhydrazine (Sigma Aldrich, \#78670) was diluted to $5 \mathrm{mg} / \mathrm{ml}$ in PBS. Each animal received $60 \mathrm{mg} / \mathrm{kg}$ body weight phenylhydrazine by intraperitoneal injection for 2 consecutive days. Anemia condition was also induced by retro-orbital bleeding of $350 \mu \mathrm{l}$ blood daily for 4 consecutive days. Hematocrit measurement and reticulocyte staining were carried out as stated above.

\section{Intracellular Staining}

Fresh bone marrow cells or splenocytes were stained with surface markers first. The cells were then fixed in 2\% PFA and permeablize the cells with $0.5 \%$ saponin for 20 minutes or with cold acetone for 20 minutes. Non-specific binding sites were blocked with human IgG for 30 minutes. The cells were stained with $1 \mu \mathrm{g} / \mathrm{ml}$ primary Hemogen antibody (Santa Cruz biotechnology, M180) at $4{ }^{\circ} \mathrm{C}$ overnight in a humid chamber. On the next day, the cells were washed with $2 \%$ FBS, stained with the secondary antibody (Invitrogen, \#A31632) for 1 hour, and analyzed by flow cytometry. 


\section{RNA Extraction and Real-time PCR}

RNA was extracted from sorted cells with RNAqueous kit (Ambion, \#AM1931) according to the manufacturer's instruction. Cells were pelleted and resuspended in 100 $\mu \mathrm{l}$ lysis solution. After adding $50 \mu \mathrm{l}$ ethanol, the tube was vortexed briefly. The lysate was applied to the micro-filter for a centrifugation at maximum speed for 10 seconds. The filter was washed with solution 1 , followed by wash with solution $2 / 3$ for twice, and centrifuged at maximum speed for 1 minute. RNA was finally eluted from the filter in 10 $\mu l$ elution solution, and quantified with Nanodrop.

Reverse transcription was performed with Superscript VILO kit (Invitrogen, $\# 11754$ ). For each reaction, $4 \mu 1$ VILO mix, $2 \mu$ enzyme mix, and $4 \mu$ water were added to the $10 \mu \mathrm{l}$ RNA extract. The tube was briefly vortexed, and incubated at room temperature for 10 minutes, followed by additional 60 minutes incubation at $42^{\circ} \mathrm{C}$. The tube was spun during the incubation to rid the lid from water. The reaction was terminated by heating at $85^{\circ} \mathrm{C}$ for 5 minutes. The reverse transcribed DNA was stored at $-20^{\circ} \mathrm{C}$ until use.

Real-time PCR was carried out with SYBR Green Master Mix (Applied Biosystems, \#4367659). For each reaction of $25 \mu 1,12.5 \mu 1$ master mix, $2.5 \mu 1$ diluted primers for Hemgn (Qiagen, \#QT00106099) or GAPDH (Qiagen, \#QT01658692), $8 \mu \mathrm{l}$ water and $2 \mu$ diluted template were added to each well. PCR was performed in a StepOnePlus real-time PCR system (Applied Biosystems).

\section{Cell Culture and Separation}

$\mathrm{Ba} / \mathrm{F} 3$ and 32D cells were cultured in RPMI with 10\% FBS and $10 \mathrm{ng} / \mathrm{ml} \mathrm{IL-3.}$ Primary bone marrow cells were cultured in DMEM with 15\% FBS and cytokine supplement (20 ng/ml IL-3, 50 ng/ml IL-6 and 50 ng/ml SCF, PEPRO TECH, \#200-06, \#213-13, \#250-03). The cytokine supplement was refreshed every 3 days. GPE-86 cells, NIH3T3 cells and 293T cells were cultured in DMEM with 10\% FBS.

Lin $^{-}$bone marrow cells were enriched by lineage cell depletion kit (Miltenyi Biotec, \#130090858). Mouse bone marrow cells were harvested by flushing both femurs and tibias in $2 \%$ FBS. The cells were filtered through $40 \mu \mathrm{m}$ filter, counted and pelleted as stated above. Every $10^{7}$ total cells were incubated with $10 \mu \mathrm{l}$ biotin labeled antibody cocktail in $40 \mu$ magnetic-activating cell sorting (MACS) buffer ( $2 \mathrm{mM}$ EDTA and $0.5 \%$ BSA in PBS) for 10 minutes at $4^{\circ} \mathrm{C}$, followed by incubation with $20 \mu \mathrm{l}$ anti-biotin microbeads for 15 minutes at $4^{\circ} \mathrm{C}$. The cells were washed and finally resuspended in 500 $\mu \mathrm{MACS}$ buffer, and went through LS separation column (Miltenyi Biotec, \#130042401) Cells in the flowthrough were pelleted and resuspended in culture medium with cytokine supplement. 
The retroviral vector producer cell lines, transduced $\mathrm{Ba} / \mathrm{F} 3$ and $32 \mathrm{D}$ cell lines were sorted by flow cytometry based on GFP expression.

\section{Cytokine Deprivation}

Apoptosis was induced by cytokine deprivation on lineage depleted bone marrow cells, Ba/F3 and 32D cells. Prior to cytokine deprivation, dead cells in the culture were eliminated with a dead cell removal kit (Miltenyi Biotec, \#130090101). The cultured cells were washed with PBS, pelleted and incubated in $100 \mu$ dead cell removal microbeads for 15 minutes at room temperature, and then went through MACS. Viable cells were collected from the flowthrough. Ba/F3 and 32D cells were cultured for 20 hours in RPMI with $2 \%$ FBS but without IL-3 supplement. For primary cells, lineage depleted cells were cultured in DMEM with $2 \%$ FBS without cytokine supplement for 24 hours. Apoptosis was then measured by Annexin V and DAPI staining.

\section{Annexin V Staining}

A total number of $3 \times 10^{5}$ cells (total cell count=live+dead) were washed with $\mathrm{PBS}$, and incubated in $100 \mu$ Annexin binding buffer (10 mM HEPES, $0.9 \% \mathrm{NaCl}, 2.5 \mathrm{mM}$ $\mathrm{CaCl}_{2}, 0.1 \%$ BSA) containing $10 \mu \mathrm{l}$ Annexin V-APC (Becton Dickson, \#550474) for 15 minutes at room temperature in the dark. $300 \mu$ additional cold binding buffer and $10 \mu \mathrm{l}$ DAPI solution $(0.25 \mathrm{mg} / \mathrm{ml}$ in PBS) were added to the tube. Samples went through $40 \mu \mathrm{m}$ nylon mesh and were placed on ice. The apoptotic cells were analyzed by flow cytometry soon after completion of staining.

\section{Statistics}

Statistics were done with two-tailed t-test. In platelet aggregation assay, difference factors $\left(f_{1}\right)$ and similarity factors $\left(f_{2}\right)$ were calculated with the absorption values according to reference [93]. Two curves are considered similar if $\mathrm{f}_{1}<15$ and $\mathrm{f}_{2}>50$. $\mathrm{R}_{\mathrm{t}}$ and $\mathrm{T}_{\mathrm{t}}$ are the absorption values of wild-type and knockout samples at different time points respectively, and $\mathrm{n}$ is the number of data points.

$$
\begin{aligned}
& \mathrm{f}_{1}=\left[\sum_{\mathrm{t}=1}^{\mathrm{n}}\left|\mathrm{R}_{\mathrm{t}}-\mathrm{T}_{\mathrm{t}}\right|\right] /\left[\sum_{\mathrm{t}=1}^{\mathrm{n}} \mathrm{R}_{\mathrm{t}}\right] \times 100 \\
& \mathrm{f}_{2}=50 \times \log \left\{100 \times\left[1+\frac{1}{\mathrm{n}} \sum_{\mathrm{t}=1}^{\mathrm{n}}\left(\mathrm{R}_{\mathrm{t}}-\mathrm{T}_{\mathrm{t}}\right)^{2}\right]^{-0.5}\right\}
\end{aligned}
$$




\section{Western Blot and Antibodies}

\section{Lysate Preparation}

Protein extracts were prepared with M-PER mammalian protein extraction reagent (Pierce, \#78501) supplemented with the protease inhibitors (Pierce, \#78430). The cells were pelleted by centrifugation at $2500 \mathrm{~g}$ for 10 minutes at $4{ }^{\circ} \mathrm{C}$. The volume of cell pellet was estimated by the wet weight. $1 \mathrm{mg}$ wet weight was translated into $1 \mu \mathrm{l}$ in volume. M-PER reagent was added in 10-fold volume of the cell pellet. The cells were lysed by gently inverting the tube at $4^{\circ} \mathrm{C}$ for 10 minutes, and then centrifuged at maximum speed at $4^{\circ} \mathrm{C}$ for 15 minutes. The supernatant was transferred to a clean tube and kept on ice until use or storage.

\section{Cytoplasmic and Nuclear Protein Extraction}

The procedure was carried out with NE-PER nuclear and cytoplasmic extraction reagents (Thermo Scientific, \#78833). The protocol was adopted from the manufacturer's instruction by extra washing step.

Total $10^{7}$ cells were pelleted by centrifugation at $500 \mathrm{~g}$ for 2 minutes. Ice-cold CER I buffer was added to the cell pellet. The tube was vortexed vigorously on the highest setting for 15 seconds, and left incubated on ice for 10 minutes. Ice-cold CER II was added to the tube. The tube was vortexed for 5 seconds, and then incubated on ice for 1 minute. The tube was vortexed again and centrifuged for 5 minutes at maximum speed. The supernatant (cytoplasmic extract) was immediately transferred to a pre-chilled tube, and placed on ice until use or storage. The pellet was washed with ice-cold PBS for 3 times to minimize cross contamination. The insoluble pellet fraction was resuspended in ice-cold NER. The tube underwent continuous vortexing for 15 seconds every 10 minutes, for a total of 40 minutes. The pellet was then centrifuged at maximum speed for 10 minutes. The supernatant (nuclear extract) fraction was immediately transferred to a prechilled tube, and placed on ice. The protein concentration was quantified by Nanodrop with BioRad Protein Assay Dye Reagent (BioRad, \#500-0006).

\section{Immunoblotting}

In each reaction, $13 \mu 1$ LDS Sample Buffer (Invitrogen, \#NP0008), $5 \mu 1$ Sample Reducing Agent (Invitrogen, \#NP0004) and $30 \mu \mathrm{g}$ protein extract were added. The total volume was adjusted to $35 \mu \mathrm{l}$ with water. The mixture was heated at $70^{\circ} \mathrm{C}$ for 10 minutes and loaded to 4-12\% gradient NuPAGE Bis-Tris gel (Invitrogen, \#NP0323).

Electrophoresis was carried out at $120 \mathrm{~V}$ until the dye ran out of the gel. The proteins were transferred at $30 \mathrm{~V}$ for 1 hour to $0.45 \mu \mathrm{m}$ PVDF membrane (Life Technologies, \#LC2002) that was pre-activated with methanol. The membrane was washed in $0.1 \%$ PBST, and then blocked with 5\% milk in PBST for 1 hour. The membrane was cut in 
reference to the visible markers below the bands of $75 \mathrm{kD}$ and $50 \mathrm{kD}$. The membrane was incubated with primary antibodies (1:1000 dilution in $5 \%$ milk, $200 \mathrm{ng} / \mathrm{ml})$ respectively at $4{ }^{\circ} \mathrm{C}$ overnight. On the next day, the membrane was wash twice with $5 \%$ milk, and incubated with secondary antibodies (1:1000 dilution in 5\% milk) for 1 hour. The primary antibodies used were Hemogen (Santa Cruz biotechnology, M180), HDAC1 (Santa Cruz biotechnology, 10E2), GAPDH (Millipore, MAB374). Secondary antibodies were goat anti-rabbit IgG-HRP (sc-2004, Santa Cruz biotechnology) for M180 and goat anti-mouse IgG-HRP (sc-2060, Santa Cruz biotechnology) for 10E2 and MAB374.

Bands were detected using HRP labeled secondary antibodies and developed with ECL Prime Western blotting detection reagent (GE Healthcare, \#2232). The blot was exposed in FluorChem M imaging system (ProteinSimple).

\section{Mutagenesis}

\section{PCR Mutagenesis}

PCR was carried out with high fidelity polymerase Phusion (New England BioLabs, \#M0530). PCR primers and conditions are listed in Table A-4 and Table A-5 respectively. Final PCR fragments $\triangle \mathrm{CC}$ or $\triangle \mathrm{NLS}$ were cloned into MSCV-IRES-GFP retroviral vector backbone with SpeI and DraIII. The constructs were then sequenced.

\section{Transient Transfection}

293 T cells were seeded in $10 \mathrm{~cm}$ dishes at $8 \times 10^{6}$ cells/plate in the morning. Transfection was carried out 6 hours later. For one plate, $10 \mu \mathrm{g}$ retroviral vector plasmid DNA was mixed with $5 \mu \mathrm{g}$ Old-GagPol, $1 \mu \mathrm{g}$ pCAG-VSVG, and appropriate volume of $\mathrm{H}_{2} \mathrm{O}$ to make a final volume of $450 \mu$ l. After mixing well the plasmids, $50 \mu 12.5 \mathrm{M}$ $\mathrm{CaCl}_{2}$ was added and mixed well. Additional $500 \mu \mathrm{l} 2 \times \mathrm{HBSS}$ was added to DNA-CaCl${ }_{2}$ dropwise while vortexing. $1 \mathrm{ml}$ DNA-CaCl $2-\mathrm{HBSS}$ mixture was added dropwise to each plate and mixed well by swirling the plate. The cells were cultured in transfection mixture for 18 hours. On the next day, the plates were washed twice with PBS, overlaid with $10 \mathrm{ml}$ fresh medium and incubated for 48 hours. On day 4, the supernatant was collected and filtered through $0.22 \mu \mathrm{m}$ membrane (Millipore, \#SCGP00525), and kept at $4^{\circ} \mathrm{C}$ or on ice until use.

\section{Producer Cell Line}

GPE-86 cells were seeded in $10 \mathrm{~cm}$ dishes at $5 \times 10^{5}$ cells/plate in the morning for 6 hours expansion. $5 \mathrm{ml}$ filtered supernatant from transient transfection was mixed with 5 $\mathrm{ml}$ medium (for one dish). Polybrene was added to a final concentration of $6 \mu \mathrm{g} / \mathrm{ml}$. The diluted supernatant was applied to GPE- 86 cells gently. The cells were transduced with 
retroviral vector containing supernatant twice daily for the next 5 days. Two days after the last transduction, $\mathrm{GFP}^{+}$cells were sorted and expanded. After the initial expansion, the producer cells were sorted for the second time.

\section{Retroviral Transduction}

For the transduction of primary cells, bone marrow cells were cultured in DMEM with 10\% FBS, $50 \mathrm{ng} / \mathrm{ml} \mathrm{SCF}, 20 \mathrm{ng} / \mathrm{ml} \mathrm{IL-3,} \mathrm{and} 50 \mathrm{ng} / \mathrm{ml} \mathrm{IL-6}$ for 2 days. For cell lines, no pre-stimulation was carried out. All 6-well plates were coated with RetroNectin (Takara, \#T100) at room temperature for 2 hours or $4{ }^{\circ} \mathrm{C}$ overnight, and blocked with $2 \%$ BSA for 1 hour.

Primary cells or cell lines were seeded at $5 \times 10^{5}$ cells/well. The filtered retroviral vector supernatant with cytokines (if necessary) and polybrene (final concentration 6 $\mu \mathrm{g} / \mathrm{ml}$ ) was applied to the cells. The plates were centrifuged at $2000 \mathrm{rpm}$ for 30 minutes. The cells were hit twice daily for 2 consecutive days. Two days later, the medium was changed to fresh DMEM with 10\% FBS and cytokines if required. The cells were then sorted or analyzed by flow cytometry based on GFP expression. 


\section{CHAPTER 4. RESULTS}

\section{Generation of Hemgn Knockout Mouse Model}

The wild-type mouse Hemgn allele spans $19.5 \mathrm{~kb}$ in the genome, and consists of 5 exons. The wild-type protein has 503 amino acids. Our targeting construct flanks the exons 3-5, with one loxP site at $510 \mathrm{bp}$ upstream of exon 3 , and the other with a PGK-Neo selection cassette at 302 bp downstream of exon 5 (Figure 4-1A). By this targeting strategy, $95 \%$ of the $\mathrm{C}$-terminal sequence of the protein was truncated, leaving only 26 residual amino acids at the $\mathrm{N}$-terminus.

The targeting construct was generated via $\mathrm{BAC}$ recombination in bacteria. Exons in the construct were sequenced before ES cell targeting. The construct was linearized with NotI and electroporated into W9.5 ES cells. By using a combination of G418 and ganciclovir selection, single ES cell clones were obtained and expanded for PCR and Southern blot screening. Clones with the desired recombination were checked for karyotypes and injected into blastocysts. The chimerism of the animals born was indicated by the coat color. Only animals with high chimerism were kept for further breeding. The germline transmitted pups were identified by the agouti coat color. Correct gene targeting was confirmed by PCR genotyping and Southern blotting (Figure 4-1B, C).

Progenies of chimeric animals were bred with the E2A-Cre mouse strain to produce a germline null allele. The E2A promoter has a ubiquitous expression pattern including the germline. Germline deletion of floxed sequence was confirmed by sequencing across the Cre-mediated recombination junction. $\mathrm{Hemgn}^{+/}$animals were interbred to produce knockout animals. Ablation of the protein in hematopoietic cells and round spermatids was confirmed by flow cytometry, Western blot and IHC staining with a polyclonal antibody recognizing Hemgn amino acids 181-360 (Figure4-1D, Figure 4-2A). By Western blot analysis, the molecular weight of Hemgn was approximately 75 $\mathrm{kD}$ in bone marrow cells, whereas no signal was detected in Hemgn knockout cells.

\section{Expression Pattern of Mouse Hemgn}

Although the expression pattern of rat Hemgn is well established [74, 76], its expression in mouse tissues has not been documented in detail. Sites known to express Hemgn include bone marrow progenitor cells, spleen and testis [66, 67, 94]. By IHC staining, we confirmed Hemgn expression in spleen red pulp, bone marrow, and round spermatids in the testicle (Figure 4-2B).

The expression of Hemgn mRNA was examined by quantitative real time PCR at various developmental stages of hematopoietic cells in the bone marrow compartment (Figure 4-2C). During hematopoiesis, Hemgn was first detected in the CD34-LSK long term hematopoietic stem cells (LT-HSC) and the CD $34^{+}$LSK short term hematopoietic 


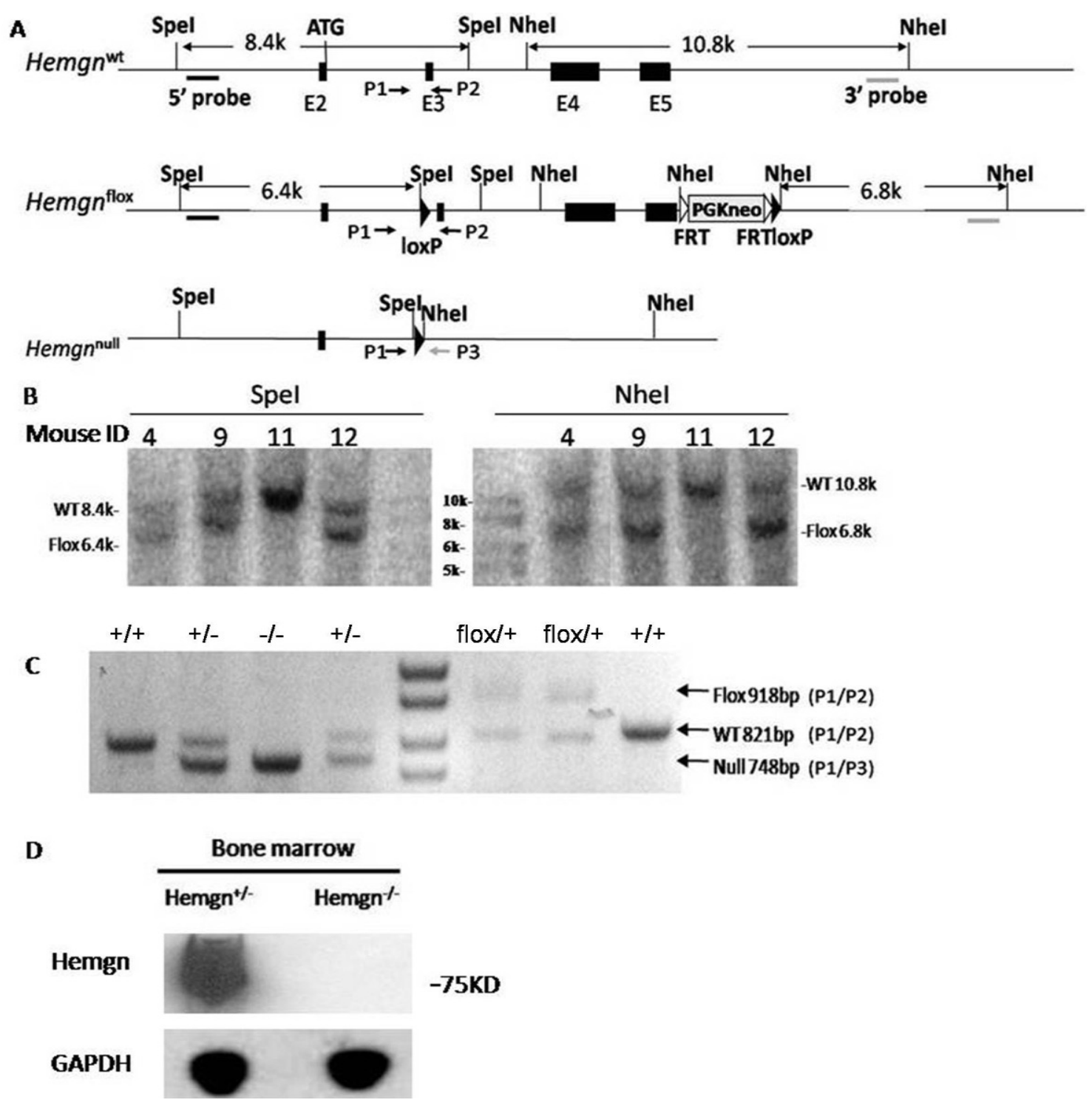

\section{Figure 4-1. Targeting strategy of Hemgn conditional allele}

(A) Hemgn wild-type, conditional and null alleles. ATG is in exon 2; exon 1 is not shown. Two loxP sites flank exon 3-5. The null allele was generated by crossing with an E2A-Cre strain. Black and grey bars indicate probes for the Southern blot; arrows point to genotyping primers. (B) Southern blot of the tail DNA from germline transmitted pups (lanes \#4, 9, 12) and control pup (lane \#11). (C) PCR genotyping of wild-type, Hemgn null and heterozygous mice. The null band was sequenced. (D) Ablation of the Hemgn protein in knockout animal was confirmed by Western blot with a polyclonal antibody. 
A

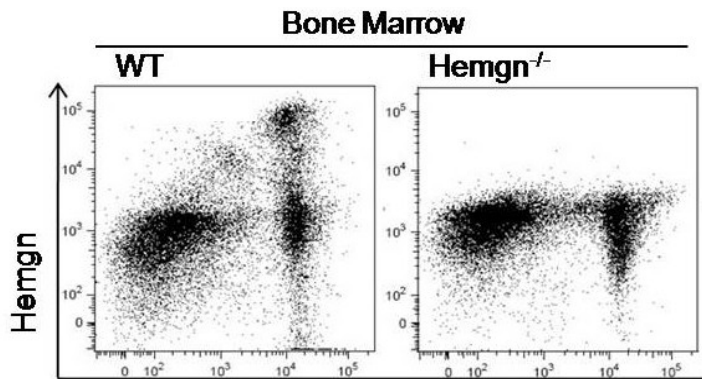

Ter119

B
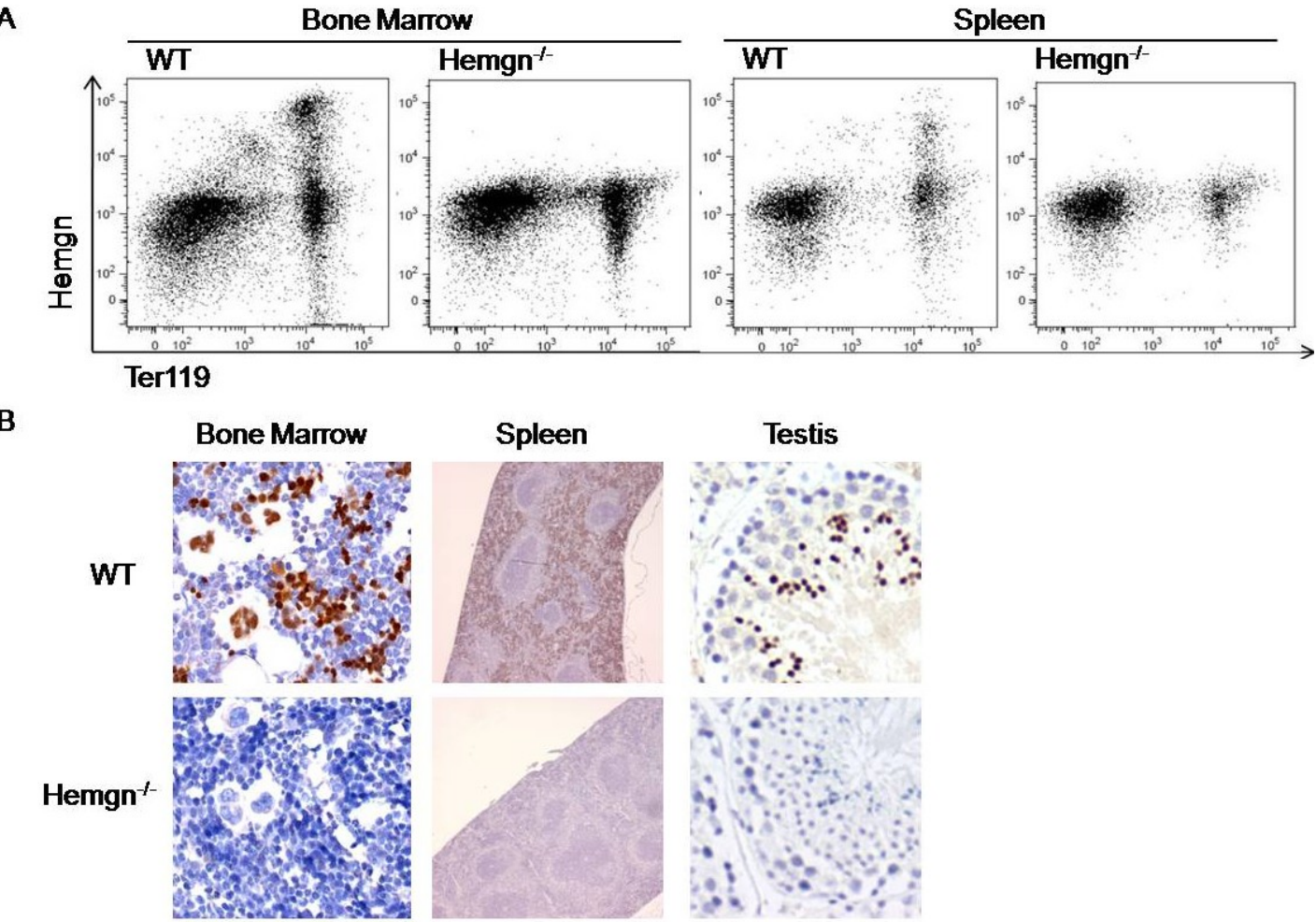

C

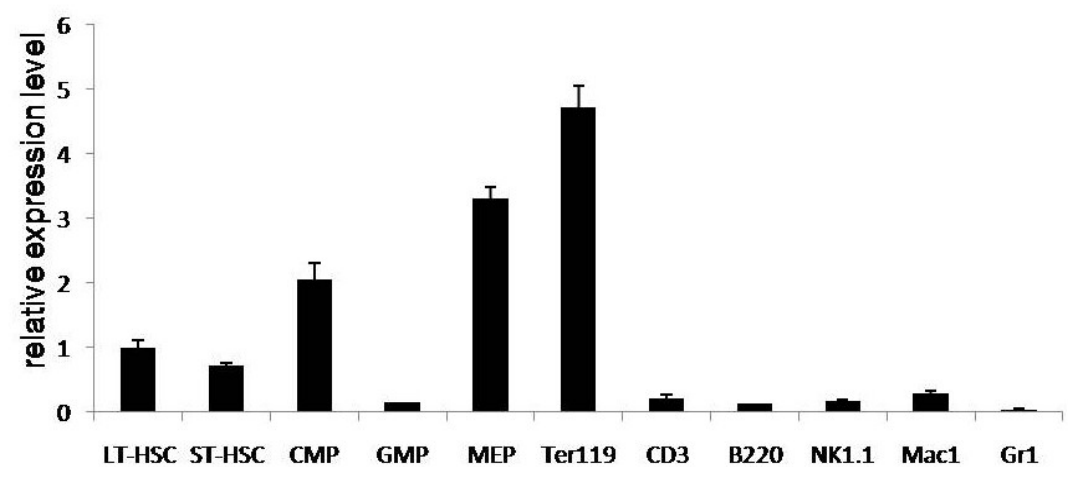

Figure 4-2. Endogenous Hemgn expression pattern

(A) Hemgn was both detected by intracellular staining in bone marrow and spleen Ter $119^{+}$cells. (B) Hemgn was detected by immunohistochemical staining in erythroblasts and megakaryocytes in bone marrow, red pulp of spleen, and round spermatids in testicle. (C) Real-time PCR showed Hemgn expression in LT-HSCs, ST-HSCs, CMPs, MEPs and erythroid cells, but low expression in B cells, T cells, NK cells, macrophages and granulocytes in bone marrow. The internal control of real-time PCR was GAPDH. 
stem cells (ST-HSC). Stem cells can further differentiate into common myeloid progenitor (CMP) and common lymphoid progenitor (CLP) cells. Hemgn expression was up-regulated in the CMPs, which can give rise to both granulocyte/monocyte progenitor (GMP) and megakaryocyte/erythroid progenitor (MEP) cells. Hemgn expression was down-regulated in GMPs, and was not further detected in mature granulocytes. Mature macrophages continued to weakly express Hemgn. However, Hemgn was further upregulated in MEPs, and the majority of $\mathrm{Hemgn}^{+}$cells were Ter $119^{+}$erythroid cells. In contrast, the expression level of Hemgn was very low in mature lymphoid lineages, including B cells, T cells and NK cells, which is consistent with published data [67]. The expression of Hemgn in CLPs was not examined specifically, but has been reported to be lower than that in HSCs [95].

This expression pattern triggered our interest in further exploring the erythroid compartment. Previous studies on the expression of Hemgn in erythroid lineages are contradictory, reporting both the presence and absence of Hemgn expression in Ter $119^{+}$ erythroid cells $[67,94]$. In our flow cytometry analysis, most Hemgn expressing cells were Ter $119^{+}$, both in the bone marrow and spleen (Figure 4-2A). Ter $119^{+}$erythroid cells are heterogeneous populations that undergo multistep maturation. In combination with the erythroid development marker CD44, Ter $119^{+}$cells can be subdivided into several stages [96]. Normal erythropoiesis begins with the pro-erythroblast stage (Ter119 low or medium), and after gaining Ter119 expression, goes through the basophilic erythroblast, polychromatic erythroblast, and orthochromatic erythroblast stages, finally becoming reticulocytes and mature red blood cells (RBC). Flow cytometry analysis confirmed the expression of Hemgn in the Ter $119^{-} \mathrm{CD} 71^{+}$progenitor population (Figure 4-3A) that has BFU-E and CFU-E activity. A further analysis of Ter $119^{+}$erythroid cells with CD44 showed that Hemgn expression was gradually up-regulated in basophilic erythroblasts and peaked in polychromatic erythroblasts and orthochromatic erythroblasts, but was lost in mature RBCs (Figure 4-3B, C). Hemgn expression was also confirmed in megakaryocytes via IHC staining of bone marrow sections (Figure 4-2B).

\section{Normal Steady-state Hematopoiesis and Stress Erythropoiesis}

Hemgn knockout animals were viable and fertile, phenotypically indistinguishable from wild-type mice. We measured hematopoiesis in peripheral blood, bone marrow, thymus and spleen.

Peripheral blood was examined by determining the complete blood count under steady-state conditions (Figure 4-4A). RBC count, white blood cell count, platelet count, mean corpuscular hemoglobin, and mean corpuscular volume were normal in knockout animals. There were no abnormalities in the morphology of RBCs in the blood smear (Figure 4-4B). Hematocrit was measured by centrifuging blood in capillary tubes for better accuracy. The percentage of reticulocytes in the peripheral blood was determined by thiazole orange staining and flow cytometry. Thiazole orange is a reliable marker as it can stain the residual RNA component in reticulocytes [97]. The percentage of reticulocytes was not significantly different from that of wild-type animals, and was 
A

C
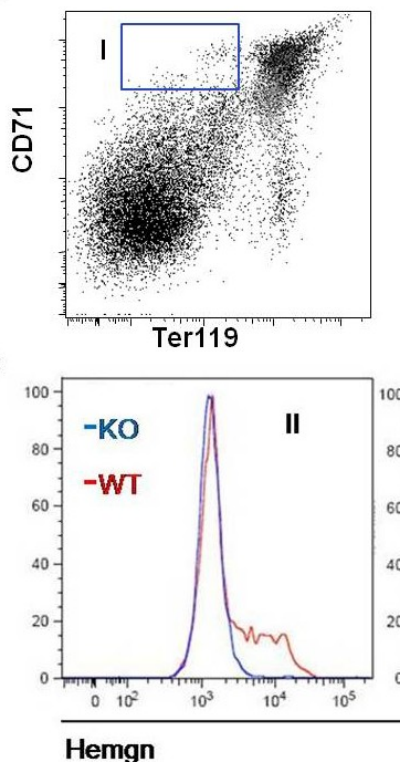

B
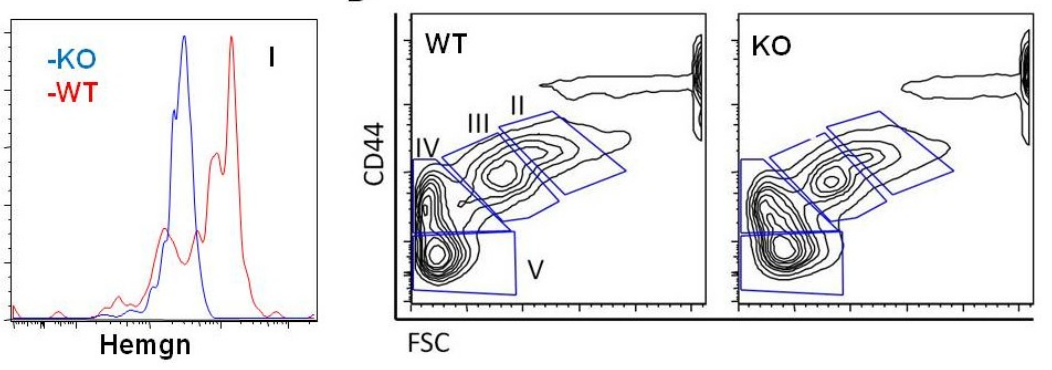

FSC
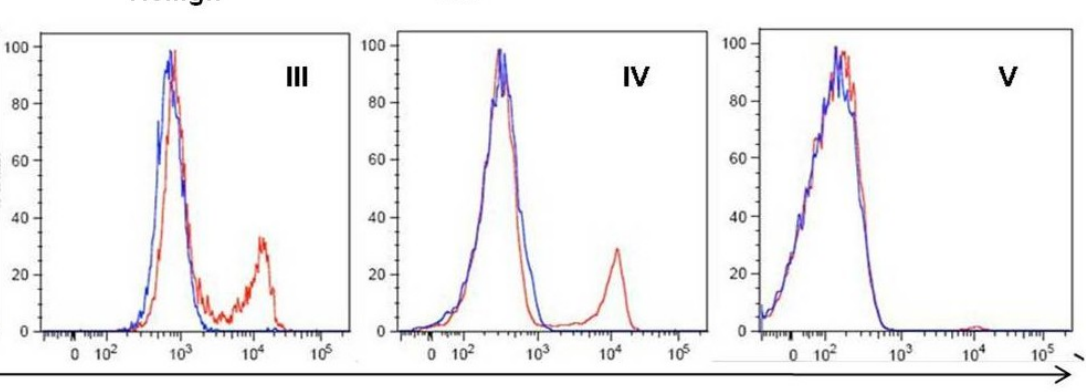

Figure 4-3. Hemgn expression in erythroblasts

(A) Hemgn expression in the Ter $119^{-} \mathrm{CD} 71^{+}$erythroid progenitors by intracellular staining. (B) Gating of Ter $119^{+}$erythroblast based on cell size and CD44 expression. Gate II: basophilic erythroblast; Gate III: polychromatic erythroblast; Gate IV: orthochromatic erythroblast; Gate V: enucleated red blood cell. (C) Hemgn expression by intracellular staining at different stages of erythroblast development. 
A
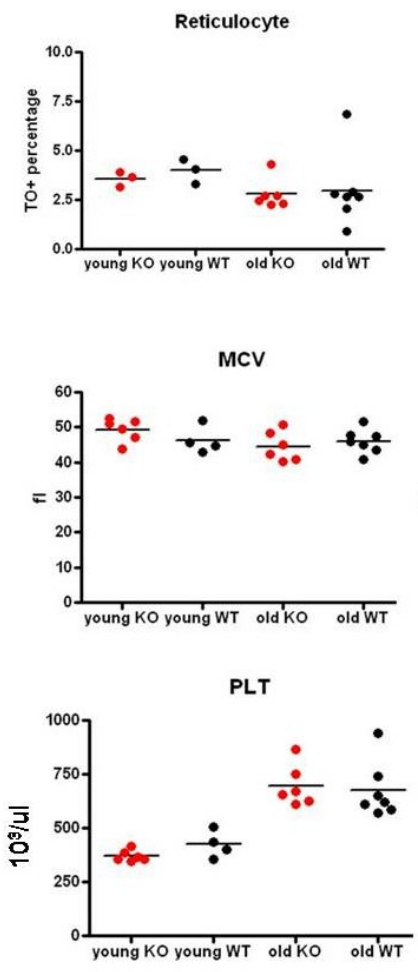

C

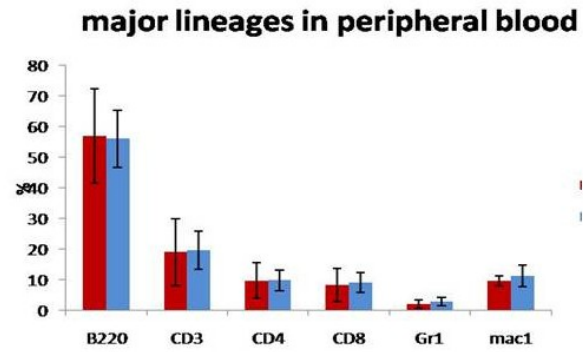

major lineages in spleen

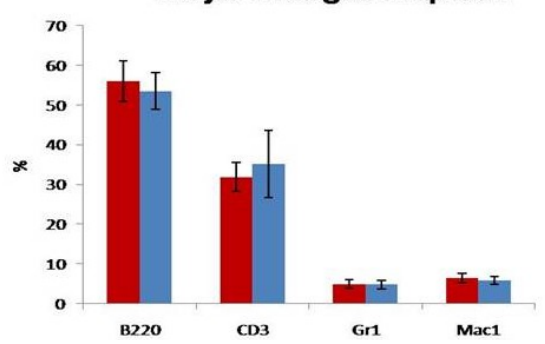

B
HCT
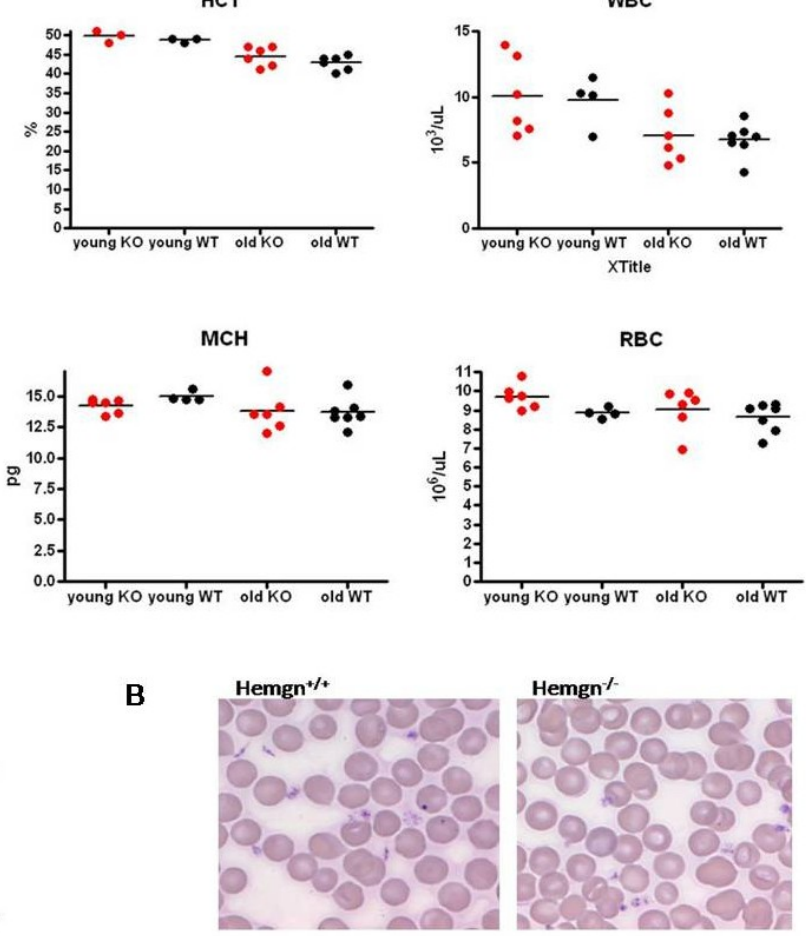

major lineages in bone marrow

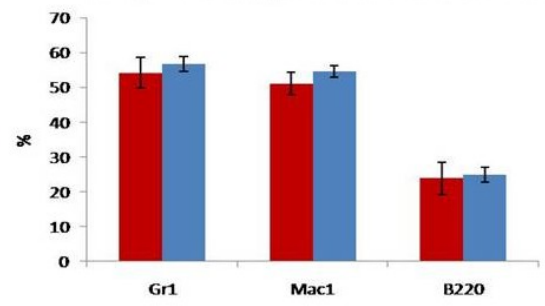

major lineages in thymus

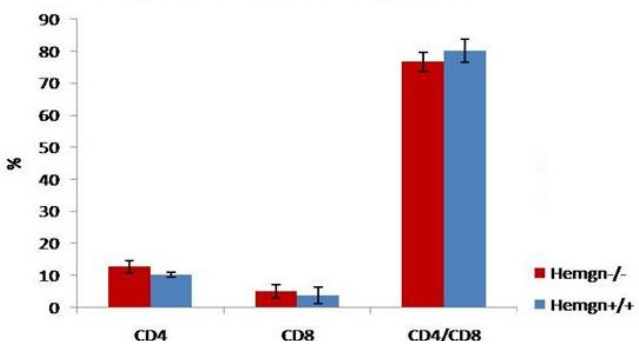

Figure 4-4. Steady-state hematopoiesis of Hemgn knockout mice

(A) Complete blood count of peripheral blood ( $\mathrm{p}>0.05$ by t-test for each parameter). Reticylocytes were stained with thiazole orange (TO). HCT: hematocrit; WBC: white blood cell count; $\mathrm{MCV}$ : mean corpuscular volume; $\mathrm{MCH}$ : mean corpuscular hemoglobin; RBC: red blood cell count; PLT: platelet count. (B) Blood smear of Hemgn knockout and wild-type mice. (C) Distribution of all blood lineages in peripheral blood, bone marrow, spleen and thymus ( $\mathrm{p}>0.05$ for each lineage). 
below the level indicative of anemia. The presence and distribution of different cell types in each of the hematopoietic organs were checked by staining with different lineage markers such as B220, CD3, CD4, CD8, Gr1 and Mac1 (Figure 4-4C). In the bone marrow, spleen peripheral blood and thymus, the percentage of each major lineage was normal. In general, steady-state hematopoiesis did not show significant defects.

The normal development of myeloid and lymphoid cells under steady-state conditions in Hemgn knockout animals might be related to the relatively low expression level of Hemgn in GMPs and CLPs. In contrast, because of the high expression of Hemgn in MEPs and erythrocytes, erythropoiesis was examined in detail. Different developmental stages of erythroid cells (basophilic, polychromatic and orthochromatic erythroblasts) were compared in bone marrow cells from knockout and wild-type animals, based on Ter119 and CD44 expression. The percentages of all subpopulations were normal in the knockout animals (Figure 4-5A).

Unlike in humans, the spleen is an important hematopoietic organ under normal steady-state conditions in the mouse. Anemic conditions are often associated with enlarged spleens and increased extramedullary hematopoiesis. The spleen weight of Hemgn knockout mice was normal (Figure 4-5B), and IHC staining confirmed the presence of Gata- $1^{+}$erythrocytes in the spleen (data not shown), indicating normal extramedullary hematopoiesis and lack of anemia. At the erythroid progenitor level, CFU-E number was measured in the bone marrow compartment by in vitro culture in an M3334 methylcellulose medium. Wild-type and Hemgn knockout bone marrow cells produced the same numbers of CFU-E (Figure 4-5C).

Erythropoietin (EPO) signaling is important for erythropoiesis. Under certain stress conditions such as bleeding, the in vivo EPO level can rise and stimulate the regeneration of RBCs. To determine the stress erythropoiesis of Hemgn knockout animals in response to elevated EPO signaling, animals were given bleeding stress or treated with phenylhydrazine, a compound used to induce hemolytic anemia [98]. After 2 doses of phenylhydrazine, the hematocrit and reticulocyte production in the peripheral blood were monitored during the regeneration phase. Both wild-type and Hemgn knockout animals produced reticulocytes and regenerated RBCs in this induced anemia model (Figure 4-5D). However, phenylhydrazine treatment can cause some RBCs in the peripheral blood to gain autofluorescence in flow cytometry, which may interrupt the real thiazole orange signal for reticulocytes. To bypass this problem, animals were retroorbitally bled $(350 \mu \mathrm{l})$ for 4 consecutive days. Similar reticulocyte production and RBC regeneration were observed (Figure 4-5E) on bleeding stress, indicating that Hemgn knockout animals can respond robustly to the elevated EPO signaling.

\section{Normal Platelet Function}

Because Hemgn is expressed at relatively high levels in megakaryocytes, we analyzed the megakaryocytes and platelets. No difference between wild-type and Hemgn knockout animals was reported by the full necropsy examination in the number or the 
A
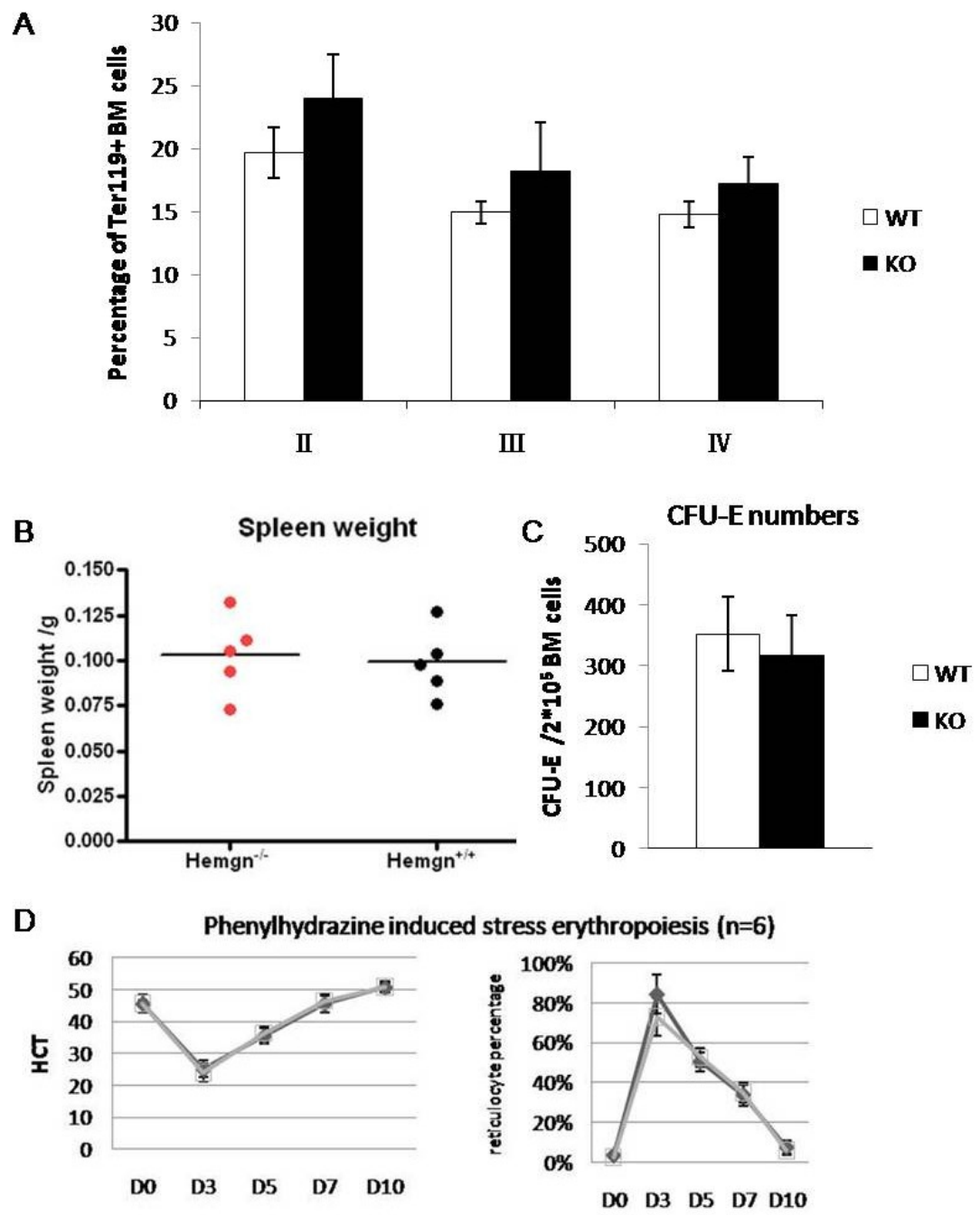

E Bleeding induced erythropoiesis
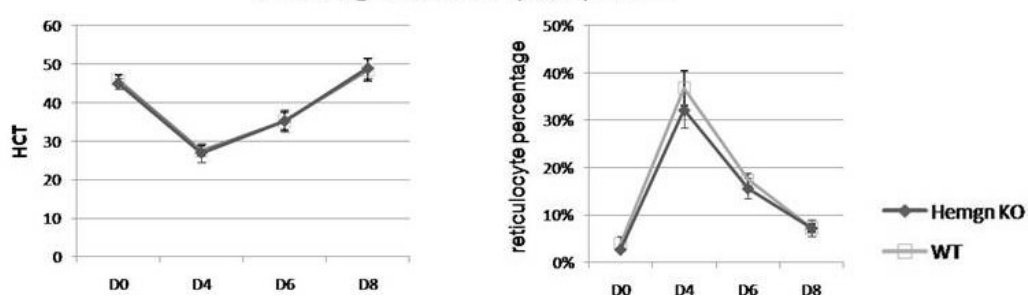

Figure 4-5. Steady-state and stress erythropoiesis

(A) Distribution of basophilic (II), polychromatic (III), orthochromatic (IV) erythroblasts in the bone marrow Ter1 $19^{+}$population based on cell size and CD44 expression $(p>0.05$ by t-test for each population). (B) Spleen weight of Hemgn knockout and wild-type animals $(p=0.75)$. (C) CFU-E numbers in bone marrow $(p=0.52)$. Cells were grown in M3334 culture. (D) HCT and reticulocyte regeneration upon phenylhydrazine induced anemia ( $p>0.05$ for each time point). (E) HCT and reticulocyte regeneration upon bleeding ( $p>0.05$ for each time point). Reticulocytes were stained with thiazole orange. 
size of megakaryocytes. Platelet counts were generally lower than expected, but comparable between knockout and wild-type animals (Figure 4-4A).

The function of platelets was tested by an aggregation assay [99]. Purified platelets were stimulated by thrombin, adenosine diphosphate (ADP) or collagen, which activate platelets through different receptors. Murine thrombin interacts with PAR-3 and PAR-4 receptors; ADP interacts with $\mathrm{P} 2 \mathrm{Y}$ receptors; and collagen interacts with GP receptors [100]. In response to the stimuli of these reagents, platelets should form clots so that aggregation can be monitored by changes in light transmission through the platelet solution. In response to these reagents, platelets from both wild-type and knockout animals aggregated completely at comparable rates (Figure 4-6), indicating normal function of platelets of Hemgn knockout animals.

\section{Normal Stem Cell Function and Defect in Lymphoid Reconstitution}

The expression level of Hemgn is lower in the HSCs than in erythroid progenitors and erythroblast cells, but still significantly higher than in other differentiated blood cells. Hemgn is a direct target of Hoxb4 in the ex vivo expansion of HSCs, which may point to a potential function in the HSC and HPC populations [69]. To determine the function of Hemgn in these cell populations, progenitor and stem cell activity was assessed by the colony forming assay in vitro and competitive repopulation of lethally irradiated animals in vivo.

Dysfunction of HSCs or HPCs often leads to bone marrow dysplasia with decreased cellularity. However, this did not occur in Hemgn knockout animals. Total nucleated bone marrow cell number for 2 femurs and 2 tibias of each mouse revealed no significant differences between wild-type and knockout animals (Figure 4-7A). To test the colony forming ability of bone marrow progenitor cells, isolated bone marrow cells were cultured in an M3434 methylcellulose medium in the presence of SCF, IL-3, IL-6 and EPO. Bone marrow cells from wild-type and knockout animals gave rise to the same number of CFUs (Figure 4-7B), indicating normal steady-state kinetics in progenitor cells. This observation was consistent with the distribution of various progenitor and stem cell populations defined by surface markers in the bone marrow. Flow cytometry analysis showed that the percentages of HSC, CMP, MEP, and erythroid progenitors were comparable between wild-type and Hemgn knockout animals in the bone marrow compartment (Figure 4-7C).

Colony formation is a measurement of progenitor activity, whereas the surface marker profile gives information only on the phenotypes but not the functions of stem cells and progenitor cells. The gold standard to test the function of HSCs is competitive repopulation of lethally irradiated animals. Donor bone marrow cells from Hemgn knockout animals were mixed with competitor cells carrying the CD45.1 surface marker in a 1:1 ratio, and transplanted into lethally irradiated recipients. By 20 weeks after transplantation, all blood lineages in the peripheral blood should be derived from the transplanted stem cells. At this point, the peripheral blood profile is generally accepted as 

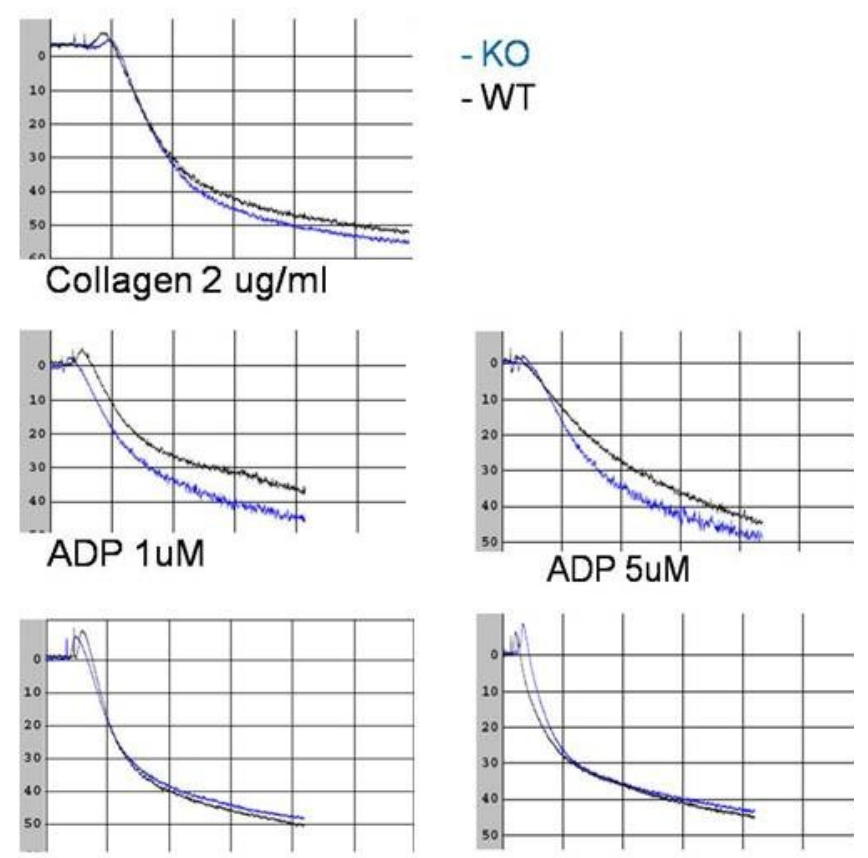

Thrombin $0.01 \mathrm{U}$

Thrombin $0.1 \mathrm{U}$

\section{Figure 4-6. Platelet aggregation}

Purified platelets from Hemgn knockout and wild-type animals were stimulated by collagen $\left(\mathrm{f}_{1}=2.7, \mathrm{f}_{2}=82.1\right)$, ADP $\left(\mathrm{f}_{1}=9.3, \mathrm{f}_{2}=56.2\right.$ for $1 \mu \mathrm{M} ; \mathrm{f}_{1}=7.5, \mathrm{f}_{2}=61.6$ for $\left.5 \mu \mathrm{M}\right)$ and thrombin $\left(\mathrm{f}_{1}=2.1, \mathrm{f}_{2}=83.8\right.$ for $0.01 \mathrm{U} ; \mathrm{f}_{1}=2.7, \mathrm{f}_{2}=71.3$ for $\left.0.1 \mathrm{U}\right)$. Aggregation was monitored by change in light transmission of the platelet solution. Difference factors $\left(\mathrm{f}_{1}\right)$ and similarity factors $\left(f_{2}\right)$ were calculated according to reference [93]. Two curves are considered similar if $\mathrm{f}_{1}<15$ and $\mathrm{f}_{2}>50$. 

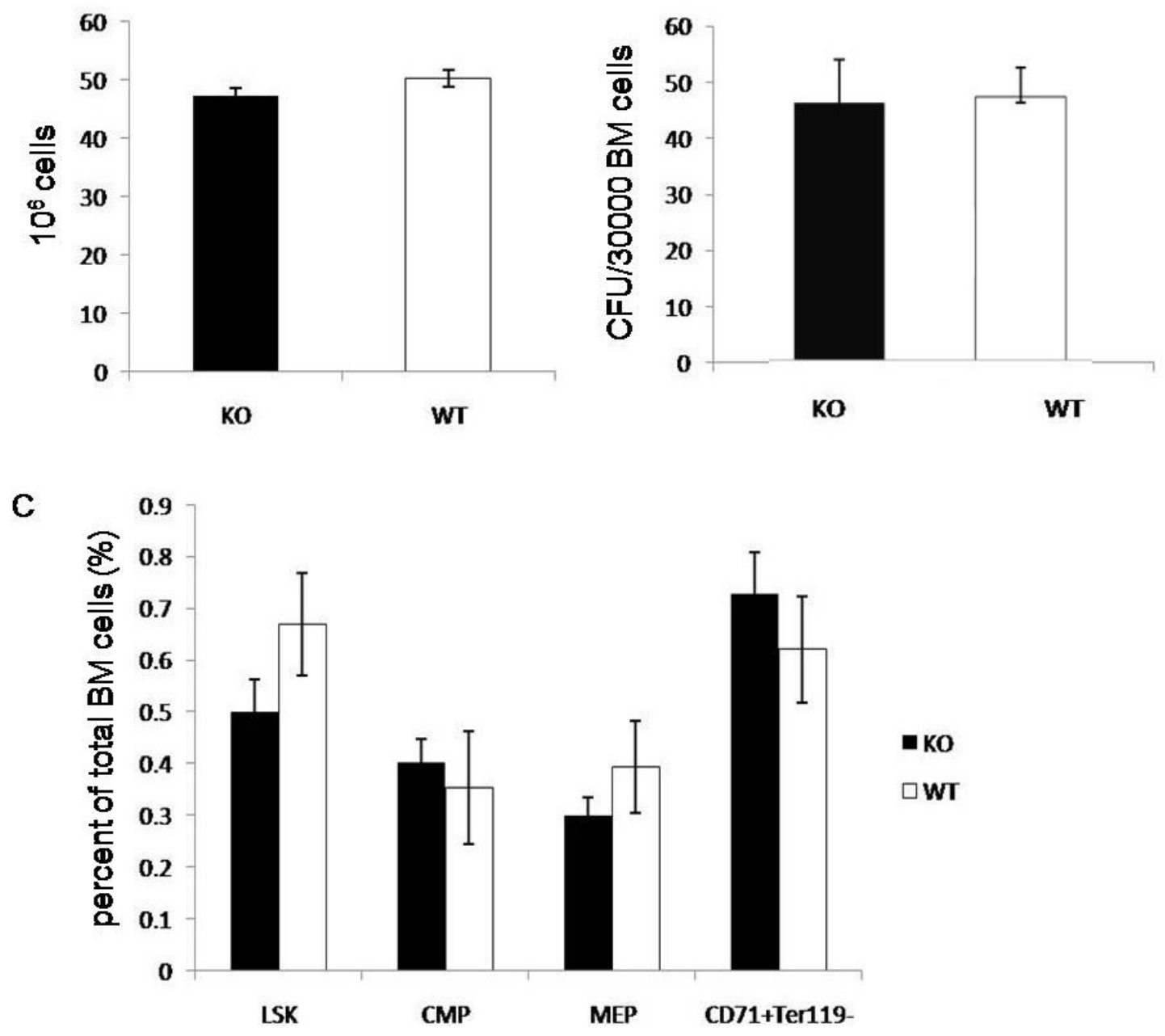

Figure 4-7. Progenitors in the bone marrow

(A) Bone marrow cellularity of 2 femurs and 2 tibias of each animal ( $\mathrm{p}=0.7$ by t-test). (B) CFU numbers of knockout and wild-type bone marrow cells cultured in an M3434 medium ( $p=0.83)$. (C) Percentages of LSK $(p=0.11)$, CMP $(p=0.59)$, MEP $(p=0.21)$ and Ter $119^{-} \mathrm{CD} 71^{+}(\mathrm{p}=0.3)$ erythroid progenitors in bone marrow, measured by flow cytometry. 
a reflection of reconstitution in the bone marrow compartment. Although myeloid cells, including macrophages and granulocytes, showed robust reconstitution from both the wild-type and Hemgn knockout cells, the contribution of Hemgn knockout cells to the lymphoid lineages, including B and T cells was slightly but significantly lower than that in the wild-type group (Figure 4-8A). This indicates a subtle defect of Hemgn knockout cells in lymphoid reconstitution upon transplantation.

\section{Sensitivity to Apoptotic Stresses}

It has been proposed that Hemgn is associated with apoptosis $[69,85,86]$. Overexpression of EDAG in the murine pro-B Ba/F3 cell line can protect the cell from IL-3 withdrawal induced apoptosis [85]; knockdown of EDAG in K562 cells can increase imatinib induced apoptosis [86]; and overexpression of Hemgn in mouse bone marrow cells can protect cells from cytokine deprivation induced apoptosis [69]. These evidences lead to the question of whether Hemgn knockout cells are more sensitive to apoptotic stresses than wild-type cells.

Mouse bone marrow progenitors may be sensitive to apoptotic stresses such as ionizing radiation and cytokine deprivation. Knockout of the anti-apoptotic Bcl-2 family member Mcl-1 results in lethality because of bone marrow failure [42], and heterozygous animals are sensitive to $\gamma$-IR. Slug knockout mice show increased sensitivity to $\gamma$-IR [40]. Radiation induced apoptosis is generally thought to be dependent on p53. Slug provides protection via its antagonizing effect on the pro-apoptotic Puma, and Slug itself is also a p53 target gene [39]. $\gamma$-IR can create DNA double strand breaks, in response to which the ATM-CHK2-p53 pathway is activated. However the ataxia telangiectasia (ATR) responds to UV radiation and chemical reagents that stall the DNA replication fork [35].

To determine the susceptibility of Hemgn knockout HSCs and HPCs to p53 dependent cell death, low dose $\gamma$-IR was given to the reconstituted competitive transplant recipient animals. The lethally irradiated recipients initially received Hemgn knockout and CD45.1 competitor bone marrow cells in a 1:1 ratio to minimize the possible effects of cell extrinsic factors. When the recipients reached a long-term reconstitution after 20 weeks, they were exposed to $4 \mathrm{G}$ or $2 \mathrm{G} \gamma$-IR to induce HSC apoptosis. If Hemgn knockout cells were more sensitive to $\gamma$-IR, their contribution to the peripheral blood would decrease after the insult. Another 20 weeks after the low dose $\gamma$-IR exposure, Hemgn knockout cells continued to make a significant contribution to all lineages in the peripheral blood, and to the same extent that the wild-type controls did (Figure 4-8B). No systemic difference was found between animals receiving $2 \mathrm{G}$ and $4 \mathrm{G} \mathrm{IR}$, implying that Hemgn knockout bone marrow cells are not more sensitive to p53 dependent apoptotic stress than wild-type cells.

On the other hand, cytokine deprivation induces apoptosis in p53 independent

pathways [101]. Fresh Hemgn knockout progenitor cells were enriched by lineage depletion, and cultured in the absence of cytokine supplements for 24 hours. Apoptosis 

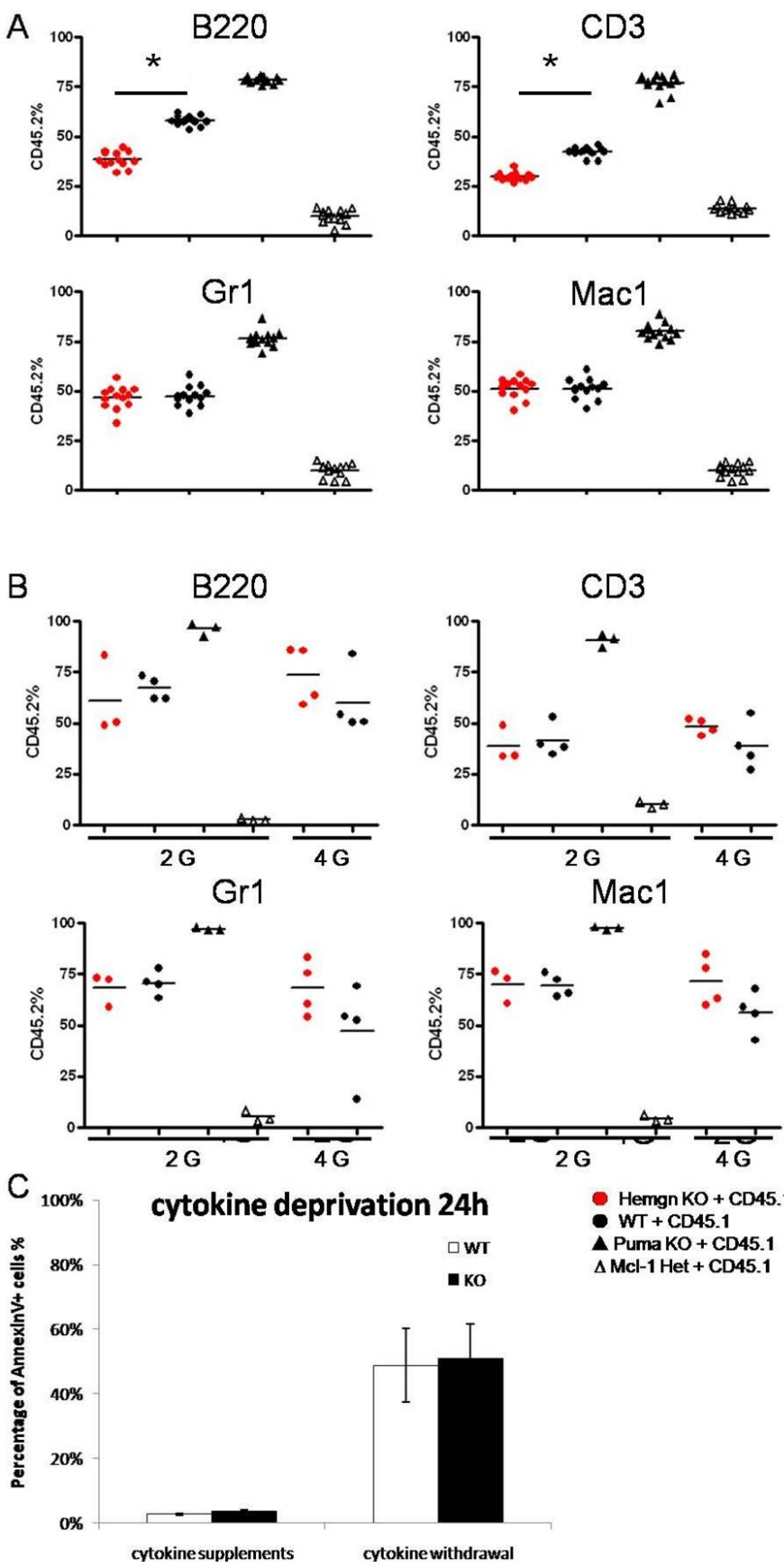

Figure 4-8. Sensitivity to ionizing radiation and cytokine deprivation

(A) Competitive repopulation in peripheral blood at 20 weeks post transplantation, before low dose ionizing radiation ( $p<0.01$ for B220 and CD3 cells, $p>0.05$ for Gr1 and Mac1 cells by t-test). Each recipient received $10^{7} \mathrm{CD} 45.2$ cells and $10^{7} \mathrm{CD} 45.1$ cells. (B) Peripheral blood profile at 20 weeks after $2 \mathrm{G}$ or $4 \mathrm{G}$ ionizing radiation $(\mathrm{p}>0.05$ for each lineage). (C) Percentage of Annexin $\mathrm{V}^{+}$cells in Lin progenitor population after cytokine deprivation $(p=0.27)$. Cells were cultured for 24 hours in DMEM with $2 \%$ FBS but without cytokine supplements, and stained with Annexin V and DAPI. 
was then analyzed by Annexin V and DAPI staining. No accelerated cell death was observed in Hemgn knockout progenitor cells (Figure 4-8C).

In summary, there was no increased sensitivity to p53 dependent or independent apoptotic stresses in Hemgn knockout primary cells.

\section{Partial Impairment of Hoxb4 Function}

Hemgn was originally identified as a Hoxb4 direct target in HSC ex vivo expansion. Knockdown of Hemgn impairs the Hoxb4 mediated expansion, but does not totally ablate its function, indicating that mechanisms other than Hemgn may also be responsible for Hoxb4 mediated expansion [69]. Similarly, when bone marrow progenitors were transduced with Hoxb4 in Hemgn knockout and wild-type backgrounds, complete knockout of Hemgn resulted in an almost 50\% reduction in the secondary colony numbers (Figure B-1). This loss of function study in combination with the previously published RNAi knockdown data demonstrated that Hemgn is required for Hoxb4 function.

\section{Nuclear Localization and Coiled-coil Domain}

Hemgn contains a predicted nuclear localization signal (NLS) at N-terminal amino acids 61-78 [67]. However, there are no experimental data to confirm the validity of this sequence. We generated a Hemgn mutant with truncation of this predicted NLS $(\triangle \mathrm{NLS})$ to test its function. The mutant was generated by PCR, cloned into a MSCV-IRES-GFP retroviral vector, and sequenced completely (Figure 4-9A). The mutant was then packaged into a retroviral vector to transduce the murine pro-B cell line $\mathrm{Ba} / \mathrm{F} 3$. Transduced $\mathrm{Ba} / \mathrm{F} 3$ cells were sorted and expanded in culture. Western blotting of Hemgn in the cytoplasmic and nuclear fractions of $\mathrm{Ba} / \mathrm{F} 3$ cells clearly showed that mutant Hemgn was located in the cytoplasm instead of the nucleus (Figure 4-9B, C). Thus the predicted NLS is required for the nuclear translocation of Hemgn.

There is little information on the overall structure of Hemgn. Hemgn has no identifiable family member in the mouse genome based on the predicted protein domains. There is only 1 predicted coiled-coil domain at the N-terminal amino acids 34-50 [67]. Part of this sequence is conserved among human, mouse and rat models. The coiled-coil motif is often associated with oligomerization or other types of protein-protein interaction [71]. Whether the functional NLS and the predicted coiled-coil have any physiological significance is not clear. To determine whether the 2 motifs are required for Hemgn function, a Hemgn mutant with deletion of the predicted coiled-coil sequence ( $\triangle \mathrm{CC}$ ) was generated together with the NLS mutant (Figure 4-9A).

A previous study has shown that human EDAG can protect $\mathrm{Ba} / \mathrm{F} 3$ cells from IL-3 deprivation induced apoptosis [85]. Therefore, the 2 mutants were tested in this system, assuming that Hemgn may exert its function as EDAG does. Stably transduced Ba/F3 


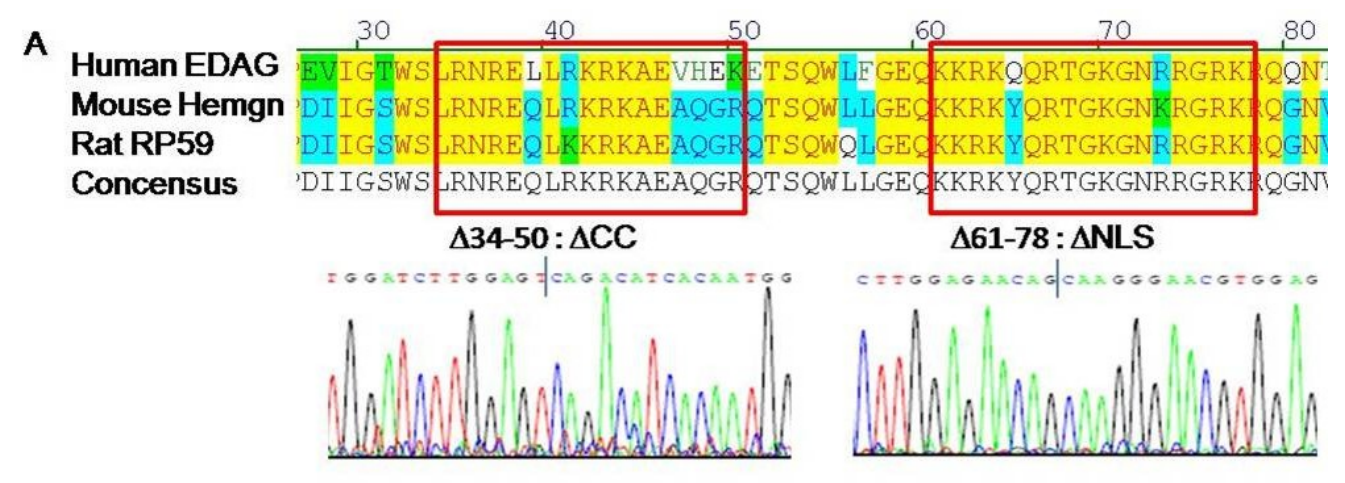

B

C

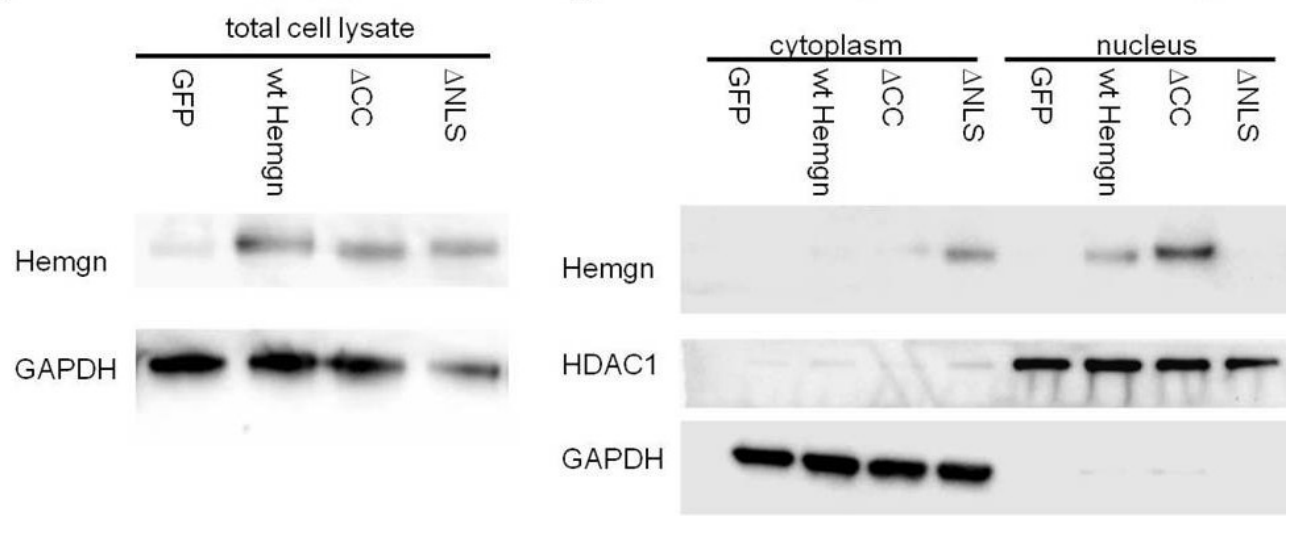

Figure 4-9. Hemgn mutagenesis

(A) Concensus sequence of the predicted coilded-coil domain (amino acids 34-50) and NLS (amino acids 61-78) among human, rat, and mouse Hemgn, and sequences of 2 mutants. (B) Western blotting on total cell lysate of $\mathrm{Ba} / \mathrm{F} 3$ cells. (C) The NLS mutant $(\triangle \mathrm{NLS})$ Hemgn is located in the cytoplasm. 
cells were sorted and expanded in the presence of IL-3. Before IL-3 withdrawal, dead cells were depleted from the culture. After 20 hours of IL-3 withdrawal, apoptosis was measured by Annexin V and DAPI staining. As expected, wild-type Hemgn protected $\mathrm{Ba} / \mathrm{F} 3$ cells from IL-3 withdrawal. However the same protective effect was not seen in cells transduced with either of the mutant Hemgn retroviral vectors (Figure 4-10). This observation indicates that both nuclear translocation and correct protein-protein interactions are required for Hemgn function.

In competitive repopulation assay, Hemgn knockout cells showed a mild defect in lymphoid reconstitution, but not in myeloid reconstitution (Figure 4-8A). In complement to the in vivo study, a myeloid cell line 32D was also used to test the function of Hemgn. In contrast to the $\mathrm{Ba} / \mathrm{F} 3$ cell line, wild-type Hemgn could not protect myeloid 32D cells from IL-3 withdrawal induced apoptosis (Figure 4-10), suggesting that the anti-apoptotic function might depend on cell context. Hemgn might require the nuclear localization and appropriate partners to carry out its function as stated above. However, such co-factors might be absent in the myeloid cellular environment. The difference between lymphoid and myeloid cells is discussed in Chapter 5 . 


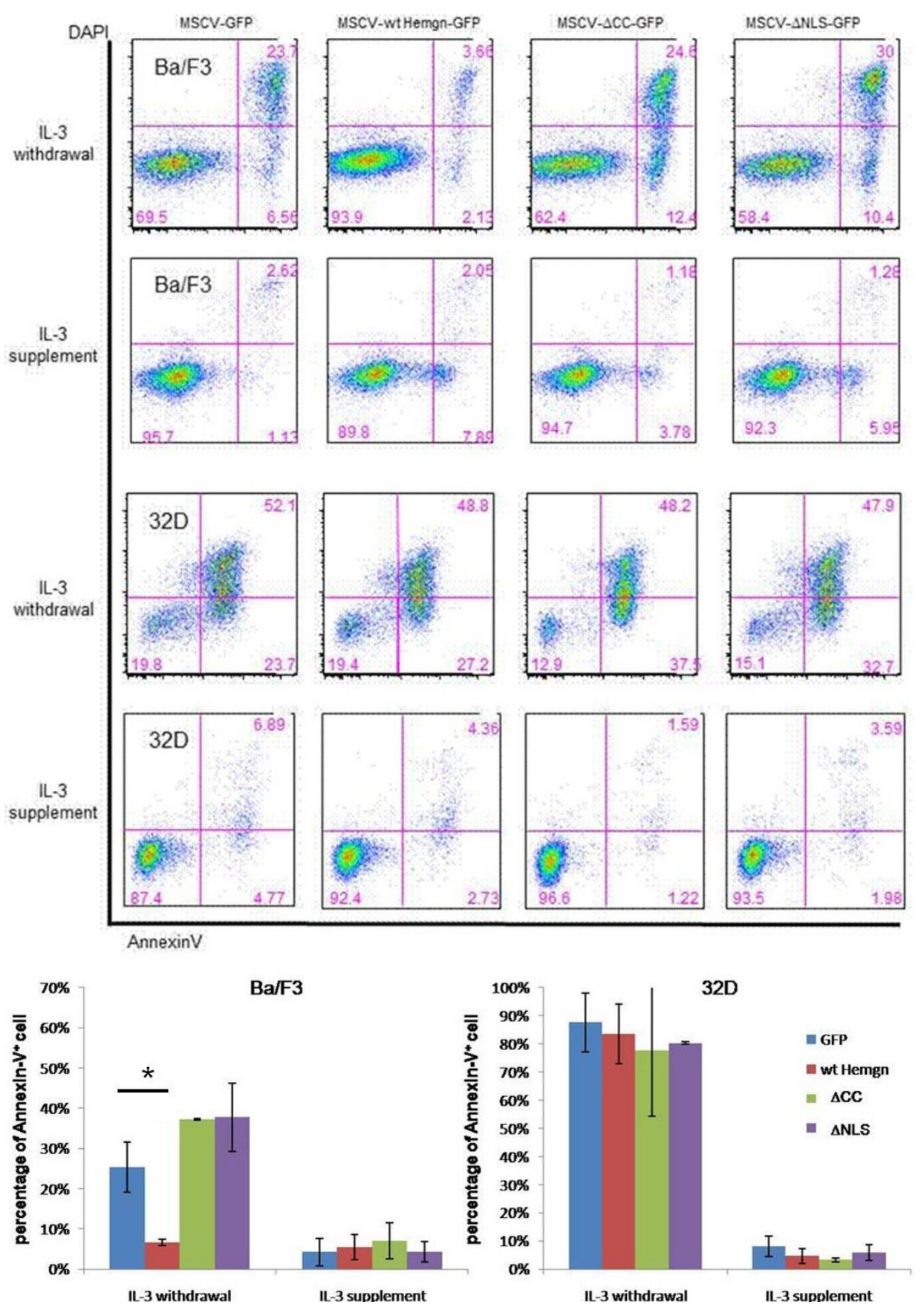

Figure 4-10. IL-3 withdrawal induced apoptosis in Ba/F3 and 32D cells

$\mathrm{Ba} / \mathrm{F} 3$ and 32D cells were transduced with wild-type and mutant Hemgn respectively. Apoptosis was induced in purified transduced cells by IL-3 withdrawal from the culture medium for 20 hours. In wild-type Hemgn transduced $\mathrm{Ba} / \mathrm{F} 3$ cells, the percentage of total Annexin $\mathrm{V}^{+}$cells was lower than that of mutant Hemgn $\left(\mathrm{p}=4 \times 10^{-7}\right.$ for $\Delta \mathrm{CC}, \mathrm{p}=0.03$ for $\Delta$ NLS, by t-test) or GFP transduced cells $(\mathrm{p}=0.007)$. This was not seen in transduced 32D cells upon IL-3 withdrawal. 


\section{CHAPTER 5. DISCUSSION}

This chapter includes discussions on the methodology, results and outlook of this study in the context of previous publications.

\section{Expression in Erythroblasts}

In this study, we confirmed Hemgn expression in mouse erythroblasts. Findings from previous studies on the expression pattern of Hemgn in mouse have been contradictory. Ter $119^{+}$erythrocytes were initially reported to be negative for Hemgn by RT-PCR [67]. However, in situ hybridization studies showed Hemgn expression in the spleen red pulp, where erythropoiesis occurs actively [67]; a thesis from the same group later confirmed that "this gene is expressed in hematopoietic stem/progenitor cells and then restricted in erythroid and megakaryocytic lineages" [94].

By studying the developmental stages of erythroid cells with surface markers such as CD44, CD71 and Ter119, we confirmed Hemgn expression in erythroid cells and megakaryocytes. Further, we found that Hemgn was expressed inTer $119^{+}$cells in the early and mid stages of erythroid cell development, but not in the final stages of erythrocyte maturation (Figure 4-3). This result is consistent with published data on the in vitro differentiation of mouse and human erythrocytes. In both species, Hemgn/EDAG expression is up-regulated during the early stages of differentiation, but is downregulated in the final stages [102]. Similar to the expression of mouse Hemgn in erythroid cells, the rat homologue RP59 is expressed in erythroblasts and megakaryocytes [74]. It is possible previous studies $[67,94]$ used Ter $119^{+}$cells from peripheral blood and bone marrow respectively that different conclusions were made. Therefore, we conclude that Hemgn is expressed by some Ter $119^{+}$erythroblasts in early and mid stages, but not late stages of erythroid development. However, the physiological significance of this expression pattern remains unclear.

\section{Apoptosis in Heterogeneous Cell Population}

In previous studies, the anti-apoptotic function of Hemgn or EDAG has been tested in $\mathrm{Ba} / \mathrm{F} 3$ cells and primary bone marrow cells $[69,85]$. EDAG overexpression can protect the cells from IL-3 withdrawal induced apoptosis, probably through NF- $\kappa B$ activation [85]. The study in $\mathrm{Ba} / \mathrm{F} 3$ is more straightforward by establishing an EDAG overexpressing cell line, in which EDAG expression is relatively homogenous. However, in primary bone marrow cells, retroviral vector transduction efficiency cannot reach $100 \%$, so both transduced and non-transduced cells exist when apoptosis is analyzed [69].

One concern about such heterogeneous cell culture is, by gating on $\mathrm{GFP}^{+}$cells for apoptosis analysis, apoptotic cells that have lost GFP expression are artificially excluded, thus the apoptosis is underestimated for $\mathrm{GFP}^{+}$population. During apoptosis, transduced 
cells lose marker expression soon. A GFP bright cell may become GFP dim but still positive, whereas a cell with moderate GFP expression may become totally GFP' ${ }^{-}$In this sense, the gating bias is especially significant in a heterogeneous population with low to moderate marker expression.

To bypass this bias from gating, prior to the induction of apoptosis, the transduced cells were sorted to a highly pure $\mathrm{GFP}^{+}$population that almost every $\mathrm{GFP}^{-}$cell was from an originally $\mathrm{GFP}^{+}$one and no cells were excluded on GFP expression for analysis. Measurement of apoptosis in a heterogeneous cell population by gating on marker expression may not be accurate.

\section{Association with Leukemia}

\section{Human EDAG and Leukemia}

Human EDAG is associated with specific types of leukemia, but the underlying evidences are arguable. EDAG is overexpressed in two Bcr-Abl ${ }^{+}$leukemia cell lines, K562 and KU812 [81]. EDAG is also overexpressed in peripheral blood mononuclear cells of patients with leukemia, and may be associated with poor prognosis in de novo AML patients [84]. EDAG is highly expressed in AML patients having high Erg expression (defined by the top $25 \%$ percentile), which predicts a poor survival [103]. Down-regulation of EDAG expression inhibits the growth of K562 cell and reduces their colony forming ability [84]. Molecular studies show that the $\mathrm{N}$-terminal region (amino acids 1-124) of EDAG physically interacts with the N-terminus (amino acids 118-187) of NPM, a known anti-apoptotic protein, and this interaction enhances the stability of NPM, whereas RNAi mediated knockdown of EDAG increases the degradation of NPM in K562 cells [86]. Other studies on apoptosis with regard to human EDAG have been mostly on murine cells, and therefore their validity is arguable. Because of the relatively low homology (46\%) between human EDAG and mouse Hemgn, human EDAG may not function in the same way as mouse Hemgn.

The prevalence of EDAG overexpression in specific leukemia types has not been studied. A claim that EDAG expression level is higher in leukemia patients than in healthy blood donor and complete remission patients [84] may need to be understood in more depth. In that study, EDAG expression levels in bone marrow mononuclear cells (BMMC) of healthy donor, leukemia patients with and without complete remission are compared by RT-PCR, and lower EDAG level is found to be associated with better chemotherapy response. However, the BMMC is a heterogeneous population consisting of both EDAG expressing leukemic cells and non-expressing cells, and RT-PCR only reflects the expression at a population level instead of individual cells. The high expression level of EDAG in BMMC can therefore be attributed to a higher percentage of leukemic cells in non-remission patients. It is possible that patients with high expression level of EDAG in individual leukemic cells responded well to chemotherapy and finally reached complete remission, in which case the overall EDAG expression fell to an 
undetectable level by RT-PCR. EDAG overexpression may not be the reason, but the manifestation of poor responses to chemotherapy. Instead, EDAG might be regarded as a marker of leukemic cells.

Cytogenetic evidence has been shown to suggest an association of EDAG with leukemia $[67,94]$. EDAG is located in the $9 q 22$ genomic region, which is a frequent leukemia breakpoint. The most frequent cytogenetic lesion involving this region is deletion. Among the 408 patients with $9 \mathrm{q} 22$ breakpoints whose data were registered at the Mitelman Database of Chromosome Aberrations and Gene Fusions in Cancer, 291 have leukemia (4 inversions, 4 translocations, 10 additions, 273 deletions) [104]. Loss of heterozygosity $(\mathrm{LOH})$ is often observed, although the overexpression of EDAG results in anti-apoptotic effects in leukemic cells and is observed in leukemia patients [84]. A plausible explanation for this seemingly contradictory observation is that the association of 9q22 LOH with leukemia incidence is via genes other than EDAG. With the available data, it is more reasonable to assume that overexpression, and not loss of function, of human EDAG, is associated with oncogenic potency. Data on the association of EDAG with leukemia are limited in patients, and the proof of this association in only a single cell line makes this conclusion weak.

Although the above observations are only suggestive of the link between EDAG and leukemia, the recent discovery of human EDAG and NPM interaction [86] may provide more definitive evidence of the leukemogenesis. NPM is a most frequently mutated gene in AML, with the most common NPM mutation being duplication of the TCTG sequence at position 956-959 of the coding sequence. This mutation results in the loss of the tryptophan residues required for nucleolar localization, and generation of novel sequences at the $\mathrm{C}$-terminus. The direct consequence is retention of mutant NPM in the cytoplasm, thus sequestrating and degrading ARF in the cytoplasm. Patients with AML having this type of NPM mutation show higher sensitivity to chemotherapy but also a higher remission rate than those without this mutation [105]. Could EDAG overexpression be related to NPM in some AML cases? It is possible that high EDAG expression increases the ability of NPM to sequester ARF in the nucleolus and inhibit ARF function in the nucleoplasm. This assumption is consistent with the observation that overexpression of NPM enhances cell growth and inhibits apoptosis [105]. But whether NPM protein increases in EDAG overexpressing primary leukemic cells is not known.

\section{Mouse Hemgn and Leukemia Models}

The association of mouse Hemgn with leukemia incidence is supported by the finding that the mouse chromosome 4B1 region, where Hemgn is located, is involved in radiation induced leukemogenesis [106]. However, with the exact mapping of Hemgn this rationale has been called into question. The distance between the Hemgn locus and the marker D4Mit89 is only approximately $60 \mathrm{~kb}$ [107], therefore D4Mit89 can be roughly regarded as a marker for the presence or absence of Hemgn. However, of the 14 radiation induced AML cases, loss of D4Mit89 occurs in 1 case only; of the 21 lymphomyeloid leukemia (L-ML) cases, loss of D4Mit89 is seen in 9 cases. The 4B1 region is 
associated with leukemia in this study, but the exact location of this region is across the junction of 4A5 and 4B1. When Hemgn was first mapped, its position was estimated to be between $4 \mathrm{~A} 5$ and $4 \mathrm{~B} 2$, and this is the primary reason to postulate Hemgn might be involved in leukemogenesis [66]. As the exact genomic location of Hemgn is now known, it is clear that both copies of Hemgn are intact in most radiation induced leukemia cases. Therefore, $\mathrm{LOH}$ of this gene is less likely to be associated with radiation induced leukemia.

From these findings in human and mouse $\mathrm{LOH}$ mutations, it is difficult to unequivocally conclude that loss of the human EDAG or mouse Hemgn is associated with leukemia. On the other hand, there is not sufficient data to conclude that overexpression of Hemgn is associated with AML incidence in mouse. Five independent AML mouse models [108-111], with known mutations in human leukemia, do not show Hemgn overexpression (Table A-7). This challenges the proposed association between Hemgn overexpression and leukemia, especially in AML. Considering that EDAG is overexpressed in two Bcr-Abl ${ }^{+}$cell lines and that knockdown of EDAG in K562 cells promotes imatinib induced apoptosis [86], could Hemgn be only associated with Bcr-Abl leukemia models? To explore this possibility, we analyzed the Gene Expression Omnibus database. In 3 independent datasets, though Hemgn expression increased in Bcr-Abl transduced Lin ${ }^{-}$cells (Figure B-3A), there is no evidence that this increase is due to Bcr-Abl expression in the LSK population (Figure B-3B, C). In all 3 models, bone marrow cells are transduced with control vector or Bcr-Abl vector and transplanted to recipients, and microarray analysis is performed on the recipients' bone marrow cells. Considering that the Bcr-Abl ${ }^{-}$cell line HEL 92.1.7 has high EDAG expression, the relationship between Bcr-Abl and EDAG or Hemgn expression appears weak because:

1. The Bcr-Abl mouse models show Hemgn overexpression in Lin ${ }^{-}$cells only;

2. The Bcr-Abl mouse models and cell lines do not consistently have EDAG/Hemgn overexpression;

3. EDAG overexpression occurs in both Bcr-Abl positive and negative human leukemia cell lines.

Thus, there is no concrete in vivo evidence of the association of mouse Hemgn overexpression with any type of leukemia. Why can EDAG be associated with leukemia while its mouse homologue Hemgn cannot? The knowledge on EDAG should be examined in retrospect. The transgenic mouse model with increased myelopoiesis is generated using human EDAG, and all leukemia studies are also conducted with human EDAG. With only $46 \%$ sequence identity between mouse Hemgn and human EDAG, it is not clear to what extent their functioning is similar. The knowledge on human EDAG may not necessarily apply to mouse Hemgn. Thus far, there is no mouse Hemgn overexpression (transgenic or transplant) model that mimics EDAG overexpression in the correct cell context. In this sense, the causal relationship between mouse Hemgn overexpression and leukemogenesis is not yet firmly established. To recapitulate the scenarios of EDAG overexpression in human, a mouse Hemgn transgenic model with a potent promoter both expressed in myeloid and lymphoid lineages needs to be developed. 


\section{Normal Hematopoiesis and Erythropoiesis}

Hematopoietic organs were examined in the Hemgn knockout mouse model based on the pattern of Hemgn expression. No gross defects were found in erythrocyte (Figure 4-5), platelet (Figure 4-6), and HSC (Figure 4-8A) function under steady-state and stress conditions.

In some cases, a gene knockout animal model may not present severe or moderate phenotype. In the hematopoietic system, there are examples of animal models with mild phenotypes that are only seen under specific conditions. The deletions of p21, CD81, Prnp and p55 result in decreased peripheral reconstitution only after secondary or tertiary transplantation [112]. Similarly, Hif1- $\alpha$ might be important for the metabolism of HSCs, considering the hypoxic microenvironment of the bone marrow niche, but a Hifl- $\alpha$ knockout model only shows apparent defect upon secondary transplantation [113]. In another glycolysis deficient model, Pdk2 and Pdk4 double knockout mice show a mild anemic phenotype. At the progenitor level, the colony forming capacity of the double knockout cells are identical to that of control cells, suggesting normal steady-state stem cell maintenance [114]. These studies suggest that in some cases, genes may have very specific functions, thus if the appropriate aspects of the HSC behavior cannot be adequately assayed, gene knockout animal models may not present severe or moderate phenotypes.

The reasons for the apparent lack of phenotype may be complex. Lack of phenotype may be attributed to the redundancy of paralogous genes, in which case one or more members of the gene family could make up the absent gene. It has been estimated that $50 \%$ of mouse genes have a related member in the genome [115]. Since Hemgn has no identifiable family members in the genome, it is likely that this genetic robustness arises from non-paralogous genes or at the network level. The highly specific spatial and temporal expression pattern of Hemgn limits its potential to participate in a wide variety of protein-protein interactions and transcriptional networks, thereby reducing its importance in the network. The only characterized partner of human EDAG thus far is NPM [86], and no co-factor of mouse Hemgn has been reported. It has been postulated that a protein with many protein-protein interactions is more likely to have an essential role [115]. Hemgn might lack a broad protein-protein interaction network that knockout of this gene may not produce any detectable abnormalities.

\section{Relationship with NPM}

The anti-apoptotic function of human EDAG in K562 cells has been attributed to its interaction with NPM [86], a ubiquitously expressed phosphoprotein that is primarily found in the nucleolus. As discussed above, EDAG overexpression may be associated with leukemia [84], possibly by affecting NPM protein. NPM may be involved in various biological processes, such as rRNA synthesis, regulation of chromatin structure and transport of rRNA and ribosomal proteins. However, a knockout mouse model suggests 
that NPM may be dispensable in these biological processes [116]. The anti-apoptotic function of NPM is related to p53. It has been postulated that NPM may physically interact with p53 and ARF $[117,118]$. The tumor suppressor ARF forms a complex with MDM2, an E3 ligase of p53 [117]. Because NPM and MDM2 may compete for ARF binding [117] and ARF primarily functions in nucleoplasm, when the majority of ARF molecules are sequestered by NPM in the nucleolus, MDM2 is released from ARF-MDM2 complex to promote the degradation of p53 (Figure B-2A).

NPM knockout mice are embryonic lethal due to accumulation of DNA damage, activation of $\mathrm{p} 53$ and increased apoptosis $[116,119]$. The apoptosis phenotype can be rescued by simultaneous deletion of p53 and NPM, though the embryonic lethality remains [119]. The NPM heterozygous animals are viable and fertile [119], but develop a hematological syndrome similar to human MDS with mild dysplasia in erythroid and megakaryocytic lineages [116]. These models establish the anti-apoptotic role of NPM in the context of p53.

On the one hand, siRNA mediated knockdown of EDAG decreases the level of NPM in K562 cells and increased the apoptosis induced by imatinib [86], which is a p53 dependent process [120]. Overexpression of EDAG can enhance the stability of NPM at the protein level, possibly by preventing ARF or ubiquitin mediated NPM degradation, while not affecting NPM mRNA expression [86]. The physical interaction between the 2 proteins requires the N-terminal amino acids 1-124 of EDAG and N-terminal amino acids 118-187 of NPM [86]. The predicted NLS and coiled-coil motif of EDAG both locate in the required region. It is not known whether additional domains are also required for their physical binding. It is also unclear whether this EDAG-NPM interaction exists in stem cells or other cell types and has any physiological significance. As both Hemgn and NPM are expressed in mouse HSCs [121, 122], it is possible that this interaction occurs in HSCs. Interestingly, in a cohort of cytogenetically normal acute myeloid leukemia (CN-AML) patients, EDAG is significantly down-regulated at the RNA level in patients with NPM mutations [123], indicating that NPM might regulate the expression of EDAG indirectly. NPM is not a transcription factor per se, but can be an essential co-activator of transcription factors such as Miz1, NF- $\kappa$ B and IRF1 [105]. The NPM mutation also increases the transcription rate of RNA polymerase II, which may have a global effect on transcription [105].

In contrast to NPM, the expression of Hemgn and EDAG is restricted to hematopoietic cells, including HSCs. Based on the rationale that EDAG stabilizes NPM to protect cells from p53 dependent apoptosis, the role of NPM needs to be specifically reviewed in the HSC compartment. To differentiate overexpression models from loss of function models, NPM deficiency in HSCs needs to be analyzed. Specifically, in normal human lymphoblasts and Fanconi anemia associated AML patient cells, knockdown of NPM increases DNA damage induced apoptosis in a p53 dependent manner [124]. However, in Hemgn knockout HSCs, we did not observe increased sensitivity to ionizing radiation, which is a p53 dependent process (Figure 4-8B). This result leads to the questions whether mouse Hemgn is a functional equivalent of human EDAG, and whether NPM and Hemgn interact at the protein level across different cell contexts. 
To answer the two questions, the physical interaction of mouse Hemgn and NPM may be tested both in vitro and in vivo. It is possible that mouse Hemgn, though similar to human EDAG, does not interact with NPM at all. MEL cell is a mouse erythroleukemia cell line with high level of endogenous Hemgn and NPM expression [125]. Ba/F3 cell line with Hemgn overexpression is now also established by this study. A Co-IP experiment in these two models may be necessary to tell whether Hemgn could physically interact with NPM as EDAG does. It is possible the Hemgn-NPM interaction might require a third partner, or additional posttranslational modification, such as the reported serine 380 phosphorylation of Hemgn [73]. Such phosphorylation may be also required for NPM function [126, 127]. It is not known whether these posttranslational modifications affect the ability of Hemgn and NPM to physical interact and their appropriate functions. The absence of the correct subcellular localization, posttranslational modification or the required co-factors may reduce the possibility and the significance of the Hemgn-NPM interaction under physiological conditions.

Further studies may be needed on the in vivo interaction between Hemgn and NPM. As it is known that this physical interaction regulates NPM at the posttranslational level, a differential expression profile may not reveal any changes in the absence of Hemgn. The Hemgn-NPM interaction may be examined by Co-IP in the erythroid cells where both proteins are present. If Hemgn-NPM interaction can be confirmed in erythroid cells, considering the mild erythroid dysplasia in $\mathrm{NPM}^{+/-}$mice [116], additional loss of Hemgn may exacerbate the phenotype in erythrocytes by further reduction of NPM protein.

The anti-apoptotic effect seen in $\mathrm{Ba} / \mathrm{F} 3$ cells may need further analysis in light of NPM and p53. Whether this phenotype could be attributed to a possible Hemgn-NPM interaction is not known, but NPM has robust expression in the $\mathrm{Ba} / \mathrm{F} 3$ cell line [128]. Because cytokine deprivation induced apoptosis is generally regarded as being independent of p53, in the context of NPM and p53, the protective effect of Hemgn overexpression may become more significant when other stresses are applied to induce p53-dependent apoptosis. The same assumption could be made to the myeloid 32D cell line to explain the lack of protective effect, which may be due to lack of appropriate cofactors or absence of p53 activation induced by IL-3 withdrawal. In the latter case, with stresses to induce p53 activation, a protective effect might be seen in cells overexpressing Hemgn.

\section{Defect in Lymphoid Cell Reconstitution}

In 2 competitive repopulation assays, bone marrow cells from Hemgn knockout animals showed a minor defect in B cell and $\mathrm{T}$ cell reconstitution, whereas all other lineages, including granulocyte and macrophage had normal reconstitution (Figure 4-8A). In the setting of competitive repopulation, all cell extrinsic factors that may affect survival, proliferation and differentiation of donor cells have been provided by recipients' cells and competitor cells. Thus the observed defect must be attributed to autonomous 
factors of donor cells. The absence of a similar phenotype in myeloid lineages implies that HSCs develop normally. According to published databases, Hemgn expression is lower in CLP [95] and pre-B cell stages [129] than in HSCs. Despite low level of expression, Hemgn might be required in lymphoid cell development. This observation also reinforces the proposition that Hemgn function may require appropriate cell contexts or posttranslational modification. The anti-apoptotic function was also confirmed in pro-B Ba/F3 cell, but not in the myeloid 32D cell line (Figure 4-10).

Based on these preliminary data on lymphoid cell development, the Hemgn knockout mouse model could be further analyzed by in vivo and in vitro assays. The lymphoid progenitors of the Hemgn knockout model have not been thoroughly examined under steady-state conditions. We found that under physiological conditions, the knockout animal did not show defect in the number of B cells and T cells (Figure 4-4C). However, any subtle defect in CLP or other lymphoid progenitor populations might be compensated for later during development by another genetic pathway in the in vivo environment such as pathways involving multiple cytokines. Such attenuation in phenotypes occurs in the Flt3 knockout model. The reduction of CLP in the Flt3 knockout animal is almost 10 -fold, whereas the mature B cell reduces only slightly and the number of pre-T cells is normal [130]. The Hemgn knockout bone marrow cells have been tested for the ability to form myeloid colonies, but their ability to form lymphoid colonies in vitro still remains unclear. At this point, in vitro colony assay specific for B cells and T cells may be necessary.

The NPM-Hemgn interaction might also provide a mechanism for the observed defect in lymphoid reconstitution. NPM is expressed at relatively high level in the CLPs [95]. Because NPM is actively involved in multiple biological processes such as ribosome biogenesis, centrosome duplication and cell cycle, it is premature to postulate that the lymphoid defect in Hemgn knockout cells is due to NPM and p53 related apoptosis, as discussed later in light of NF- $\mathrm{kB}$ signaling. As the NPM RNA level is not affected in the absence of EDAG [86], a comparison of NPM protein level in the CLPs or other lymphoid cells of Hemgn knockout and wild-type animals by flow cytometry may provide valuable information. A decrease in the NPM protein level is expected in Hemgn knockout CLPs or lymphoid cells.

The defect of Hemgn knockout cells to reconstitute lymphoid cells might be related to NF-kB signaling, a regulator of lymphopoiesis (Figure B-2B). It has not yet been fully established whether NF- $\kappa B$ signaling has an important function in early lymphopoiesis, but upon transplantation it can protect early lymphocytes from tumor necrosis factor (TNF) induced cell death [131]. NF- $\mathrm{kB}$ also plays an important role during the later stages of lymphopoiesis, including pre-BCR and pre-TCR signaling, positive and negative selection, and maintenance of the lymphocytes [131]. NF- $\kappa B$ activation occurs in human EDAG overexpressing $\mathrm{Ba} / \mathrm{F} 3$ cells [85]. Again this relationship might be mediated via NPM. The level of NPM may directly affect the activity of NF- $\mathrm{B}$ [132]. NPM interacts physically with p50 and p65, both members of the NF- $\kappa B$ family [132]. A mutant NPM with cytoplasmic localization has been associated with reduced NF- $\mathrm{KB}$ activity in AML patients [133]. All these evidences 
suggest that lack of Hemgn may decrease NF- $\kappa B$ activity through reduced NPM stability, and reduction of NF- $\kappa \mathrm{B}$ activity specifically affects lymphopoiesis. However, if this is true, a competitive repopulation setting may no longer be the best assay to test the role of

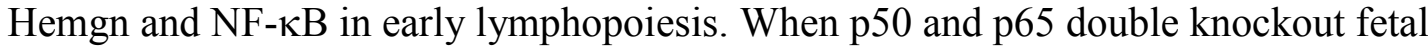
liver cells are transplanted, TNF production is associated with increased granulopoiesis, and kills the lymphoid progenitors [131, 134]. However a co-transfer of the wild-type cells with NF- $\kappa \mathrm{B}$ knockout fetal liver may reduce the TNF produced by excessive granulopoiesis, thus attenuating the proposed phenotype [134]. This might also explain why only a mild reduction in lymphopoiesis was seen in this study. The normal reconstitution of the myeloid cells in these recipient animals would not produce the excessive TNF that is necessary to initiate lymphoid cell death. For the same reason, as no endogenous TNF signal is present under steady-state conditions, the lymphopoiesis of Hemgn knockout animal is also normal.

\section{Differences between Myeloid and Lymphoid Cells}

In the primary cells, Hemgn knockout bone marrow cells showed reconstitution defect only in lymphoid lineages but not in myeloid lineages (Figure 4-8A), whereas in cell lines, Hemgn overexpression only showed protection on $\mathrm{Ba} / \mathrm{F} 3$ cells but not $32 \mathrm{D}$ cells (Figure 4-10). Similarly, this discrepancy between lymphoid and myeloid cells is also seen for human EDAG. EDAG overexpression in $\mathrm{Ba} / \mathrm{F} 3$ cells increases NF- $\mathrm{KB}$ signaling [85] while EDAG knockdown does not lead to reduced NF- $\kappa$ B activity in K562 cells [84].These different phenotypes between lymphoid and myeloid cells may be attributed to 2 possibilities. The first explanation is Hemgn may interact with specific cofactors only in lymphoid cells. This depends on whether such co-factors are expressed with the required posttranslational modification in the specific cell types. However, even if Hemgn interacts with a common set of co-factors and regulates the same signaling pathway in both lymphoid and myeloid cells, their responses can still be very different. For example, lymphoid and myeloid cells show different dependence of NF- $\kappa$ B signaling for survival. While no NF- $\kappa \mathrm{B}$ activity can be detected in the resting monocytes, it may be correlated to the activation process [135]. Inhibition of $\mathrm{NF}-\kappa \mathrm{B}$ can be associated with increased apoptosis of granulocytes only under inflammatory or stress conditions [135]. On the contrary, the functions of NF- $\kappa \mathrm{B}$ in the lymphoid cells are better established by knockout mouse model. In animals transplanted with the p50 and p65 double knockout cells, the myelopoiesis increases relatively whereas lymphopoiesis is impaired [134]. However, it is not clear whether lymphoid and myeloid cell lines have different dependence on NF- $\mathrm{KB}$ signaling, as shown in the knockout mouse model.

\section{Relationship with Hoxb4}

Hemgn is characterized as a direct target gene during Hoxb4 mediated ex vivo HSC expansion [69]. Hemgn knockdown significantly impairs the Hoxb4 function, but does not totally ablate Hoxb4 mediated HSC expansion [69], indicating that other mechanisms also control Hoxb4 function. Similarly, complete knockout of Hemgn 
caused an approximately $50 \%$ reduction in secondary colony numbers when transduced with Hoxb4 (Figure B-1). This loss of function study in combination with previous in vitro data demonstrated that Hemgn is a direct target of Hoxb4 and is required for Hoxb4 mediated HSC expansion. It is also possible this HSC expansion is mediated by the Hemgn-NPM interaction. Hoxb4 does not regulate NPM expression per se, as seen by the expression profile of Hoxb4 overexpressing bone marrow cells [69].

The defect in lymphoid reconstitution might be contradictory to what is known in a Hoxb4 overexpressing mouse model. Hoxb4 overexpression leads to increased Hemgn level [69] and decreased lymphoid reconstitution upon transplantation [87]. Following this rationale, Hemgn overexpression, instead of knockout, should be related with defect of lymphoid cells. The human EDAG transgenic mouse model show inhibition of lymphopoiesis [77]. However, the Hemgn knockout bone marrow cells showed defect in lymphoid reconstitution too (Figure 4-8A). Similar phenotypes are observed in mouse models with totally opposite Hemgn expression status. This can be explained by the difference between gain of function model and loss of function model. Hoxb4 is a master gene in hematopoiesis, whose overexpression initiates a series of changes in the expression profile, among which elevated Hemgn expression is only one. The decreased lymphopoiesis seen in the Hoxb4 overexpression model may not necessarily be physiological, or be attributed to increased Hemgn level. In the overexpression model, excessive Hoxb4 may bind to the promoters or enhancers of its non-physiological targets and regulate transcription. Also, Hoxb4 can directly bind to promoters of lymphoid genes such as B220 [136]. It is also possible that Hoxb4 regulates key lymphoid genes that have greater functions than NPM or NF- $\kappa \mathrm{B}$. On the other hand, the phenotypes seen in gene knockout model are closer to physiological scenarios, as it is loss of function right in the cells with endogenous Hemgn expression.

\section{Potential Use of Hemgn Knockout and Mutants to Characterize Co-factors}

As discussed above, to elucidate the anti-apoptotic function of Hemgn, it may be necessary to characterize its binding partners in cell lines and primary cells. NPM might be a candidate, but not exclusively. To answer whether such binding partners exist, cell lysate may be extracted from primary bone marrow cells or $\mathrm{Ba} / \mathrm{F} 3$ cells, and analyzed by non-reducing and non-denaturing Western blot. If such co-factors of Hemgn do exist, it is possible Hemgn shows higher molecular weight in the non-reducing and non-denaturing gel than its size in the reducing and denaturing environment. However, if majority of Hemgn molecules are in the free form, or its binding partners are too small, it may be difficult to detect any change in the apparent molecular weight in migration.

A pull-down assay with Hemgn antibody in appropriate cell type followed by mass spectrum analysis may be a viable method to indentify its binding partners, similar to the characterization of NPM as a binding partner of human EDAG [86]. In pull-down assays, to minimize the background from IgG heavy chain and light chain, Hemgn antibody should be conjugated to the immobilized beads covalently. Although the available Hemgn antibody is competent to perform the immunoprecipitation, its 
polyclonal nature will inevitably result in significant non-specific binding in the assay. To eliminate the false positive candidates, the cells from Hemgn knockout animals can be used as negative control for primary cells, including erythroblasts and other progenitor cells. In the $\mathrm{Ba} / \mathrm{F} 3$ cell line, the presence of low level of endogenous Hemgn may prevent the usage of wild-type $\mathrm{Ba} / \mathrm{F} 3$ as a perfect negative control. In this case, the NLS or coiled-coil motif mutant transduced $\mathrm{Ba} / \mathrm{F} 3$ cells can be used as negative controls. The loss of NLS or coiled-coil motif possibly ablates the physical interaction between Hemgn and its partners, and any proteins pulled down by these two mutants might be nonspecific partners.

\section{Clinical Relevance}

The finding that knockdown of EDAG in K562 cells leads to increased imatinib induced apoptosis [86], and decreased ability of colony formation and cell growth [137], suggests a potential application of EDAG inhibitors in combination with imatinib in some patients with myeloid or erythroid leukemia. The EDAG-NPM interaction also provides grounds for a potential therapy in AML patients carrying the NPM mutation.

Clinical resistance to imatinib is common in patients with acute leukemia, and occurs within 3-6 months of treatment in more than $70 \%$ of patients [138]. Imatinib resistance develops via selection of leukemic cells with mutant Bcr-Abl or by $\mathrm{Mdr}$ overexpression. Once resistance develops, the disease progresses rapidly and is aggressive in most patients. Besides drugs that directly target the Bcr-Abl variants or Mdr, agents that enhance apoptosis selectively in leukemic cells have been tested in combination with imatinib in cell cultures with the aim of finding an additive or synergistic effect, and results have been encouraging. Such drugs include $\mathrm{As}_{2} \mathrm{O}_{3}$, flavopiridol (cyclin-dependent kinase inhibitor), suberoylanilide hydroxamic acid (histone deacetylase inhibitor), and TNF related apoptosis-inducing ligands [139]. Ideally, candidate drugs should be effective, have few side effects or systemic toxicity, and be selective for leukemic cells. Whether a potential EDAG inhibitor can be candidate drug remains an open question.

A possible inverse relationship has been reported between the expression level of EDAG and response to chemotherapy [84], possibly through activation of NF- $\mathrm{KB}$ signaling [85], though the exact chemotherapy reagents used in the study is not specified. Before such small molecule inhibitors are developed, the safety of targeting EDAG needs to be examined. By ablation of EDAG's homologous gene Hemgn in mouse genome, this study demonstrated that there was no gross defect or hematopoietic abnormality in the mouse model. This implies that EDAG might not play an important role in normal human hematopoiesis, and might be safe to target in leukemic cells because of its highly restricted expression pattern. EDAG is pathologically up-regulated in leukemic cells [84]. If inhibition of EDAG function causes no defects in HSCs, RBCs and sperm development in humans, as seen for mouse Hemgn, but enhances the efficacy of imatinib as seen in K562 cells, the safety and efficacy of such inhibitor can be further examined. 


\section{A Proposed Model for Hemgn Function}

As discussed above, it is possible Hemgn may interact with specific co-factors through a coiled-coil motif in the lymphoid cell context and possibly in certain leukemic cells, thus may protect the cells from apoptosis induced by specific signaling. The proposed protein-protein interaction might require its correct subcellular localization in the nucleus, and correct posttranslational modifications such as the S380 phosphorylation [73]. The anti-apoptotic protein NPM could be a candidate co-factor of Hemgn. In the proposed model, by stabilizing NPM from degradation, Hemgn indirectly inhibits p53 activity (Figure B-2A) and/or increases the pro-survival NF- $\kappa$ B activity (Figure B-2B), as the human EDAG does $[85,86]$. As NF- $\kappa \mathrm{B}$ signaling has been proposed to participate in early lymphopoiesis by regulating TNF induced apoptosis [131], the mild lymphoid defect in Hemgn knockout cells upon transplantation might be related to decreased $\mathrm{NF}-\kappa \mathrm{B}$ activity, and needs to be further explored. 


\section{LIST OF REFERENCES}

1. Ramalho-Santos, M. and H. Willenbring, On the origin of the term "Stem Cell". Cell Stem Cell, 2007. 1(1): p. 35-38.

2. Maehle, A.-H., Ambiguous cells: the emergence of the stem cell concept in the nineteenth and twentieth centuries. Notes and Records of the Royal Society, 2011. 65(4): p. 359-378.

3. Konstantinov, I.E., In search of Alexander A. Maximow: The man behind the unitarian theory of hematopoiesis. Perspectives in Biology and Medicine, 2000. 43(2): p. 269.

4. Till, J.E. and E.A. McCulloch, A direct measurement of the radiation sensitivity of normal mouse bone marrow cells. Radiation Research, 1961. 14(2): p. 213-222.

5. Negrin, R.S. and K.G. Blume, Principles of hematopoietic cell transplantation, in Williams Hematology, M.A. Lichtman, Editor. 2006, McGraw-Hill. p. 301.

6. Food, C.E., et al., Cytological identification of radiation chimeras. Nature, 1956. 177: p. 452.

7. Goldschneider, I., L.K. Gordon, and R.J. Morris, Demonstration of Thy-1 antigen on pluripotent hemopoietic stem cells in the rat. The Journal of Experimental Medicine, 1978. 148(5): p. 1351.

8. Spangrude, G.J., S. Heimfeld, and I.L. Weissman, Purification and characterization of mouse hematopoietic stem cells. Science, 1988. 241(4861): p. 58-62.

9. Kiel, M.J., et al., SLAM family receptors distinguish hematopoietic stem and progenitor cells and reveal endothelial niches for stem cells. Cell, 2005. 121(7): p. $1109-1121$.

10. Bunting, K.D., ABC transporters as phenotypic markers and functional regulators of stem cells. Stem Cells, 2002. 20(1): p. 11-20.

11. Lin, K.K., et al., Detection of hematopoietic stem cells by flow cytometry, in Methods in Cell Biology. 2011, Academic Press. p. 21-30.

12. Shizuru, J.A., R.S. Negrin, and I.L. Weissman, Hematopoietic stem and progenitor cells: Clinical and preclinical regeneration of the hematolymphoid system. Annual Review of Medicine, 2005. 56(1): p. 509-538.

13. Weissman, I.L., D.J. Anderson, and F. Gage, Stem and progenitor cells: Origins, phenotypes, lineage commitments, and transdifferentiations. Annual Review of Cell and Developmental Biology, 2001. 17(1): p. 387-403. 
14. Morrison, S.J., et al., Identification of a lineage of multipotent hematopoietic progenitors. Development, 1997. 124(10): p. 1929-1939.

15. Kondo, M., I.L. Weissman, and K. Akashi, Identification of clonogenic common lymphoid progenitors in mouse bone marrow. Cell, 1997. 91(5): p. 661-672.

16. Lichtman, M.A., et al., Williams hematology. 2006: McGraw-Hill Professional.

17. Lenox, L.E., et al., Extramedullary erythropoiesis in the adult liver requires BMP-4/Smad5 dependent signaling. Experimental Hematology, 2009. 37(5): p. 549-558.

18. Lymperi, S., F. Ferraro, and D.T. Scadden, The HSC niche concept has turned 31. Annals of the New York Academy of Sciences, 2010. 1192(1): p. 12-18.

19. Zhang, J., et al., Identification of the haematopoietic stem cell niche and control of the niche size. Nature, 2003. 425(6960): p. 836-841.

20. Calvi, L.M., et al., Osteoblastic cells regulate the haematopoietic stem cell niche. Nature, 2003. 425(6960): p. 841-846.

21. Taniguchi, H., et al., Presence of hematopoietic stem cells in the adult liver. Nature Medicine, 1996. 2(2): p. 198-203.

22. Sugiyama, T., et al., Maintenance of the hematopoietic stem cell pool by CXCL12-CXCR4 chemokine signaling in bone marrow stromal cell niches. Immunity, 2006. 25(6): p. 977-988.

23. Kiel, M.J. and S.J. Morrison, Maintaining hematopoietic stem cells in the vascular niche. Immunity, 2006. 25(6): p. 862-864.

24. Jackson, K.A., T. Mi, and M.A. Goodell, Hematopoietic potential of stem cells isolated from murine skeletal muscle. Proceedings of the National Academy of Sciences, 1999. 96(25): p. 14482-14486.

25. Morrison, S.J., D.E. Wright, and I.L. Weissman, Cyclophosphamide/granulocyte colony-stimulating factor induces hematopoietic stem cells to proliferate prior to mobilization. Proceedings of the National Academy of Sciences, 1997. 94(5): p. 1908-1913.

26. Wright, D.E., et al., Physiological migration of hematopoietic stem and progenitor cells. Science, 2001. 294(5548): p. 1933-1936.

27. Abkowitz, J.L., et al., Evidence that the number of hematopoietic stem cells per animal is conserved in mammals. Blood, 2002. 100(7): p. 2665-2667.

28. Boggs, D.R., The total marrow mass of the mouse: A simplified method of measurement. American Journal of Hematology, 1984. 16(3): p. 277-286. 
29. de Haan, G., W. Nijhof, and G. Van Zant, Mouse strain-dependent changes in frequency and proliferation of hematopoietic stem cells during aging: correlation between lifespan and cycling activity. Blood, 1997. 89(5): p. 1543-1550.

30. Wilson, A., et al., Hematopoietic stem cells reversibly switch from dormancy to self-renewal during homeostasis and repair. Cell, 2008. 135(6): p. 1118-1129.

31. Kiel, M.J., et al., Haematopoietic stem cells do not asymmetrically segregate chromosomes or retain BrdU. Nature, 2007. 449(7159): p. 238-242.

32. Cheshier, S.H., et al., In vivo proliferation and cell cycle kinetics of long-term self-renewing hematopoietic stem cells. Proceedings of the National Academy of Sciences, 1999. 96(6): p. 3120-3125.

33. Foudi, A., et al., Analysis of histone 2B-GFP retention reveals slowly cycling hematopoietic stem cells. Nature Biotechnology, 2009. 27(1): p. 84-90.

34. Zilman, A., V.V. Ganusov, and A.S. Perelson, Stochastic models of lymphocyte proliferation and death. PLoS ONE, 2010. 5(9): p. e12775.

35. Roos, W.P. and B. Kaina, DNA damage-induced cell death by apoptosis. Trends in Molecular Medicine, 2006. 12(9): p. 440-450.

36. Domen, J., K.L. Gandy, and I.L. Weissman, Systemic overexpression of Bcl-2 in the hematopoietic system protects transgenic mice from the consequences of lethal irradiation. Blood, 1998. 91(7): p. 2272-2282.

37. Matsuzaki, Y., et al., Role of Bcl-2 in the development of lymphoid cells from the hematopoietic stem cell. Blood, 1997. 89(3): p. 853-862.

38. Yu, H., et al., Deletion of Puma protects hematopoietic stem cells and confers long-term survival in response to high-dose $\gamma$-irradiation. Blood, 2010. 115(17): p. 3472-3480.

39. Wu, W.-S., et al., Slug antagonizes p53-mediated apoptosis of hematopoietic progenitors by repressing Puma. Cell, 2005. 123(4): p. 641-653.

40. Inoue, A., et al., Slug, a highly conserved zinc finger transcriptional repressor, protects hematopoietic progenitor cells from radiation-induced apoptosis in vivo. Cancer Cell, 2002. 2(4): p. 279-288.

41. Domen, J. and I.L. Weissman, Hematopoietic stem cells need two signals to prevent apoptosis; Bcl-2 can provide one of these, Kitl/C-KIT signaling the other. The Journal of Experimental Medicine, 2000. 192(12): p. 1707-1718.

42. Opferman, J.T., et al., Obligate role of anti-apoptotic Mcl-1 in the survival of hematopoietic stem cells. Science, 2005. 307(5712): p. 1101-1104. 
43. Nijhawan, D., et al., Elimination of Mcl-1 is required for the initiation of apoptosis following ultraviolet irradiation. Genes \& Development, 2003. 17(12): p. $1475-1486$.

44. Huber, T.L., et al., Haemangioblast commitment is initiated in the primitive streak of the mouse embryo. Nature, 2004. 432(7017): p. 625-630.

45. Mikkola, H.K.A. and S.H. Orkin, The journey of developing hematopoietic stem cells. Development, 2006. 133(19): p. 3733-3744.

46. McGrath, K.E. and J. Palis, Hematopoiesis in the yolk sac: More than meets the eye. Experimental Hematology, 2005. 33(9): p. 1021-1028.

47. Cumano, A., et al., Intraembryonic, but not yolk sac hematopoietic precursors, isolated before circulation, provide long-term multilineage reconstitution. Immunity, 2001. 15(3): p. 477-485.

48. Mikkola, H.K.A., et al., Placenta as a site for hematopoietic stem cell development. Experimental Hematology, 2005. 33(9): p. 1048-1054.

49. Rhodes, K.E., et al., The emergence of hematopoietic stem cells is initiated in the placental vasculature in the absence of circulation. Cell Stem Cell, 2008. 2(3): p. 252-263.

50. Cridland, S.O., et al., Indian hedgehog supports definitive erythropoiesis. Blood Cells, Molecules, and Diseases, 2009. 43(2): p. 149-155.

51. Van Den Berg, D.J., et al., Role of members of the Wnt gene family in human hematopoiesis. Blood, 1998. 92(9): p. 3189-3202.

52. McGrath, K., J. Palis, and J.B. James, Ontogeny of erythropoiesis in the mammalian embryo, in Current Topics in Developmental Biology. 2008, Academic Press. p. 1-22.

53. O'Driscoll, M. and P.A. Jeggo, The role of double-strand break repair - insights from human genetics. Nature Review Genetics, 2006. 7(1): p. 45-54.

54. San Filippo, J., P. Sung, and H. Klein, Mechanism of eukaryotic homologous recombination. Annual Review of Biochemistry, 2008. 77(1): p. 229-257.

55. Jackson, S.P. and J. Bartek, The DNA-damage response in human biology and disease. Nature, 2009. 461(7267): p. 1071-1078.

56. Nagy, A., Manipulating the mouse embryo: a laboratory manual. 2003: Cold Spring Harbor, NY: Cold Spring Harbor Laboratory Press. 
57. Scacheri, P.C., et al., Bidirectional transcriptional activity of PGK-neomycin and unexpected embryonic lethality in heterozygote chimeric knockout mice. Genesis, 2001. 30(4): p. 259-263.

58. Wilson, T. and I. Kola, The LoxP/CRE system and genome modification, in Gene Knockout Protocols, M. Tymms and I. Kola, Editors. 2001, Humana Press. p. 8394.

59. Le, Y. and B. Sauer, Conditional gene knockout using cre recombinase. Methods in Molecular Biology, 2000. 136: p. 477-486.

60. Sauer, B., Inducible gene targeting in mice using the Cre/lox system. Methods, 1998. 14(4): p. 381-392.

61. Schwartzberg, P.L., S.P. Goff, and E.J. Robertson, Germ-line transmission of a cAbl mutation produced by targeted gene disruption in ES cells. Science, 1989. 246(4931): p. 799-803.

62. Zimmer, A. and P. Gruss, Production of chimaeric mice containing embryonic stem (ES) cells carrying a homoeobox Hox 1.1 allele mutated by homologous recombination. Nature, 1989. 338(6211): p. 150-153.

63. Thompson, S., et al., Germ line transmission and expression of a corrected HPRT gene produced by gene targeting in embryonic stem cells. Cell, 1989. 56(2): p. 313-321.

64. Goldstein, J.L., Laskers for 2001: Knockout mice and test-tube babies. Nature Medicine, 2001. 7(10): p. 1079-1080.

65. Dolgin, E., Mouse library set to be knockout. Nature, 2011. 474(7351): p. 262263.

66. Li, V.Y., et al., Alternative promoters and polyadenylation regulate tissuespecific expression of Hemogen isoforms during hematopoiesis and spermatogenesis. Developmental Dynamics, 2003. 228(4): p. 606-616.

67. Yang, L.V., et al., Hemogen is a novel nuclear factor specifically expressed in mouse hematopoietic development and its human homologue EDAG maps to chromosome $9 q 22$, a region containing breakpoints of hematological neoplasms. Mechanisms of Development, 2001. 104(1-2): p. 105-111.

68. Yang, L.V., et al., The GATA site-dependent hemogen promoter is transcriptionally regulated by GATA1 in hematopoietic and leukemia cells. Leukemia, 2006. 20(3): p. 417-425.

69. Jiang, J., et al., Hemgn is a direct transcriptional target of HOXB4 and induces expansion of murine myeloid progenitor cells. Blood, 2010. 116(5): p. 711-719. 
70. Godlewski, J., et al., Targeting of the Bmi-1 oncogene/stem cell renewal factor by microRNA-128 inhibits glioma proliferation and self-renewal. Cancer Research, 2008. 68(22): p. 9125.

71. Mason, J.M. and K.M. Arndt, Coiled coil domains: Stability, specificity, and biological implications. ChemBioChem, 2004. 5(2): p. 170-176.

72. Burkhard, P., J. Stetefeld, and S.V. Strelkov, Coiled coils: a highly versatile protein folding motif. Trends in Cell Biology, 2001. 11(2): p. 82-88.

73. Griaud, F., et al., BCR/ABL modulates protein phosphorylation associated with the etoposide-induced DNA damage response. Journal of Proteomics, 2012. 77(1): p. 14-26.

74. Krüger, A., et al., RP59, a marker for osteoblast recruitment, is also detected in primitive mesenchymal cells, erythroid cells, and megakaryocytes. Developmental Dynamics, 2002. 223(3): p. 414-418.

75. Wurtz, T., et al., A new protein expressed in bone marrow cells and osteoblasts with implication in osteoblast recruitment. Experimental Cell Research, 2001. 263(2): p. 236-242.

76. Krüger, A., et al., Rat enamel contains RP59: A new context for a protein from osteogenic and haematopoietic precursor cells. Cell and Tissue Research, 2005. 320(1): p. 141-148.

77. Li, C.Y., et al., Overexpression of a hematopoietic transcriptional regulator EDAG induces myelopoiesis and suppresses lymphopoiesis in transgenic mice. Leukemia, 2007. 21(11): p. 2277-2286.

78. Fett-Conte, A.C., et al., Atypical chromosome abnormalities in acute myeloid leukemia type M4. Genetics and Molecular Biology, 2007. 30(1): p. 6-9.

79. Takahashi, M., et al., The FOXE1 locus is a major genetic determinant for radiation-related thyroid carcinoma in Chernobyl. Human Molecular Genetics, 2010. 19(12): p. 2516.

80. Mitelman, F., F. Mertens, and B. Johansson, A breakpoint map of recurrent chromosomal rearrangements in human neoplasia. Nature Genetics, 1997. 15: p. 417-474.

81. Wooster, R. Transcription profiling of human multiple cancer cell lines. 201212-28; Available from: www.ebi.ac.uk/gxa/experiment/E-MTAB37/ENSG00000136929.

82. Grosveld, G., et al., The chronic myelocytic cell line K562 contains a breakpoint in bcr and produces a chimeric bcr/c-abl transcript. Molecular and Cellular Biology, 1986. 6(2): p. 607-616. 
83. Huang, M., et al., Inhibition of Bcr-Abl kinase activity by PD180970 blocks constitutive activation of Stat5 and growth of CML cells. Oncogene, 2002. 21(57): p. 8804.

84. An, L.L., et al., High expression of EDAG and its significance in AML. Leukemia, 2005. 19(8): p. 1499-1502.

85. Li, C.Y., et al., EDAG regulates the proliferation and differentiation of hematopoietic cells and resists cell apoptosis through the activation of nuclear factor- $\kappa B$. Cell Death and Differentiation, 2004. 11(12): p. 1299-1308.

86. Zhang, M.-J., et al., Erythroid differentiation-associated gene interacts with NPM1 (nucleophosmin/B23) and increases its protein stability, resisting cell apoptosis. FEBS Journal, 2012. 279(16): p. 2848-2862.

87. Antonchuk, J., G. Sauvageau, and R.K. Humphries, HOXB4-induced expansion of adult hematopoietic stem cells ex vivo. Cell, 2002. 109(1): p. 39.

88. Shen, S., et al., In vivo epitope tagging of Trypanosoma brucei genes using a one step PCR-based strategy. Molecular and Biochemical Parasitology, 2001. 113(1): p. 171-173.

89. Ding, Y., et al., Overexpression of EDAG in the myeloid cell line 32D: Induction of GATA-1 expression and erythroid/megakaryocytic phenotype. Journal of Cellular Biochemistry, 2010. 110(4): p. 866-874.

90. Grosveld, F., et al., Position-independent, high-level expression of the human $\beta$ globin gene in transgenic mice. Cell, 1987. 51(6): p. 975-985.

91. Vassar, R., et al., Tissue-specific and differentiation-specific expression of a human K14 keratin gene in transgenic mice. Proceedings of the National Academy of Sciences, 1989. 86(5): p. 1563-1567.

92. Liu, P., N.A. Jenkins, and N.G. Copeland, A highly efficient recombineeringbased method for generating conditional knockout mutations. Genome Research, 2003. 13(3): p. 476-484.

93. FDA, Guidance for industry: Dissolution testing of immediate-release solid oral dosage forms, 1997, Food and Drug Administration, Center for Drug Evaluation and Research (CDER). p. 8.

94. Li, Y., Study of a novel gene, Hemogen/EDAG, in hematopoiesis and spermatogenesis, 2002, Wayne State University ETD Collection.

95. Norddahl, Gudmundur L., et al., Accumulating mitochondrial DNA mutations drive premature hematopoietic aging phenotypes distinct from physiological stem cell aging. Cell Stem Cell, 2011. 8(5): p. 499-510. 
96. Chen, K., et al., Resolving the distinct stages in erythroid differentiation based on dynamic changes in membrane protein expression during erythropoiesis.

Proceedings of the National Academy of Sciences, 2009. 106(41): p. 1741317418.

97. Lee, L.G., C.-H. Chen, and L.A. Chiu, Thiazole orange: A new dye for reticulocyte analysis. Cytometry, 1986. 7(6): p. 508-517.

98. Beutler, E., Drug-induced hemolytic anemia. Pharmacological Reviews, 1969. 21(1): p. 73-103.

99. Fabre, J.-E., et al., Decreased platelet aggregation, increased bleeding time and resistance to thromboembolism in P2Y1-deficient mice. Nature Medicine, 1999. 5(10): p. 1199-1202.

100. Angiolillo, D.J., D. Capodanno, and S. Goto, Platelet thrombin receptor antagonism and atherothrombosis. European Heart Journal, 2010. 31(1): p. 17-28.

101. Jeffers, J.R., et al., Puma is an essential mediator of p53-dependent andindependent apoptotic pathways. Cancer Cell, 2003. 4(4): p. 321-328.

102. Keller, M.A., et al., Transcriptional regulatory network analysis of developing human erythroid progenitors reveals patterns of coregulation and potential transcriptional regulators. Physiological Genomics, 2007. 28(1): p. 114-128.

103. Marcucci, G., et al., Overexpression of the ETS-related gene, ERG, predicts a worse outcome in acute myeloid leukemia with normal karyotype: A cancer and leukemia group B study. Journal of Clinical Oncology, 2005. 23(36): p. 92349242.

104. Mitelman, F., B. Johansson, and F. Mertens, Mitelman database of chromosome aberrations and gene fusions in cancer, 2012.

105. Meani, N. and M. Alcalay, Role of nucleophosmin in acute myeloid leukemia. Expert Review of Anticancer Therapy, 2009. 9(9): p. 1283-1294.

106. Cleary, H., E. Boulton, and M. Plumb, Allelic loss on chromosome 4 (Lyr2/TLSR5) is associated with myeloid, B-lympho-myeloid, and lymphoid (B and T) mouse radiation-induced leukemias. Blood, 2001. 98(5): p. 1549-1554.

107. Ensemble Genome Browser. 2013-1-8; Available from: http://useast.ensembl.org/Mus_musculus/Gene/Summary?g=ENSMUSG0000002 $\underline{8332 ; \mathrm{r}=4: 46393989-46413506 .}$.

108. Ma, Y., et al., SALL4, a novel oncogene, is constitutively expressed in human acute myeloid leukemia (AML) and induces AML in transgenic mice. Blood, 2006. 108(8): p. 2726. 
109. Wang, Y., et al., The Wnt/b-Catenin pathway is required for the cevelopment of leukemia stem cells in AML. Science, 2010. 327(5973): p. 1650-1653.

110. Li, Z., et al., Developmental stage-selective effect of somatically mutated leukemogenic transcription factor GATA1. Nature Genetics, 2005. 37(6): p. 613619.

111. Kirstetter, P., et al., Modeling of C/EBPa mutant acute myeloid leukemia reveals a common expression signature of committed myeloid leukemia-initiating cells. Cancer Cell, 2008. 13(4): p. 299-310.

112. Rossi, L., et al., Less is more: Unveiling the functional core of hematopoietic stem cells through knockout mice. Cell Stem Cell, 2012. 11(3): p. 302-317.

113. Takubo, K., et al., Regulation of the HIF-1 $\alpha$ level is essential for hematopoietic stem cells. Cell Stem Cell, 2010. 7(3): p. 391-402.

114. Takubo, K., et al., Regulation of glycolysis by Pdk functions as a metabolic checkpoint for cell cycle quiescence in hematopoietic stem cells. Cell Stem Cell, 2013. 12(1): p. 49-61.

115. Barbaric, I., G. Miller, and T.N. Dear, Appearances can be deceiving: phenotypes of knockout mice. Briefings in Functional Genomics \& Proteomics, 2007. 6(2): p. 91-103.

116. Grisendi, S., et al., Role of nucleophosmin in embryonic development and tumorigenesis. Nature, 2005. 437(7055): p. 147-153.

117. Sherr, C.J., Divorcing ARF and p53: An unsettled case. Nature Review Cancer, 2006. 6(9): p. 663-673.

118. Naoe, T., et al., Nucleophosmin: A versatile molecule associated with hematological malignancies. Cancer Science, 2006. 97(10): p. 963-969.

119. Colombo, E., et al., Nucleophosmin is required for DNA integrity and p19Arf protein stability. Molecular and Cellular Biology, 2005. 25(20): p. 8874-8886.

120. Wendel, H.-G., et al., Loss of 533 impedes the antileukemic response to $B C R-A B L$ inhibition. Proceedings of the National Academy of Sciences, 2006. 103(19): p. 7444-7449.

121. Rossi, D.J., et al., Cell intrinsic alterations underlie hematopoietic stem cell aging. Proceedings of the National Academy of Sciences of the United States of America, 2005. 102(26): p. 9194-9199.

122. Ragu, C., et al., The transcription factor Srf regulates hematopoietic stem cell adhesion. Blood, 2010. 116(22): p. 4464-4473. 
123. Becker, H., et al., Favorable prognostic impact of NPM1 mutations in older patients with cytogenetically normal de novo acute myeloid leukemia and associated gene- and microRNA-expression signatures: A cancer and leukemia group B study. Journal of Clinical Oncology, 2010. 28(4): p. 596-604.

124. Li, J., et al., Negative regulation of p53 by nucleophosmin antagonizes stressinduced apoptosis in human normal and malignant hematopoietic cells. Leukemia Research, 2005. 29(12): p. 1415-1423.

125. Chaturvedi, C.-P., et al., Dual role for the methyltransferase G9a in the maintenance of $\beta$-globin gene transcription in adult erythroid cells. Proceedings of the National Academy of Sciences, 2009. 106(43): p. 18303-18308.

126. Okuda, M., et al., Nucleophosmin/B23 is a target of CDK2/cyclin E in centrosome duplication. Cell, 2000. 103(1): p. 127-140.

127. Tarapore, P., et al., Thr199 phosphorylation targets nucleophosmin to nuclear speckles and represses pre-mRNA processing. FEBS Letters, 2006. 580(2): $\mathrm{p}$. 399-409.

128. Basham, B., et al., In vivo identification of novel STAT5 target genes. Nucleic Acids Research, 2008. 36(11): p. 3802-3818.

129. Karnowski, A., et al., Silencing and nuclear repositioning of the $\lambda 5$ gene locus at the pre-B cell stage requires Aiolos and OBF-1. PLoS ONE, 2008. 3(10): $\mathrm{p}$. e3568.

130. Sitnicka, E., et al., Key role of flt3 ligand in regulation of the common lymphoid progenitor but not in maintenance of the hematopoietic stem cell pool. Immunity, 2002. 17(4): p. 463-472.

131. Siebenlist, U., K. Brown, and E. Claudio, Control of lymphocyte development by nuclear factor- $\kappa B$. Nature Review Immunology, 2005. 5(6): p. 435-445.

132. Dhar, S.K., et al., Identification of nucleophosmin as an NF- $\kappa B$ co-activator for the induction of the human SOD2 gene. Journal of Biological Chemistry, 2004. 279(27): p. 28209-28219.

133. Cilloni, D., et al., Increase sensitivity to chemotherapeutical agents and cytoplasmatic interaction between NPM leukemic mutant and NF- $\kappa B$ in AML carrying NPM1 mutations. Leukemia, 2008. 22(6): p. 1234-1240.

134. Horwitz, B.H., et al., Failure of lymphopoiesis after adoptive transfer of $N F-\kappa B$ deficient fetal liver cells. Immunity, 1997. 6(6): p. 765-772.

135. Bottero, V., S. Withoff, and I.M. Verma, NF-kappa B and the regulation of hematopoiesis. Cell Death Differ, 2006. 13(5): p. 785-797. 
136. Lee, H.M., et al., Downstream targets of HOXB4 in a cell line model of primitive hematopoietic progenitor cells. Blood, 2010. 116(5): p. 720-730.

137. Ling, B.I.N., et al., Down-regulation of EDAG expression by retrovirus-mediated small interfering RNA inhibits the growth and IL-8 production of leukemia cells. Oncology Reports, 2007. 18(3): p. 659-664.

138. Gambacorti-Passerini, C.B., et al., Molecular mechanisms of resistance to imatinib in Philadelphia-chromosome-positive leukaemias. The Lancet Oncology, 2003. 4(2): p. 75-85.

139. Nardi, V., M. Azam, and G.Q. Daley, Mechanisms and implications of imatinib resistance mutations in BCR-ABL. Current Opinion in Hematology, 2004. 11(1): p. 35-43.

140. Ema, H., et al., Quantification of self-renewal capacity in single hematopoietic stem cells from nrmal and Lnk-deficient mice. Developmental Cell, 2005. 8(6): p. 907-914. 


\section{APPENDIX A. SUPPLEMENTARY TABLES}

Table A-1. Estimated HSC frequency in mouse bone marrow

\begin{tabular}{ccc}
\hline Surface markers & Frequency in BM & Single cell reconstitution \\
\hline $\mathrm{CD} 150^{+} \mathrm{CD} 48^{-} \mathrm{Sca}-1^{+} \mathrm{Lin}^{-} \mathrm{c}-\mathrm{Kit}^{+}$ & $5.8 \pm 1.2 \times 10^{-5}$ & $47 \pm 7 \%[9]$ \\
$\mathrm{CD} 150^{+} \mathrm{CD} 48^{-} \mathrm{CD} 41^{-}$ & $6.5 \pm 0.9 \times 10^{-5}$ & $45 \%[9]$ \\
$\mathrm{CD} 150^{+} \mathrm{CD} 48^{-}$ & $8.4 \pm 2.8 \times 10^{-5}$ & $21 \%[9]$ \\
$\mathrm{CD} 34^{-} \mathrm{Sca}-1^{+} \mathrm{Lin}^{-} \mathrm{c}-\mathrm{Kit}^{+}$ & $5 \times 10^{-5}$ & $25 \%[140]$ \\
\hline
\end{tabular}

Sources: Ema, H., et al., Quantification of self-renewal capacity in single hematopoietic stem cells from nrmal and Lnk-deficient mice. Developmental Cell, 2005. 8(6): p. 907914. Kiel, M.J., et al., SLAM Family Receptors Distinguish Hematopoietic Stem and Progenitor Cells and Reveal Endothelial Niches for Stem Cells. Cell, 2005. 121(7): p. 1109-1121. 
Table A-2. PCR conditions and cloning strategies for targeting construct

\begin{tabular}{|c|c|c|c|c|c|c|}
\hline Description & $\begin{array}{c}\text { Primers } \\
\text { (Table A-3) }\end{array}$ & $\begin{array}{c}\text { Annealing } \\
\left({ }^{\circ} \mathrm{C}\right)\end{array}$ & $\begin{array}{l}\text { Extension time } \\
\text { (minute:second) }\end{array}$ & $\begin{array}{l}\text { Size } \\
\text { (bp) }\end{array}$ & $\begin{array}{c}\text { Digestion } \\
\text { enzymes }\end{array}$ & Vector \\
\hline 5' $\mathrm{BAC}$ retrieving arm & Gp001, Gp002 & 56 & $1: 30$ & 1049 & BamHI, PstI & VP101 \\
\hline 3' BAC retrieving arm & Gp003, Gp004 & 56 & $1: 30$ & 1050 & PstI, NotI & VP101 \\
\hline loxP-neo-loxP 5 ' mini arm & Gp009, Gp010 & 56 & $0: 30$ & 329 & KpnI, EcoRI & PL452 \\
\hline loxP-neo-loxP 3 ' mini arm & Gp011, Gp012 & 56 & $0: 30$ & 425 & BamHI, NotI & PL452 \\
\hline FRT-neo-FRT-loxP 5' mini arm & Gp013, Gp014 & 56 & $0: 30$ & 296 & KpnI, EcoRI & PL451 \\
\hline FRT-neo-FRT-loxP 3' mini arm & Gp015, Gp016 & 56 & $0: 30$ & 305 & BamHI, NotI & PL451 \\
\hline Single loxP ESC screen & Gp079, Gp083 & 58 & $6: 00$ & 5668 & & \\
\hline FRT-neo-FRT-loxP ESC screen & Gp088, Gp091 & 58 & $8: 00$ & 7557 & & \\
\hline 5' Southern probe & Gp005, Gp006 & 56 & $0: 45$ & 528 & & \\
\hline 3' Southern probe & Gp007, Gp008 & 56 & $0: 45$ & 610 & & \\
\hline
\end{tabular}


Table A-3. Primer sets for targeting constructs and ES cell screening

\begin{tabular}{|c|c|c|c|}
\hline Name & Description & Strand & Sequence (restriction enzyme sites underlined) \\
\hline Gp001 & BAC 5' retrieving-arm & sense & CGCGGATCCTTGAACTATCACCCAACTA \\
\hline Gp002 & BAC 5' retrieving-arm & antisense & AACTGCAGCTCTGCCCTCTACCTCT \\
\hline Gp003 & BAC 3' retrieving-arm & sense & 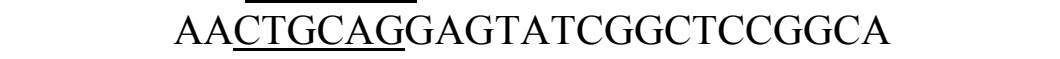 \\
\hline Gp004 & BAC 3' retrieving-arm & antisense & AAGGAAAAAAGCGGCCGCGCTTCCAGGAGCTGCAAT \\
\hline Gp005 & 5' southern & sense & GTGGCACTGTAACTCACAGCAG \\
\hline Gp006 & 5 ' southern & antisense & CCAAGGCCATTCTCTGTG \\
\hline Gp007 & 3' southern & sense & TGTTTTCTTACCTCTTGGACCC \\
\hline Gp008 & 3' southern & antisense & CACAGCTGTGATCCCATAAATG \\
\hline Gp009 & loxP-neo-loxP 5' mini arm & sense & GGGGTACCAAAATGCCTGCTCCAGC \\
\hline Gp010 & loxP-neo-loxP 5 ' mini arm & antisense & CGGAATTCACTAGTTATGTAGCCTGGGTCTGGA \\
\hline Gp011 & loxP-neo-loxP 3 ' mini arm & sense & CGCGGATCCCTGAGACTCCTATTTC \\
\hline Gp012 & loxP-neo-loxP 3' mini arm & antisense & AAGGAAAAAAGCGGCCGCTCACCACAGAATCTTGT \\
\hline Gp013 & FRT-neo-FRT-loxP 5' mini arm & sense & GGGGTACCTCTTAGTTTATGCGGGGATG \\
\hline Gp014 & FRT-neo-FRT-loxP 5' mini arm & antisense & CGGAATTCCAACCACATGGTGGCT \\
\hline Gp015 & FRT-neo-FRT-loxP 3' mini arm & sense & CGCGGATCCGCTAGCCTGGGATTTGAACTCG \\
\hline Gp016 & FRT-neo-FRT-loxP 3' mini arm & antisense & AAGGAAAAAAGCGGCCGCACACTGTTTCCTTGGG \\
\hline Gp041 & Exon2 sequencing & sense & ACCCAGGCATACACTGGCAC \\
\hline Gp042 & Exon3 sequencing & sense & CACATGCAGGCAAAAACACC \\
\hline Gp043 & Exon4 sequencing & sense & TAAGGCCATGTAACAAGGCC \\
\hline Gp044 & Exon4 sequencing & sense & AGACAGCTGTGCCCCAAACC \\
\hline Gp045 & Exon4 sequencing & sense & GAAGCAGTTGAACCTGAATT \\
\hline Gp046 & Exon5 sequencing & sense & GACAGTGCCAACGTTGTTTA \\
\hline Gp047 & Exon5 sequencing & sense & GTAGTTCTGAGGAGAAGATAGC \\
\hline Gp079 & Single loxP ESC screening & antisense & GGTTATTGAATATGATCGGAATT \\
\hline Gp083 & Single loxP ESC screening & sense & AGGGTCAGACATTCCAAACTCAA \\
\hline Gp088 & 3' loxP ESC screening & sense & GCTCAGGAGGGTTTACTTAC \\
\hline Gp091 & 3' loxP ESC screening & antisense & AGACAGAGGCAGGCAGATCC \\
\hline
\end{tabular}


Table A-4. Primers for mutagenesis and sequencing

\begin{tabular}{ccc}
\hline Name & Description & Sequence \\
\hline Gp113 & $\Delta 34-50$ sense & ATCATTGGATCTTGGAGTCAGACATCACAATGGCTC \\
Gp114 & $\Delta 34-50$ antisense & GAGCCATTGTGATGTCTGACTCCAAGATCCAATGAT \\
Gp115 & $\Delta 61-78$ sense & TGGCTCCTTGGAGAACAGCAAGGGAACGTGGAGCAA \\
Gp116 & $\Delta 61-78$ antisense & TTGCTCCACGTTCCCTTGCTGTTCTCCAAGGAGCCA \\
Gp117 & MSCV backbone & ACTAGTTAGCTAACTAGCTC \\
Gp118 & IRES backbone & CACAACGTGGCACTGGGGTT \\
Gp119 & Sequencing & TAGGCTGCTTGTGAAGTC \\
Gp120 & Sequencing & TGCCAGGAAACAACTGTGTC \\
Gp121 & Sequencing & GAGCCTAAACACAGCCTTCC \\
\hline
\end{tabular}


Table A-5. PCR parameters for mutagenesis

\begin{tabular}{ccccc}
\hline Name & Primers & $\begin{array}{c}\text { Annealing } \\
\left({ }^{\circ} \mathbf{C}\right)\end{array}$ & $\begin{array}{c}\text { Extension } \\
\text { (minute:second) }\end{array}$ & Template \\
\hline$\Delta 34$ & Gp117, Gp114 & 56 & $1: 00$ & MSCV-Hemgn-iGFP \\
$\Delta 50$ & Gp113, Gp118 & 56 & $1: 00$ & MSCV-Hemgn-iGFP \\
$\Delta 61$ & Gp117, Gp116 & 56 & $1: 00$ & MSCV-Hemgn-iGFP \\
$\Delta 78$ & Gp115, Gp118 & 56 & $1: 00$ & MSCV-Hemgn-iGFP \\
$\Delta$ CC & Gp117, Gp118 & 56 & $1: 30$ & $\Delta 34+\Delta 50$ \\
$\Delta$ NLS & Gp117, Gp118 & 56 & $1: 30$ & $\Delta 61+\Delta 78$ \\
\hline
\end{tabular}


Table A-6. Leukemia mouse models do not show Hemgn overexpression

\begin{tabular}{ccc}
\hline Leukemia model & Disease condition & Leukemia cell \\
\hline MLL-AF9 & AML & Lin $^{-} \mathrm{Sca}-1^{-} \mathrm{c}-\mathrm{Kit}^{\mathrm{high}} \mathrm{FcR} \gamma^{+} \mathrm{CD} 34^{+}[109]$ \\
HoxA9/Meis1 & AML & $\mathrm{Lin}^{-} \mathrm{Sca}-1^{-} \mathrm{c}-\mathrm{Kit}^{\text {high }} \mathrm{FcR} \gamma^{+} \mathrm{CD} 34^{+}[109]$ \\
Gata-1 delta N & M7 AML & Megakaryocytes $[110]$ \\
Cebpa & AML & $\mathrm{Mac1}^{+},{\mathrm{c}-\mathrm{Kit}^{+}}^{+}$myeloid progenitor [111] \\
SALL4B & leukemia, MDS-like & N/A [108] \\
\hline
\end{tabular}

Sources: Li, Z., et al., Developmental stage-selective effect of somatically mutated leukemogenic transcription factor GATA1. Nature Genetics, 2005. 37(6): p. 613-619. Ma, Y., et al., SALL4, a novel oncogene, is constitutively expressed in human acute myeloid leukemia (AML) and induces AML in transgenic mice. Blood, 2006. 108(8): p. 2726. Kirstetter, P., et al., Modeling of C/EBPa mutant acute myeloid leukemia reveals a common expression signature of committed myeloid leukemia-initiating cells. Cancer Cell, 2008. 13(4): p. 299-310. Wang, Y., et al., The Wnt/b-Catenin pathway is required for the cevelopment of leukemia stem cells in AML. Science, 2010. 327(5973): p. 16501653. 


\section{APPENDIX B. SUPPLEMENTARY FIGURES}

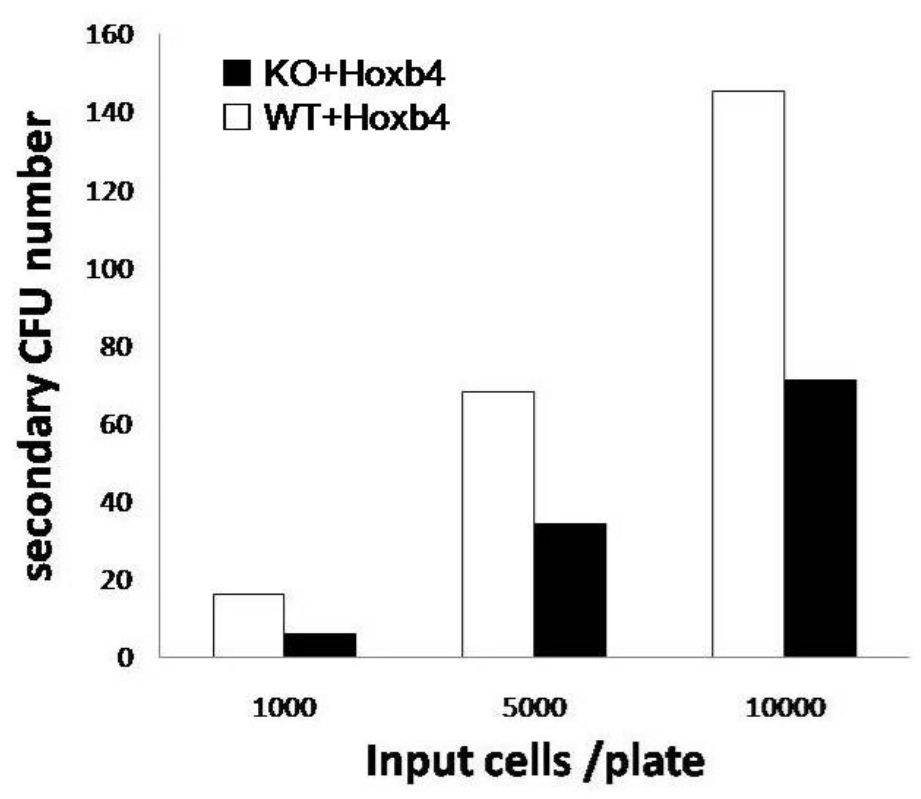

Figure B-1. Impairment of Hoxb4 function in Hemgn knockout bone marrow cells

Both wild-type and Hemgn knockout bone marrow cells were transduced with MSCV-Hoxb4-IRES-GFP retroviral vector. The transduced cells were cultured in M3434 medium for the growth of primary colonies. Primary colonies were collected 7 days later. The cells were pooled and replated for the growth of secondary colonies. The colony numbers were counted 7 days later. This experiment was carried out only once by Hui Yu in Brian Sorrentino lab. 

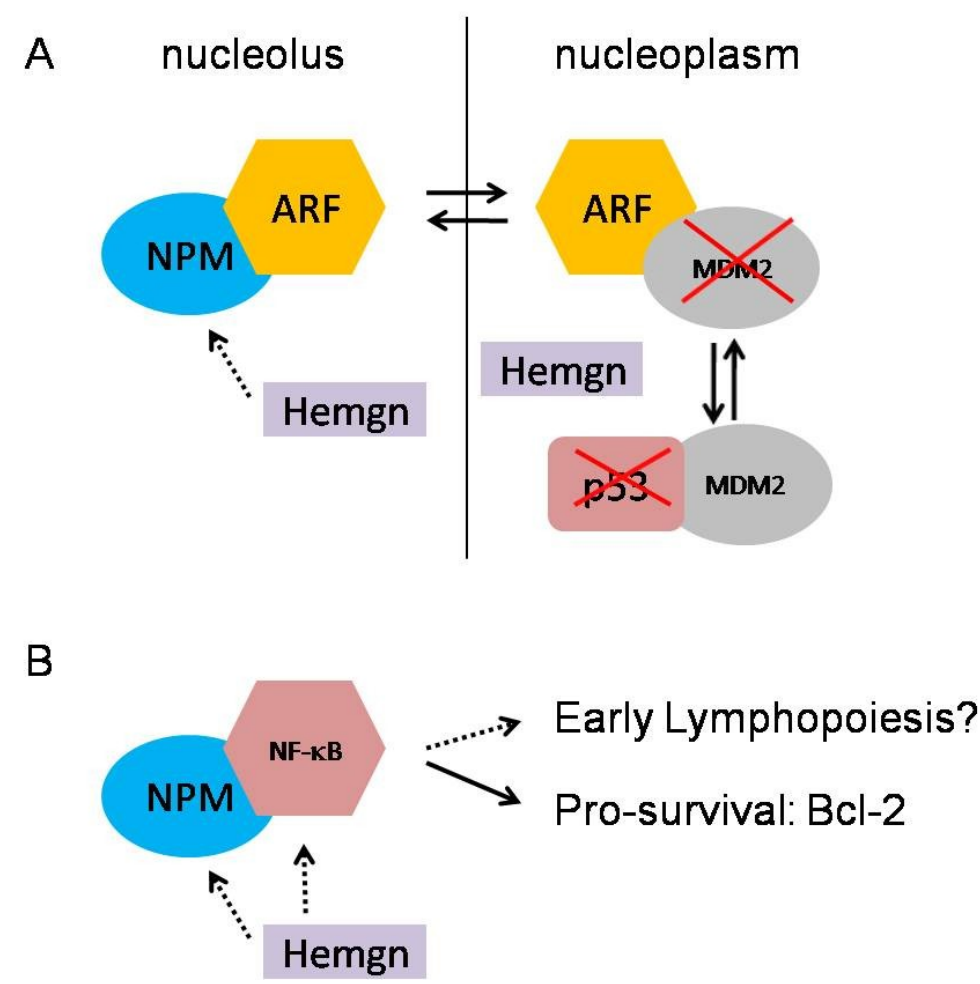

Figure B-2. Hemgn and NPM in relation to p53 and NF- $\mathrm{KB}$

(A) Hemgn might interact with NPM to affect p53 activity through ARF and MDM2. (B) Hemgn might regulate NF- $\kappa$ B signaling though its interaction with NPM. NF- $\kappa B$ may be required for early lymphopoiesis. 

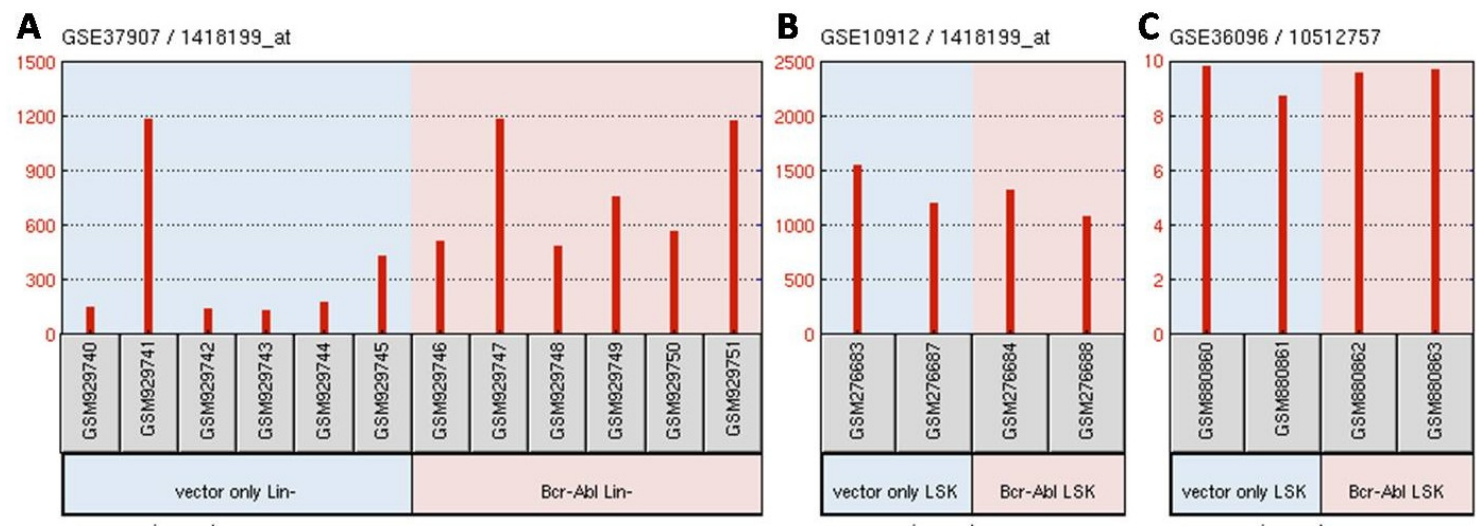

Figure B-3. Hemgn expression is not associated with Bcr-Abl

Hemgn expression levels of 3 independent Bcr-Abl leukemia mouse models are compared with data from Gene Expression Omnibus database. All 3 models transplanted Bcr-Abl transduced bone marrow cells to recipients and analyzed the bone marrow Lin ${ }^{-}$ or LSK population as indicated here by differential gene expression array after reconstitution. (A) GSE37907; (B) GSE10912; (C) GSE36096.

Sources: GSE37907, GSE10912 and GSE36096 of Gene Expression Omnibus repository. Available from: www.ncbi.nlm.nih.gov/gds. 


\section{VITA}

Gao Peng was born in Tianjin, China in 1984. He was the first prize winner of 2002 China Biology Olympiad. In 2007 he earned a Bachelor of Science degree in Biotechnology from Nanjing University, where he was taught by Prof., Dr., Dr. h.c. Kenneth J. Hsu across a broad spectrum of scientific disciplines, including particle physics, evolution, geology and biology. He entered the University of Tennessee Health Science Center at Memphis, Tennessee, in the fall of 2007. He will graduate with Doctor of Philosophy degree. 